ETIENNE AMÉRICO CARTOLANO JÚNIOR

\title{
PROPOSTA DE UM SISTEMA DE INFORMAÇÃO ORIENTADO A SERVIÇOS SOBRE A BIODIVERSIDADE DE ABELHAS
}

\author{
Dissertação apresentada à Escola \\ Politécnica da Universidade de São Paulo \\ para obtenção do título de Mestre em \\ Engenharia.
}

São Paulo 
Este exemplar foi revisado e alterado em relação à versão original, sob responsabilidade única do autor e com a anuência de seu orientador.

São Paulo, de setembro de 2009.

Assinatura do autor

Assinatura do orientador

FICHA CATALOGRÁFICA

Cartolano Júnior, Etienne Américo

Proposta de um sistema de informação orientado a serviços sobre a biodiversidade de abelhas / E.A. Cartolano Júnior. -ed.rev. -- São Paulo, 2009.

$157 \mathrm{p}$.

Dissertação (Mestrado) - Escola Politécnica da Universidade de São Paulo. Departamento de Engenharia de Computação e Sistemas Digitais.

1. Arquitetura orientada a serviços 2. Sistemas de informação

3. Biodiversidade 4. Abelhas I. Universidade de São Paulo. Escola Politécnica. Departamento de Engenharia de Computação e Sistemas Digitais II. t. 
ETIENNE AMÉRICO CARTOLANO JÚNIOR

\title{
PROPOSTA DE UM SISTEMA DE INFORMAÇÃO ORIENTADO A SERVIÇOS SOBRE A BIODIVERSIDADE DE ABELHAS
}

\author{
Dissertação apresentada à Escola \\ Politécnica da Universidade de São Paulo \\ para obtenção do título de Mestre em \\ Engenharia.
}

Área de Concentração: Sistemas Digitais

Orientador: Antonio Mauro Saraiva

São Paulo 
À minha Flor,

que é a minha força,

meu alento

e minha alegria de viver!! 


\section{AGRADECIMENTOS}

Ao meu orientador, Prof. Dr. Antonio Mauro Saraiva, pela orientação e dedicação na condução deste trabalho e, sobretudo, pela confiança, pulso firme, oportunidades e amizade que permitiram o meu crescimento profissional e pessoal desde o meu primeiro dia de POLI.

À minha família que vê em mim um ponto de confiança, e a quem nunca vou decepcionar. Em especial, aos futuros politécnicos, Lucas e Bruno, que ainda sentarão nos bancos desta Escola e darão muito orgulho ao tio.

Ao Prof. Dr. Pedro Luiz Pizzigatti Corrêa pela contribuição, incentivo e experiência compartilhada durante todo o trabalho, e aos Prof. Dr. Carlos Eduardo Cugnasca e ao Prof. Dr. André Riyuiti Hirakawa, pelo apoio e incentivo nesses quase nove anos de Laboratório de Automação Agrícola.

À Profa. Dr. Vera Lucia Imperatriz-Fonseca, à doutoranda Tereza Cristina Giannini e aos colegas do Laboratório de Abelhas do IB-USP. Ao Eng. Renato De Giovanni do CRIA, pelas valorosas contribuições.

Aos companheiros de pesquisa do LAA, em especial, Diogo, Jorge, Pablo, Paulo, Jésus, Osvaldo, César e Edson, que contribuíram diretamente para a realização deste trabalho, e àqueles que já passaram por lá, e que têm grande participação na Webbee, Renato, Alerso, e Eduardo Salomão.

Aos amigos, que contribuem com os bons momentos do dia a dia e com o enriquecimento da minha formação nas atividades extracurriculares. Afinal, aqui não tem.

Ao Conselho Nacional de Desenvolvimento Científico e Tecnológico - CNPq pela concessão da Bolsa de Mestrado ao autor.

À minha Escola Politécnica que, definitivamente, transformou minha vida. 


\section{RESUMO}

Os polinizadores prestam um importante serviço no resultado das colheitas e na conservação de ecossistemas. Estima-se que os valores gerados pelos seus serviços somem 200 bilhões de dólares ao ano. Entretanto, a FAO, braço das Nações Unidas para a Agricultura, indica um declínio significativo dos polinizadores, apontando para uma "crise de polinização". As ações para a conservação e o uso sustentável dos polinizadores em resposta a esta crise, demandam um significativo suporte das Tecnologias da Informação em várias das suas atividades. Em particular, na integração de diferentes fontes e tipos de dados, que é decorrência da complexidade dos processos biológicos que se pretende entender e manejar, e da velocidade com que essas áreas evoluem. Devido às ações de resposta ao declínio dos polinizadores, a comunidade científica brasileira e internacional, que necessitam de mais acesso aos dados sobre biodiversidade, demandam um novo papel da Webbee, um sistema de informação sobre a biodiversidade brasileira em abelhas nativas. Ela deve incorporar os dados regionais e se integrar às redes de dados globais sobre biodiversidade como referência em informações sobre espécies e espécimes de abelhas nativas brasileiras, e de polinização por estas abelhas. Visando proporcionar uma fundamentação para o desenvolvimento de ferramentas que atendam esses requisitos de integração e de interoperabilidade para a Webbee, é proposta uma arquitetura orientada a serviços que adota as ferramentas de padronização e de comunicação de dados sobre biodiversidade utilizados e mantidos por entidades internacionais, tais como GBIF, IABIN-PTN e TDWG. Dada a importância da interação para o processo de polinização, e devido à ausência de um padrão específico para a troca deste tipo de dado, um esquema conceitual de dados de interação entre espécimes foi desenvolvido em um processo iterativo com a participação da comunidade científica via TDWG. Este esquema é a base de um estudo de caso proposto para a realização de provas de conceito, sob a forma de uma ferramenta de digitalização, catalogação e publicação de dados sobre espécimes e interação entre eles.

Palavras-chave: Arquitetura de software, sistemas de informação, biodiversidade, abelhas 


\begin{abstract}
Pollinators provide an important service in agriculture and the conservation of ecosystems. It is estimated that the values generated by their services reach 200 billion dollars a year. However, the Food and Agriculture Organization of the United Nations indicates a significant decline of pollinators, pointing to a "crisis of pollination". The actions for the conservation and sustainable use of pollinators in response to this crisis demand significant support from Information Technology. Particularly, in the integration of diverse sources and type of data, that is a consequence of the complexity of the biological processes that one strives to understand and manage, and of the high speed at which area evolves. As a response to the pollinators decline, the international and Brazilian scientific communities, that need greater access to biodiversity data, demand a new role to Webbee, an information systems about the Brazilian biodiversity on native bees. It should incorporate regional data and integrate to global biodiversity data networks as a reference for information on species and specimens of Brazilian native bees, and pollination by those bees. Aiming to provide a foundation for the development of tools that meet these requirements of integration and interoperability of Webbee, it is proposed a service-oriented architecture based on tools and services for standardization and communication of biodiversity data used by international entities such as GBIF, IABIN-PTN and TDWG. Given the importance of interaction in the pollination process, and due to the absence of specific standards for the exchange of such data, a conceptual data schema about interaction between specimens was developed in an iterative process involving the scientific community via TDWG. This schema is the base of a case study proposed to conduct a proof of concept, in the form of a tool for digitization, cataloging and publishing data on specimens and interactions between them.
\end{abstract}

Keywords: Software architecture, information systems, biodiversity, bees. 


\section{LISTA DE FIGURAS}

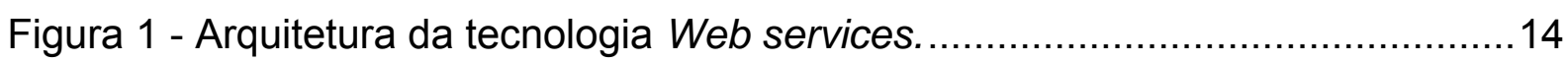

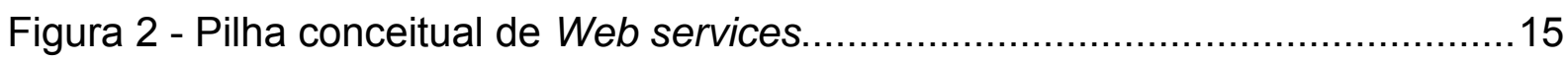

Figura 3 - Framework para implementação de arquiteturas do tipo SOA ................19

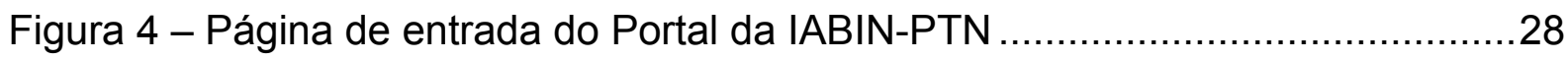

Figura 5 - Divisão de atuação entre Bioinformática e Informática da Biodiversidade 34

Figura 6 - Portal do Global Biodiversity Information Facility - GBIF.........................40

Figura 7 - Exemplo de Arquitetura de Consultas Distribuídas ................................43

Figura 8 - Arquitetura baseada em Armazenamento temporário de Dados ..............45

Figura 9 - Arquitetura e Principais Componentes da Webbee...............................58

Figura 10 - Diagrama de Entidade-Relacionamento mínimo (sem atributos) ............60

Figura 11 - Imagens de Fichas de Espécies ...................................................61

Figura 12 - Lista de Espécies de Plantas visitadas pela Espécie de Abelha..............61

Figura 13 - Estrutura do weblab de monitoração de variáveis em colméias .............67

Figura 14 - Arquitetura de software do Portal GBIF ............................................. 71

Figura 15 - Arquitetura da Rede Temática de Polinizadores - IABIN-PTN ................72

Figura 16 - Representação gráfica do Modelo de Interação entre espécimes .........78

Figura 17 - Estrutura do elemento de interação do esquema ABCD......................... 82

Figura 18 - Estrutura do elemento Interactions do esquema Plinian Core v2.0.........83

Figura 19 - Proposta de arquitetura de referência para o desenvolvimento da nova

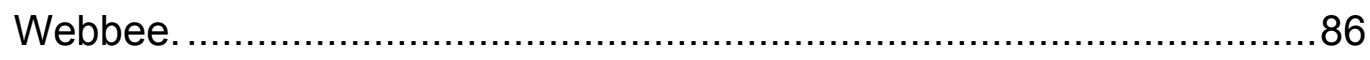

Figura 20 - Arquitetura do Portal da proposta para a SOWB. ..............................87

Figura 21 - Estrutura de operação do Agregador de dados da SOWB....................88

Figura 22 - Arquitetura de entrada e manipulação de dados na Webbee ..................89

Figura 23 - Componente de esquemas conceituais da arquitetura de referência. ....90

Figura 24 - Esquema conceitual de interação publicado no TDWG - Interaction

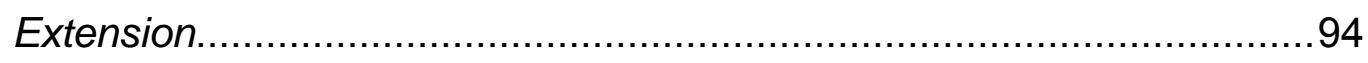

Figura 25 - Esquema conceitual de especialização em polinização publicado no

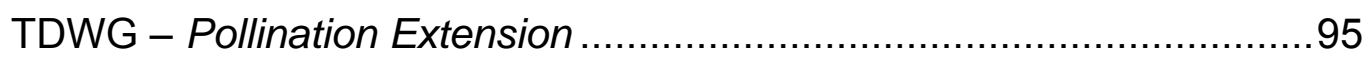

Figura 26 - Esquema conceitual de especialização em medidas ambientais publicado no TDWG - Environment Measurements Extension ..............................95

Figura 27 - Agregação dos esquemas de interação em um registro Darwin Core ....97 
Figura 28 - Diagrama de Entidade-Relacionamento (sem atributos) do núcleo ......102 Figura 29 - Implementação relacional da entidade Taxonomic Elements do Darwin

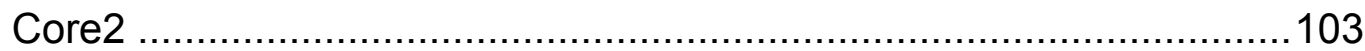

Figura 30 - Esquema da arquitetura de software da PDD ................................104

Figura 31 - Arquitetura de software do provedor TapirLink ...............................106

Figura 32 - Exemplo de mapeamento de campos no Tapilink ............................107

Figura 33 - Estrutura do sistema de informação da Webbee e interface entre os módulos ...................................................................................... 136

Figura 34 - Diagrama de Entidade-Relacionamento mínimo (sem atributos) .........137

Figura 35 - Janela da Interface de Operação, para inserção dos dados das colônias

Figura 36 - Catálogo das Espécies de Abelhas e Plantas..............................140

Figura 37 - Estrutura de Navegação da Ficha de Espécies da Webbee. ...............141

Figura 38 - Imagens de Fichas de Espécies ...............................................142 


\section{LISTA DE ABREVIATURAS E SIGLAS}

$A B C D$ - Access to Biological Collections Data

BEELAB - Laboratório de Abelhas - IBUSP

BioCASE - Biological Collection Access Service for Europe

CDB - Convenção sobre Diversidade Biológica

COP - Conferência das Partes

DiGIR - Distributed Generic Information Retrieval

DTD - Document Type Definition

DwC - Darwin Core

EoL - Encyclopedia of Life

FAO - Food and Agriculture Organization of the United Nations

GBIF - Global Biodiversity Information Facility

HTML - Hypertext Markup Language

HTTP - Hypertext Transfer Protocol

IABIN - Inter-American Biodiversity Information Network

IABIN-PTN - IABIN Pollinators Thematic Network

IB - Informática da Biodiversidade

IBP - Iniciativa Brasileira dos Polinizadores

ITIS - Integrated Taxonomic Information System

LAA - Laboratório de Automação Agrícola

OASIS - Organization for the Advancement of Structured Information Standards

PDD - Pollinator Data Digitizer

PHP - Hypertext Preprocessor

PliC - Plinian Core

PTN - Pollinator Thematic Network

SGML - Standard Generalized Markup Language

SOA - Service-oriented Architectures

SOAP - Simple Object Access Protocol

SOWB - Service-Oriented Webbee

SQL - Structured Query Language

TAPIR - TDWG Access Protocol for Information Retrieval

TDWG - Biodiversity Information Standards (Taxonomic Database Working Group) 
TI - Tecnologia da Informação

UDDI - Universal Description, Discovery and Integration

URI - Uniform Resource Identifier

WSDL - Web Services Description Language

WS - Web Services

XML - eXtensible Markup Language 


\section{SUMÁRIO}

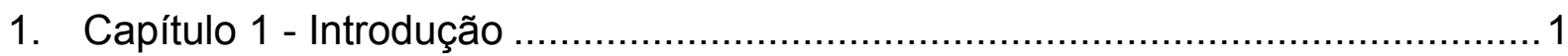

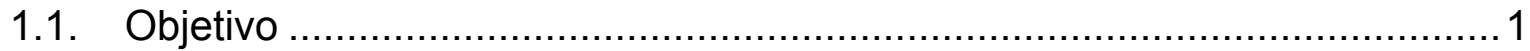

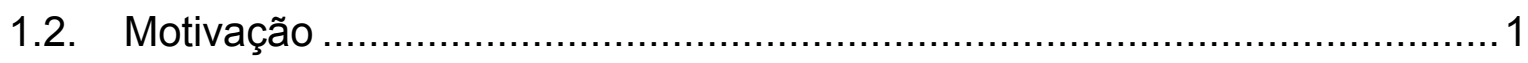

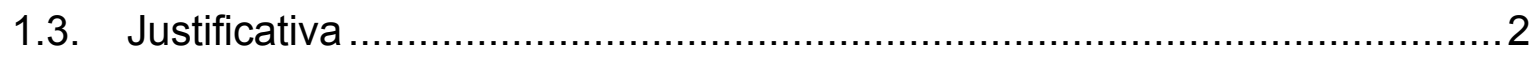

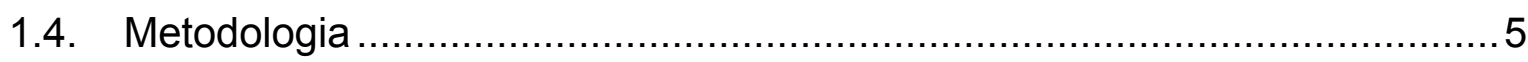

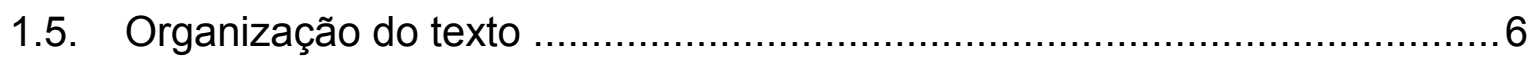

2. Capítulo 2 - Conceitos de Computação Aplicados a Biodiversidade ..................8

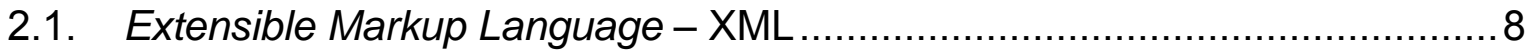

2.1.1. Espaço de Nomes: XML Namespaces...................................... 9

2.1.2. Gramática: DTD e XML Schema.......................................... 10

2.1.3. Aplicações XML e Restrições.................................................. 11

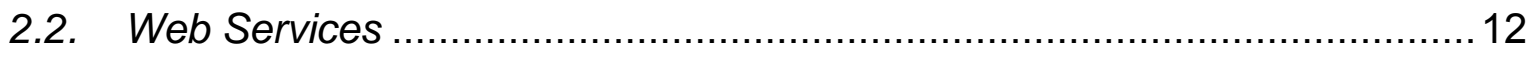

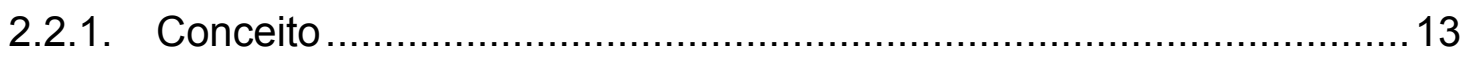

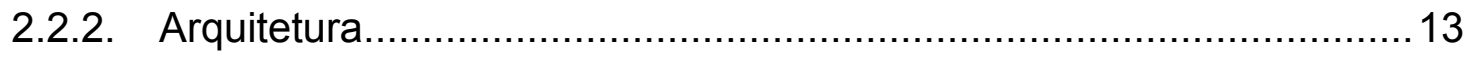

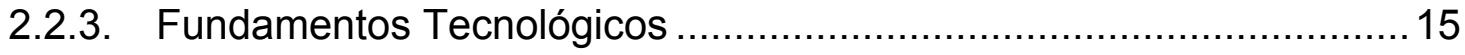

2.3. Service Oriented Architecture - SOA ............................................. 16

2.3.1. Propriedades dos Serviços ............................................... 17

2.3.2. Modelo de Referência ......................................................... 18

2.3.3. Implementação da Arquitetura ............................................. 20

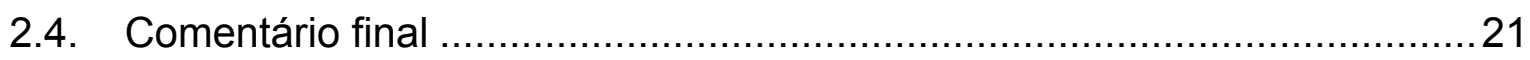

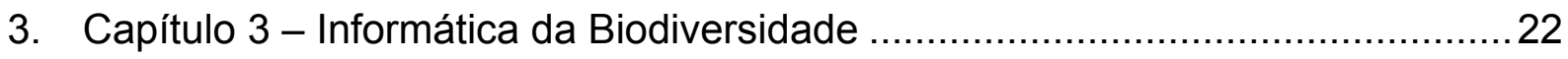

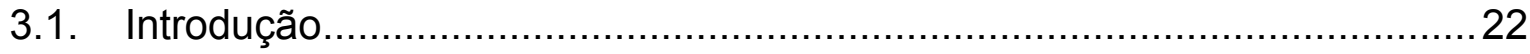

3.2. Iniciativas para facilitar o acesso às informações científicas sobre biodiversidade .23

3.2.1. Iniciativa Brasileira dos Polinizadores - IBP .............................. 25

3.2.2. Inter-American Biodiversity Information Network - IABIN ................27

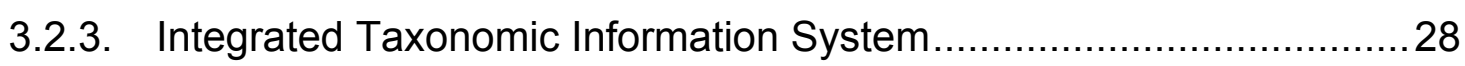

3.2.4. Global Biodiversity information Facility - GBIF ...........................29

3.2.5. Biodiversity Information Standards - TDWG ............................. 30

3.3. Conceitos básicos da Informática da Biodiversidade .............................. 33

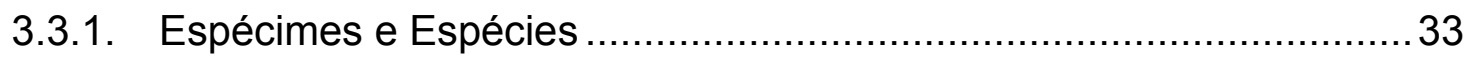


3.3.2. Dados Primários - Ocorrência de Espécies..................................... 35

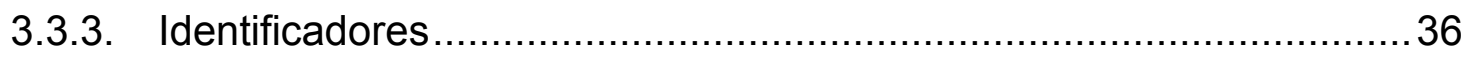

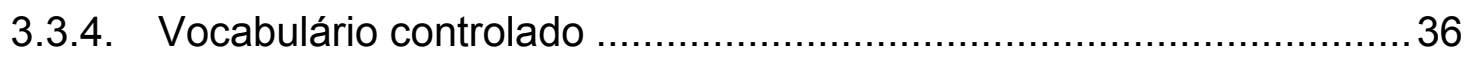

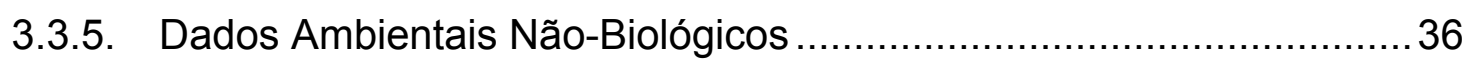

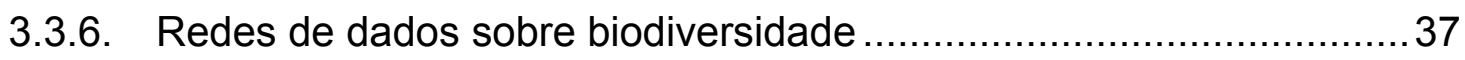

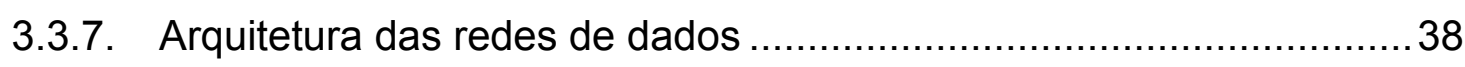

3.4. Ferramentas e serviço da Informática da Biodiversidade ..........................48

3.4.1. Protocolos de Troca de Dados sobre biodiversidade ........................48

3.4.2. Esquemas conceituais de dados................................................. 49

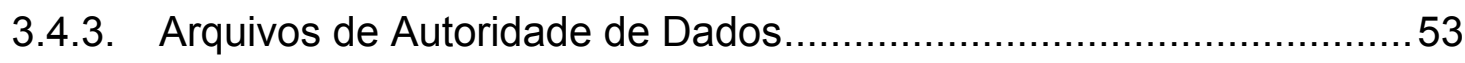

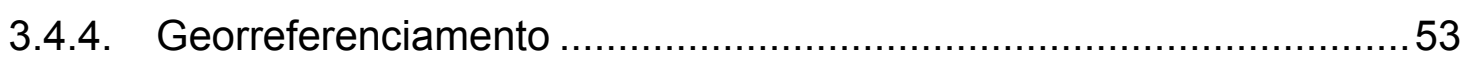

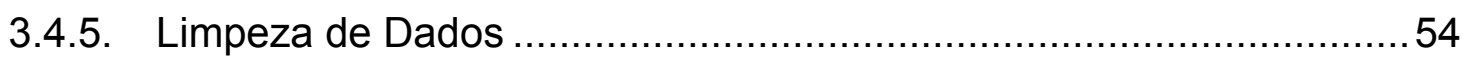

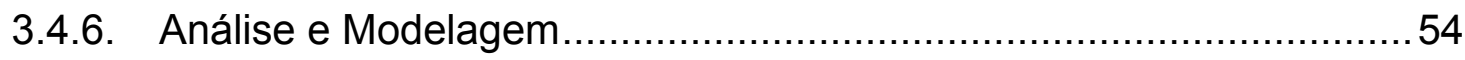

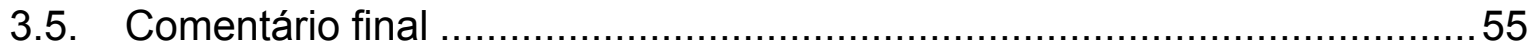

4. Capítulo 4 - Especificação e PROPOSTA de ARQUITETURA da Service-

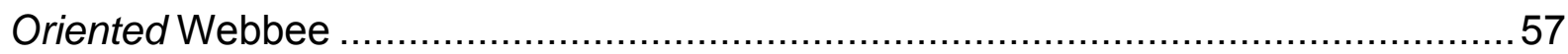

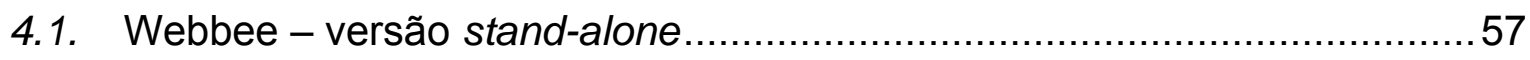

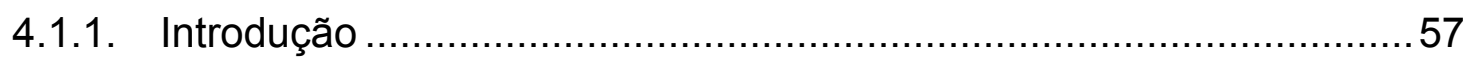

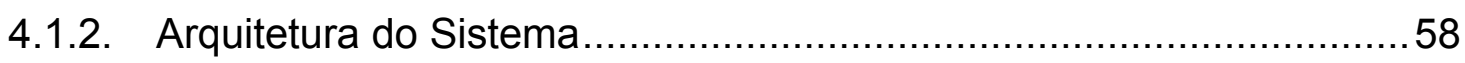

4.2. Especificação dos Requisitos da nova versão da Webbe ..........................62

4.2.1. Integração com as redes de dados sobre biodiversidade ..................62

4.2.2. Concentração de provedores locais .................................................63

4.2.3. Utilização de dados de espécimes no sistema..................................64

4.2.4. Utilização de dados de interação entre espécimes .............................65

4.2.5. Facilidade para integrar novas aplicações ....................................... 66

4.2.6. Segurança, créditos e qualidade dos dados .....................................68

4.3. Análise dos requisitos da arquitetura de referência .................................... 68

4.3.1. Identificação das redes de dados e sistemas de interesse ................69

4.3.2. Definição do tratamento computacional dos dados de Interação.......72

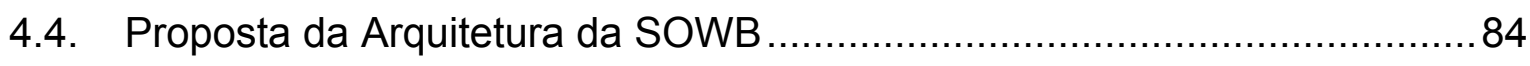

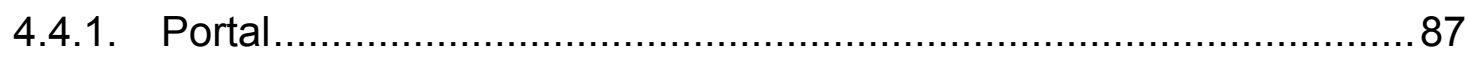

4.4.2. Agregador e Harvester ............................................................ 87

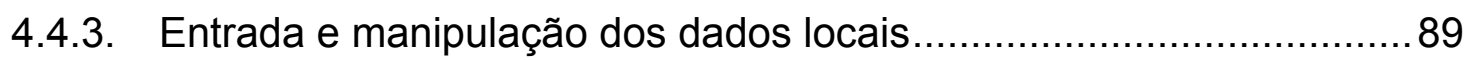

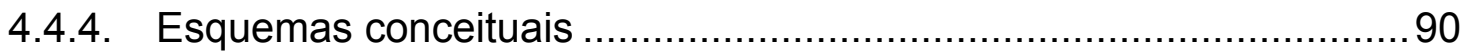




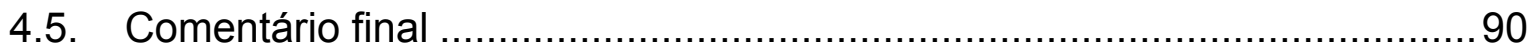

5. Capítulo 5 - Implementações para Provas de Conceitos ……........................ 92

5.1. Esquema Conceitual de Dados de Interação entre Espécimes - Interaction

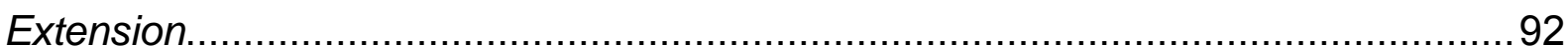

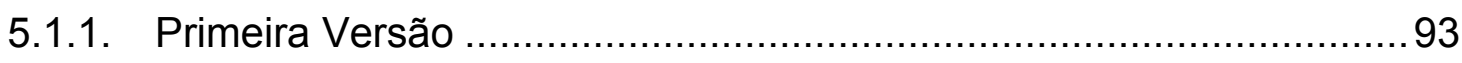

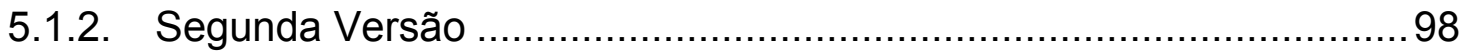

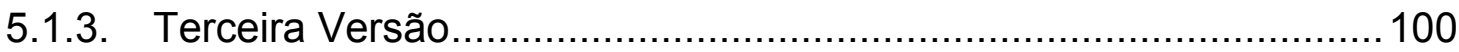

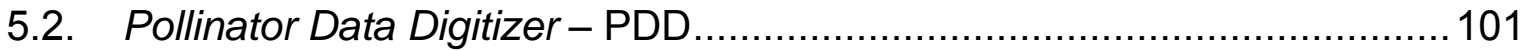

5.2.1. Implementação relacional do Simple Darwin Core e das extensões

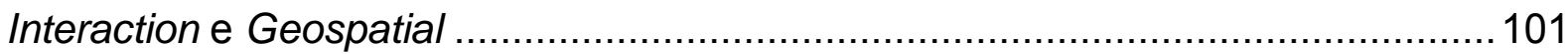

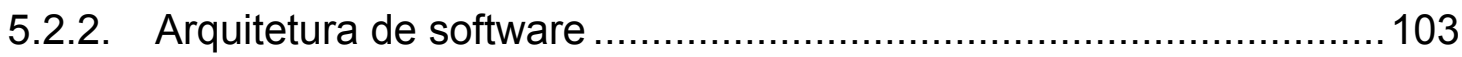

5.2.3. Provedor de dados de Espécimes e de Interação entre Espécimes 105

5.2.1. Primeira Versão da PDD ................................................................ 107

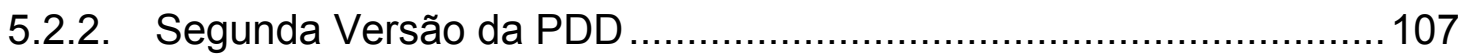

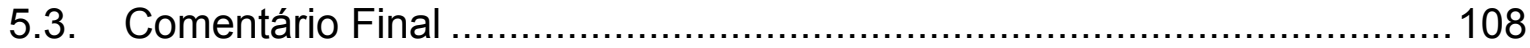

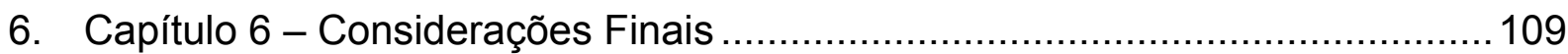

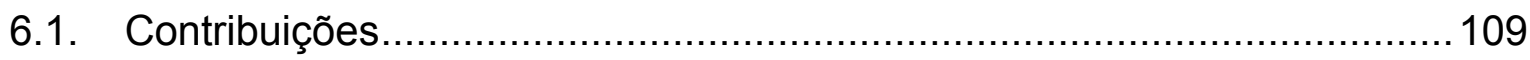

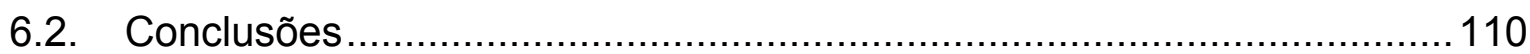

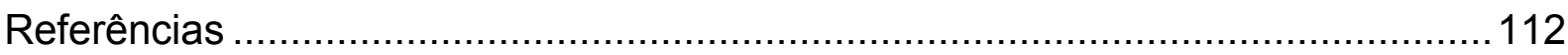

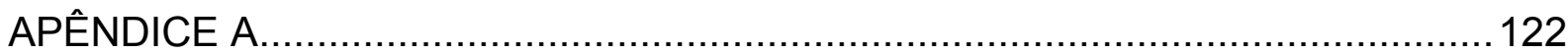

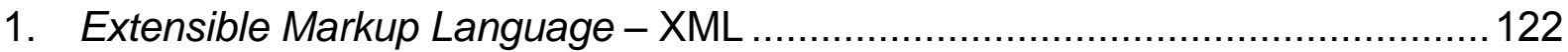

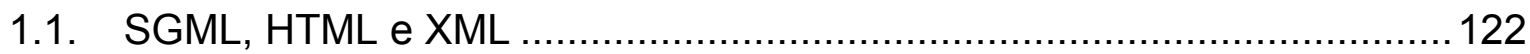

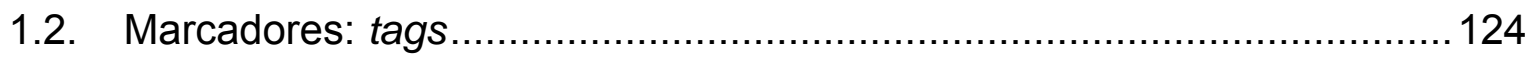

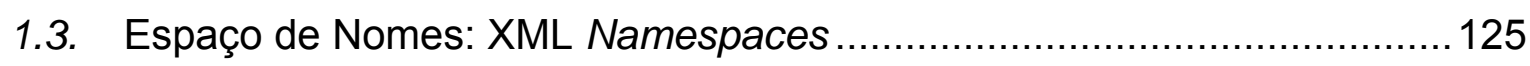

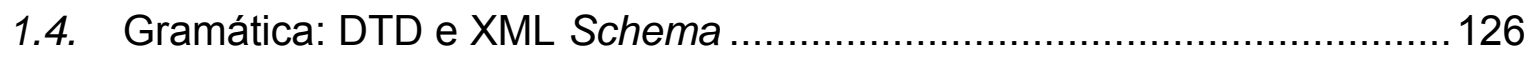

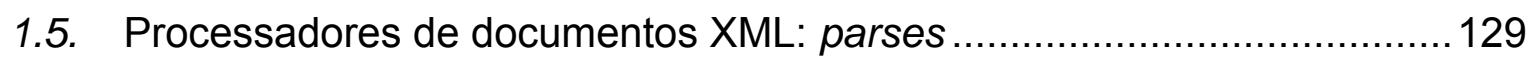

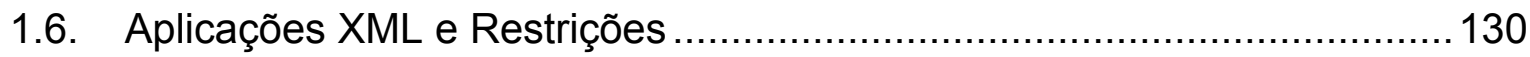

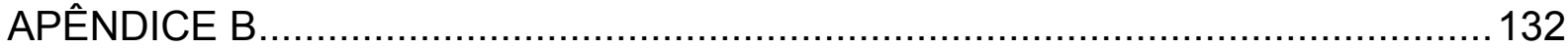

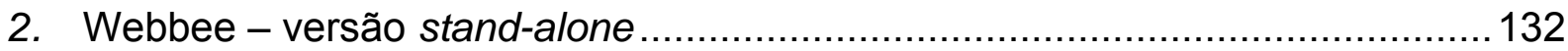

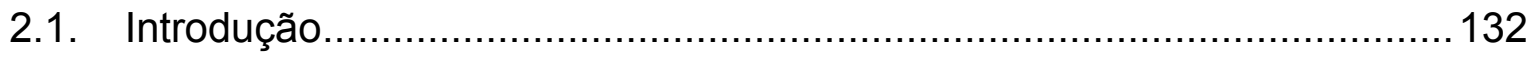

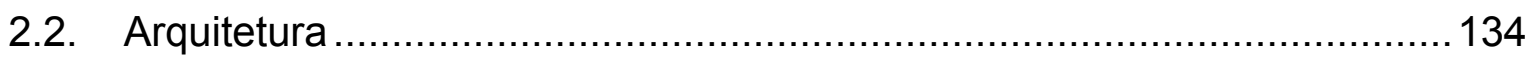

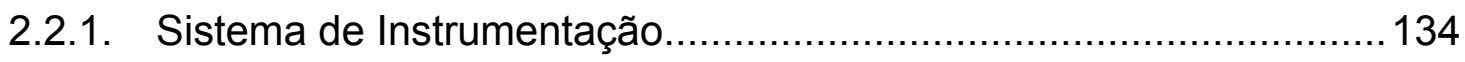

2.2.2. Sistema de Informação ..............................................................134 


\section{CAPÍTULO 1 - INTRODUÇÃO}

\subsection{Objetivo}

O objetivo deste trabalho é criar uma arquitetura de referência orientada a serviços para sistemas de informação sobre biodiversidade. Ela será utilizada na evolução do sistema Webbee, guiando o desenvolvimento da nova versão deste sistema, que deverá catalogar, integrar e prover dados de espécies e espécimes de abelhas nativas brasileiras e de polinização por abelhas. Também serão realizadas provas de conceito sobre partes desta arquitetura de referência.

\subsection{Motivação}

Entre as várias espécies ameaçadas destacam-se os agentes polinizadores, que têm influência direta na manutenção dos fragmentos florestais e na agricultura sustentável (Imperatriz-Fonseca et al., 2007). A polinização tem sido considerada um dos mais importantes serviços de ecossistemas (Kremen et al., 2007) e o uso e conservação dos polinizadores foram enfatizados pela Convenção sobre Diversidade Biológica (CDB) (CDB, 2008), que foi o primeiro acordo global a cobrir todos os aspectos da diversidade biológica. No entanto, o sucesso das ações de conservação está diretamente ligado ao conhecimento sobre os agentes polinizadores, que inclui aspectos da biologia e da interação com o meio ambiente (Imperatriz-Fonseca et al., 2004).

Essas informações demandam um esforço de coleta e reunião, armazenamento, integração, análise, visualização e intercâmbio de enormes quantidades de dados, o que é essencialmente impossível de ser realizado sem o uso das técnicas e tecnologias computacionais e de comunicação modernas (Saraiva, 2003). Um novo campo da computação, a Informática da Biodiversidade (IB), tem evoluído na criação de ferramentas e padrões para atender estas 
demandas, possibilitando o surgimento de diversos sistemas e redes de dados sobre biodiversidade.

Dentre as diversas iniciativas para facilitar o acesso aos dados sobre biodiversidade, a Webbee se destaca como uma rede (de cooperação) brasileira que provê um local de integração das informações sobre biologia e criação das diversas espécies de abelhas nativas e sobre seus habitats, englobando textos, imagens e vídeos voltados para diversos públicos.

Em um cenário de fortalecimento da importância dos polinizadores, da organização da comunidade científica brasileira e do maior acesso aos dados sobre biodiversidade, apoiado principalmente pela evolução da Informática da Biodiversidade, ganha força a demanda da comunidade científica para que a Webbee incorpore os dados regionais e se integre às redes de dados sobre biodiversidade como referência em informações sobre espécies e espécimes de abelhas nativas brasileiras, e de polinização por estas abelhas.

\subsection{Justificativa}

Diversas iniciativas têm trabalhado para facilitar e incentivar a disseminação e a integração dos dados sobre biodiversidade com o uso da Informática da Biodiversidade. Elas coordenam ou incentivam os projetos e redes de dados sobre biodiversidade, que contam com a participação de instituições (museus, herbários, centros de pesquisa, universidade, etc.) espalhadas pelo mundo.

O TDWG (Taxonomic Database Working Group), atualmente chamado de Biodiversity Information Standards, uma importante iniciativa para a padronização da Informática da Biodiversidade (descrita no item 3.2.5), registrava em seu portal, até a época da publicação deste texto, mais de 612 projetos e 53 redes de dados sobre biodiversidade (TDWG, 2007). Estes projetos e redes de dados podem ter escopos diferentes, mas, em geral, propõem-se a viabilizar e organizar de forma cooperativa a catalogação, integração e publicação dos dados sobre biodiversidade.

No portal do TDWG, assim como nas referências utilizadas neste texto, algumas iniciativas se destacam por tentar integrar todos os tipos de dados sobre 
biodiversidade (biológicos, genéticos, históricos, etc.) de todas as espécies, tais como, Encyclopedia of Life (EoL), Species 2000 e Global Biodiversity Information Facility (GBIF). No entanto, outras iniciativas se destacam por se especializar em um determinado conjunto de espécies, ou em regiões geográficas, ou ambos: China Invasive Species Network, Oceania Pollinator Initiative, Fauna Europea, European Register of Marine Species, Euro-Mediterranean Plant Diversity e Pollinators Thematic Network - Inter-American Biodiversity Information Network (IABIN-PTN), por exemplo.

A especialização de um projeto ou rede de dados sobre biodiversidade em um grupo de espécies ou em uma região é importante para o usuário, pois concentra as informações de interesse em um mesmo lugar, e também permite a publicação de dados e serviços mais específicos. Do lado dos coletores, integradores e provedores dos dados, a especialização facilita a manipulação dos dados, além de refletir a capacidade científica de um determinado grupo (de pesquisadores, museus, herbários, etc.) e, em determinados casos, ela viabiliza o interesse financeiro de patrocinadores.

Por isso, a atuação da Webbee como referência em dados de espécies e espécimes de abelhas e de polinização por abelhas é justificada pela demanda (nacional e internacional) de informações sobre abelhas nativas, especialmente pela IABIN-PTN, já que ela é uma especialização dessa rede de dados sobre biodiversidade de polinizadores nas Américas. No entanto, a Webbee trabalha isolada e não integra dados com outros sistemas.

A adoção de uma arquitetura orientada a serviços (SOA) permitirá a integração da Webbee às redes de dados sobre biodiversidade. Essas redes de dados de interesse (GBIF, IABIN, etc.), já trocam dados de espécimes e espécies de abelhas (objetivos da Webbee) de forma padronizada utilizando serviços na Internet, organizados sob o paradigma SOA. Por isso, para se integrar, a Webbee precisa adotar esses padrões, ou sugerir outros dentro do mesmo paradigma.

A utilização de SOA pelos principais sistemas de informação sobre a biodiversidade se deve, principalmente, pela heterogeneidade da capacidade tecnológica e a distribuição geográfica dos seus nós, que são características inerentes aos sistemas do seu domínio. Eles aproveitam a interoperabilidade, 0 suporte e a simplicidade das tecnologias Web Services para construir os seus 
serviços, que são independentes de plataformas, de regionalização ou de outros serviços (Copp; De Giovanni, 2008).

Essa independência entre os serviços contribui para a escalabilidade do sistema, facilitando a incorporação de novas ferramentas (Louridas, 2006), que é outra demanda da nova Webbee. A Webbee tem à sua disposição dados de espécimes e de polinização gerados pelas instituições brasileiras, mas que dependem de novas ferramentas para serem incorporados ao sistema. A criação de novas ferramentas não atende a essa demanda por completo. Além disso, esse desenvolvimento é descentralizado, gerando ferramentas quem utilizam apenas partes do sistema legado da Webbee, ou então, que são apenas referenciadas no seu portal.

Seguindo um modelo de referência para a implementação de arquiteturas orientadas a serviços, o OASIS SOA Reference Model (OASIS, 2007), este trabalho propõe uma arquitetura de referência para guiar o desenvolvimento da nova Webbee. Esta arquitetura de referência é, basicamente, um padrão ou conjunto de padrões de arquitetura predefinido, projetado em determinados contextos de negócios (OASIS, 2007).

A escolha desses padrões deve considerar o trabalho realizado pelas redes de dados de interesse da Webbee, pela necessidade de integração, e pela importância e experiência já adquiridas por elas no desenvolvimento da Informática da Biodiversidade. Entretanto, deve-se considerar, e priorizar, a utilização ou criação de padrões que atendam as demandas específicas da Webbee, que é um sistema especializado em abelhas. Neste contexto, os padrões que determinam a especialização da arquitetura de referência, comparada às arquiteturas das redes de interesse, devem ser analisados em provas de conceito.

Pretende-se que esta arquitetura de referência seja utilizada pelas diversas equipes que compõe o projeto Webbee para padronizar o seu desenvolvimento e considerar os seus objetivos principais: incorporar os dados regionais e se integrar às redes de dados sobre biodiversidade como referência em informações sobre espécies e espécimes de abelhas nativas brasileiras, e de polinização por estas abelhas. 


\subsection{Metodologia}

Para atingir os objetivos do trabalho, foi preciso determinar quais ferramentas e padrões da Informática da Biodiversidade (IB) deveriam ser adotados, ou criados, na arquitetura de referência para integrar a Webbee às redes de dados sobre biodiversidade, considerando o conjunto de requisitos que faz parte das novas atribuições da Webbee.

Como requisito básico para a participação nas redes de dados sobre biodiversidade, a Webbee precisava padronizar os seus dados e a sua comunicação com os sistemas que compõem estas redes. A princípio, foi preciso determinar e avaliar tecnicamente as redes de interesse (que compartilham dados de interesse da Webbee), avaliar a distância para a comunicação efetiva, a aderência com os novos requisitos de negócio, para, então, propor a arquitetura de referência. Dentro desta proposta, a metodologia de trabalho adotada considerou as seguintes etapas:

- Revisar na literatura as técnicas computacionais que embasam a padronização dos dados e a comunicação entre sistemas da Informática da Biodiversidade na Internet;

- Revisar na literatura as ferramentas e padrões da IB, procurando enfatizar a padronização dos dados e a comunicação entre sistemas, e identificar as iniciativas, com seus respectivos sistemas de informação, de interesse da Webbee;

- A partir do status atual da Webbee, avaliar a distância dos novos requisitos e encaminhar as possíveis soluções com base nas revisões da literatura;

- Analisar e estruturar as principais adaptações da Webbee para atender aos novos requisitos e propor uma arquitetura de referência; 
- Implementar provas de conceito para validar a arquitetura de referência proposta;

\subsection{Organização do texto}

Este texto é composto de seis capítulos e 2 apêndices, distribuídos nesta sequência:

- O capítulo 2 apresenta a XML como principal tecnologia para a padronização dos dados sobre biodiversidade, e lista os principais conceitos dos Web Services e das arquiteturas do tipo SOA para a comunicação e a organização dos sistemas.

- O capítulo 3 introduz a importância da Biodiversidade e apresenta o surgimento de um novo campo da computação, a Informática da Biodiversidade, enfatizando os padrões de dados e de comunicação entre sistemas, e as ferramentas e serviços que embasam as funcionalidades da nova Webbee.

- O capítulo 4 apresenta a especificação da arquitetura de referência. Ele parte de uma avaliação do status atual da Webbee, para então discutir os novos requisitos de negócio e encaminhar a análise desses requisitos com base nas ferramentas da Informática da Biodiversidade e nas redes de dados de interesse da Webbee.

- O Capítulo 5 traz as implementações realizadas para as provas de conceito. É apresentado o esquema conceitual de interações entre espécimes e a ferramenta de digitalização, integração e publicação de dados de espécimes e de interação entre espécimes, a Pollinator Data Digitizer - PDD. 
- As contribuições e as conclusões deste trabalho, e os demais trabalhos futuros são apresentados no capítulo 6 .

- Por fim, os apêndices aprofundam a discussão sobre a XML e detalham a estrutura da versão atual da Webbee. 


\section{CAPÍTULO 2 - CONCEITOS DE COMPUTAÇÃO APLICADOS A BIODIVERSIDADE}

Segundo Saraiva (2003), a complexidade e a abrangência da Ciência da Biodiversidade exigem o suporte da Tecnologia da Informação (TI). O surgimento da Informática da Biodiversidade (IB) é uma indicação do papel decisivo da tecnologia no apoio às decisões sobre as ações de conservação e uso sustentável da biodiversidade.

Diversas técnicas computacionais têm sido empregadas neste novo domínio, tais como algoritmos de modelagem, computação gráfica, inteligência artificial, otimização de processamento e armazenamento, entre outras (JOHNSON, 2007). Entretanto, este trabalho se atém somente às técnicas de padronização de dados e de comunicação entre sistemas aplicadas na IB.

Neste âmbito, este capítulo faz uma revisão das tecnologias Internet que, segundo Copp; De Giovanni (2008), são base para o desenvolvimento de padrões de dados e de protocolos de comunicação na IB, devido, principalmente, à natureza heterogênea dos nós e dos dados das redes de informações sobre a biodiversidade.

\subsection{Extensible Markup Language - XML}

A eXtensible Markup Language (XML), é um conjunto de regras para concepção de arquivos do tipo texto que permitem a estruturação dos dados (em blocos de endereços, parâmetros de configuração, transações financeiras, desenhos técnicos, e outros) de forma não-ambígua, extensível e insensível aos problemas de internacionalização/localização e de dependência de plataformas computacionais (W3C, 2007a). Ela é um padrão aberto, um projeto patrocinado pelo World Wide Web Consortium (W3C), que supervisiona o seu desenvolvimento através dos W3C's XML Working Groups. 
O uso da XML nas aplicações comerciais tem se mostrado cada vez maior. Ela tem substituído tecnologias da informação e da comunicação de diversos domínios, principalmente na Internet. Para os sistemas de informação que trabalham com a biodiversidade, a XML tem um papel fundamental, pois é ela quem padroniza os dados trocados e viabiliza a comunicação entre aplicações diferentes, que são inerentes ao domínio (Copp; De Giovanni, 2008). Numerosas publicações abordam o assunto, como (Saraiva, 2003), (Copp; De Giovanni, 2008), (Muller, 2006), (Ma, 2005), além do site de desenvolvimento da XML no W3C (W3C, 2007a), que foram as fontes para este texto, que aborda os conceitos básicos da tecnologia.

A XML também é uma metalinguagem, ou seja, uma linguagem para descrever outras linguagens e, portanto, permite definir linguagens de marcação (aplicações) específicas para classes diferentes de documentos. Criada a partir dos aspectos mais utilizados e menos complexos da SGML (Standard Generalized Markup Language), a XML tornou-se uma metalinguagem mais fácil de entender, de utilizar para o desenvolvimento de aplicações e para promover a interoperabilidade, em particular, na Internet.

\subsubsection{Espaço de Nomes: XML Namespaces}

Os espaços de nomes (XML Namespaces) são objeto de recomendação da W3C desde janeiro de 1999. Eles permitem evitar conflitos potenciais entre os nomes dos marcadores e dos atributos quando se desejar mesclar o vocabulário de duas aplicações diferentes em um mesmo documento XML. Um namespace permite essa unicidade ao identificar uma origem ou referência dos nomes utilizados no documento. Ele é uma coleção de nomes de elementos e atributos, identificada por um nome único, referenciada por um URI (Uniform Resource Identifier).

Mesmo com nomes (titulo) duplicados, a especificação do namespace ao qual se referem, dirime a ambigüidade, ao criar um nome com duas partes, uma das quais é o namespace. Não é o prefixo que identifica o espaço de nomes e sim, o seu URI associado ao prefixo. 


\subsubsection{Gramática: DTD e XML Schema}

A definição da estrutura legal de um documento XML, ou a sua gramática, é a responsável por especificar quais marcações (tags) estão disponíveis, onde e quantas vezes elas podem ocorrer no documento e como elas se relacionam. Herdadas da sua origem na SGML, as construções coletadas em um documento do tipo Document Type Definition (DTD) (ou no próprio documento XML) podem definir uma gramática para a linguagem de marcação atribuída ao documento XML.

Quando um documento XML atende as regras de construção de uma DTD, o documento XML é dito válido. Apesar de permitir a sua validação, essas construções apresentam algumas deficiências para definir documentos XML. Elas são muito limitadas em relação aos tipos de dados que oferecem. Além disso, a própria sintaxe das construções difere daquela do XML, o que é um empecilho ao seu aprendizado. Elas também não permitem utilizar o conceito de namespaces, para identificação unívoca dos nomes. Para preencher estas lacunas, uma aplicação XML foi especificada pela W3C (maio 2001), a XML Schema Language.

A principal vantagem da XML Schema Language é a sua capacidade de estruturação. Com ela, é possível criar um rico espectro de tipos de dados como os comumente encontrados nas linguagens de programação (inteiro, string, booleano, data e hora, etc.), inclusive, o tipo complexo, que se vale de outra propriedade da aplicação, o reuso. Pode-se quebrar um schema em componentes previamente definidos e aproveitá-los na composição de outros elementos. A XML Schema também trabalha com o conceito de herança, de forma que se podem criar esquemas derivando características de outros existentes. Outra característica distintiva da XML Schema Language é sua integração com o conceito de XML Namespaces, considerada uma importante ausência nas DTDs.

Por fim, os XML Schema também são documentos XML e, portanto, seguem suas regras de formação e podem ser manipulados por suas ferramentas, diferentemente dos DTDs. Desse modo, um schema comum permite que, tanto do lado do servidor como do cliente, os documentos XML possam ser validados de maneira fácil e eficiente. Por todas essas características, os schemas podem modelar dados complexos eficientemente, facilitando o processamento, além de 
fazê-lo de um modo elegante e de mais fácil leitura pelos desenvolvedores (Saraiva, 2003).

\subsubsection{Aplicações XML e Restrições}

Diversas tecnologias XML têm sido criadas para trabalhar e expandir as funcionalidades dos arquivos XML, tais como, construtores de páginas Internet (eXtensible Hypertext Markup Language - XHTML), processadores de transformação de XML em XML e navegadores internos (Extensible Stylesheet Language Family XSL), apontadores (XML Pointer - XPointer), protocolos de comunicação (XML Remote Procedure Call - XML-RPC), etc. Estas aplicações são sintaxes com marcadores e atributos próprios que definem o seu comportamento a cada elemento de estrutura extraído pelos processadores XML.

Ao prover definições flexíveis de documentos e possibilidades de processamento, e ao separar definição de conteúdo das instruções de apresentação, a XML facilita a troca de mensagens e a formatação visual em diversas plataformas, 0 que pode ser considerada uma base para a interoperabilidade (Saraiva, 2003). Outra contribuição importante da XML é a busca e recuperação mais rápidas de informação, devido ao fato dos documentos XML também conterem metadados.

Entretanto, há limitações e pontos a serem mais bem desenvolvidos (Roy; Ramanujan, 2000) apud (Saraiva, 2003). Por exemplo, a XML pode não ser uma boa solução para sistemas stand-alone, ainda apresenta restrições do ponto de vista de segurança e quando uma comunicação de baixo nível eficiente é necessária. Outro obstáculo importante para a sua adoção é a ambigüidade na interpretação da informação, causada por adoção de schemas diferentes para a mesma atividade.

Essas limitações não são definitivas; ao contrário, são aspectos que estão sendo considerados na evolução das tecnologias XML. No caso da interpretação das informações, por exemplo, surgem entidades que trabalham na criação de vocabulários padrões para indústrias específicas (na biodiversidade, por exemplo),

que contribuem para a consistência da troca de dados. Em outro aspecto, a sua 
utilização como fundamento para diversas outras tecnologias como as que formam o coração dos Web Services, como será visto a seguir, é mais uma garantia de sua utilidade e de sua evolução.

\subsection{Web Services}

A necessidade de integrar sistemas de informação não é exclusividade da Biodiversidade (Saraiva, 2003). Cada vez mais, as organizações necessitam consolidar suas informações dispersas por sistemas independentes, adquiridos ou desenvolvidos, freqüentemente hospedados em filiais espalhadas pelo mundo. Se antes o problema era o de conectar aplicações executando em mainframes com sistemas baseados na arquitetura cliente-servidor, atualmente a questão é como integrar ambos com a Internet (Coyle, 2001), independente da plataforma.

Tecnologias de software como o COM (Component object model), o Corba/IIOP (Common object request broker architecture/Internet InterORB Protocol), e o EJB (Enterprise Java beans), foram desenvolvidas para permitir a criação de componentes reutilizáveis, e foram lançados sem a possibilidade de integrar plataformas diferentes. As tentativas posteriores de interoperabilidade não obtiveram os resultados esperados, pois, embora se encontrem soluções de integração (entre Unix e Microsoft, por exemplo), além de seus problemas de construção, elas continuam restritas a algumas plataformas (Chester, 2001).

Segundo Saraiva (2003), a questão não deve ser a de acabar com a heterogeneidade, uma vez que ela trouxe diversos benefícios às soluções da TI, mas de gerenciá-la. Este cenário tornou-se favorável para uma solução que tivesse um enfoque mais amplo, padronizado e comumente aceito. Nela, os sistemas heterogêneos continuam com suas tecnologias proprietárias, mas suas interfaces e padrões de colaboração são padronizados seguindo padrões computacionalmente leves, como os protocolos Internet e a XML.

Esse é o um dos pilares dos Web Services: encapsular as aplicações existentes ao codificar interfaces em XML, e ter os clientes e servidores comunicando via padrões Internet, de modo a permitir a integração de sistemas e 
possibilitar a interoperabilidade entre plataformas. No caso da comunicação entre os sistemas de informação sobre biodiversidade, a utilização de padrões abertos, interoperáveis e simples permite que instituições com poucos recursos tecnológicos e financeiros integrem e contribuam com uma rede de dados sem grandes investimentos.

\subsubsection{Conceito}

A tecnologia de Web Services (WS) é um esforço para levar a Internet ao seu próximo estágio: de provedora de serviços a usuários, a provedora de serviços para programas que necessitam se conectar a outros programas. Eles possibilitam o acesso dos desenvolvedores às aplicações por linguagens e protocolos padrões abertos, simplificando a integração de aplicações (Coyle, 2001).

Os Web Services são componentes de software independentes, autodescritos e autocontidos, que realizam uma tarefa específica ou um conjunto de tarefas. Esse serviço prestado é descrito e publicado na Internet, de tal modo que outros softwares aplicativos possam encontrá-los e utilizá-los.

A interoperabilidade dos WS é proporcionada pelo conceito de encapsulamento, que induz a independência da linguagem de programação e da plataforma de operação (Gottschalk et al., 2002). A definição de um protocolo de transporte de informação que independe do conteúdo da informação, da semântica ou da sintaxe, é base para a interoperabilidade (Howerton, 2007).

\subsubsection{Arquitetura}

Os Web Services provêem padrões para a interoperabilidade entre diferentes aplicações de software, executando em uma variedade de plataformas ou frameworks (arcabouços) (W3C, 2007b). A arquitetura dessas tecnologias baseia-se em três atores principais (Saraiva, 2003) (Figura 1): 
- Provedor de serviços (service providers) - cria módulos de software que desempenham tarefas específicas e os publicam para o mundo exterior, ao armazenar e registrar a sua descrição num provedor de registros;

- Provedor de registros (registry provider ou service brokers) - um intermediário que mantém um registro de serviços publicados, e armazena as suas descrições: uma espécie de catálogo de Web Services;

- Cliente de serviços (service clients ou service requesters) - descobre o serviço desejado ao procurar por ele no provedor de registros. Depois, invoca o serviço passando parâmetros para o provedor do serviço e recebendo os resultados como resposta. Se ele conhece previamente a localização do serviço, ele pode invocá-lo diretamente ou acessar a sua descrição sem utilizar o provedor de registros.

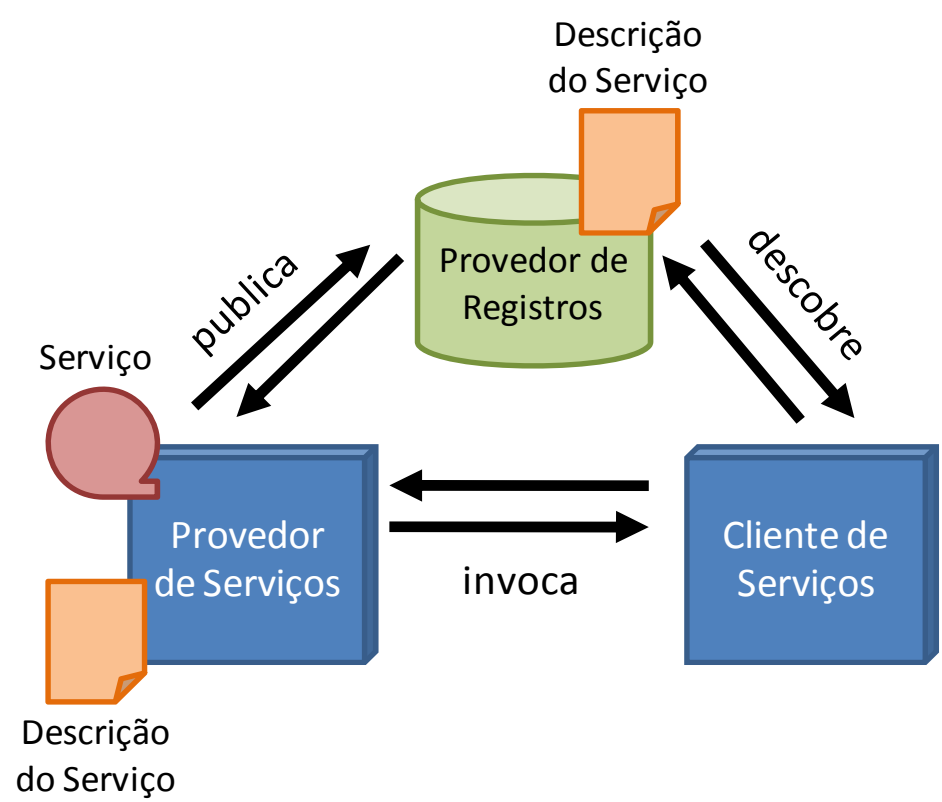

Figura 1 - Arquitetura da tecnologia Web services. 


\subsubsection{Fundamentos Tecnológicos}

As tecnologias padronizadas e de código aberto que permitem a comunicação programa-programa dos Web Services e que foram a chave do seu sucesso, podem ser representados por uma pilha conceitual, Figura 2 (Gottschalk et al., 2002).

Todos os Web Services executam sobre uma rede, que é freqüentemente baseada sobre o protocolo Hypertext Transfer Protocol (HTTP), mas que pode ter outros tipos de protocolo de aplicação que pertencem às camadas do modelo OSI (Open Systems Interconnection). Em grande parte, o termo "Web" é atribuído ao fato de o HTTP ter sido escolhido como o primeiro protocolo dos WS para troca de mensagens (Ma, 2005).

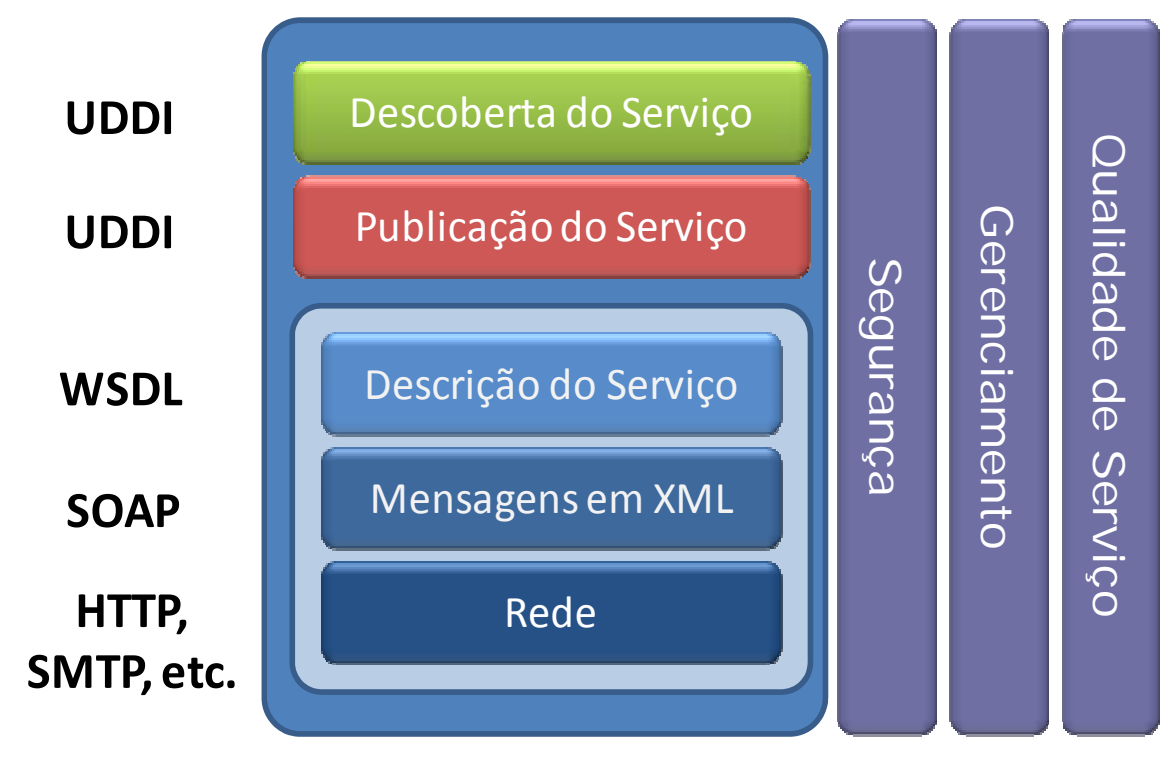

Figura 2 - Pilha conceitual de Web services

Fonte: (Gottschalk et al., 2002)

O SOAP é um protocolo simples e leve criado em 1998 para ser um RPCXML (remote procedure call) na Internet (Gottschalk et al., 2002). Sua especificação define (Leymann et al., 2002): 
- Um envelope: um quadro para expressar o que vai numa mensagem, quem deve manipular as partes individuais, e se essa manipulação é opcional ou obrigatória;

- Regras de codificação: um mecanismo de serialização para troca de instâncias de tipos de dados definidos pela aplicação;

- A representação do RPC SOAP: uma convenção para a representação de RPCs e respostas;

A descrição do serviço é feita com uma notação formal XML, a Web Services Descripton Language (WSDL), que provê todos os detalhes necessários para interação com o serviço, incluindo o formato das mensagens (que detalha a operação), os protocolos de transporte, e a sua localização (W3C, 2007d). Esta descrição pode ser descoberta e publicada em um provedor de registros, chamado de Universal Description, Discovery and Integration (UDDI), podendo ser encontrado por qualquer aplicação-cliente (UDDI, 2007).

As três primeiras camadas inferiores da pilha são suficientes para tornar os Web Services interoperáveis. Estas camadas criam uma entrada de baixo custo para os WS permitindo a estes serviços serem desenvolvidos na Internet. As camadas restantes da pilha (descoberta e publicação do serviço) são opcionais e serão usadas quando o negócio necessitar (Gottschalk et al., 2002).

Para atender as demandas atuais dos negócios, outras camadas devem ser incorporadas: segurança, gestão e qualidade do serviço. Estas estruturas estão representadas pelas torres verticais na figura 2 e devem ser endereçadas em cada camada da pilha. A solução de cada camada pode ser independente umas das outras (Gottschalk et al., 2002).

\subsection{Service Oriented Architecture - SOA}

Segundo o OASIS (2007), a Service-Oriented Architecture (SOA) é um paradigma para a organização e organização de competências distribuídas que 
estão sob o controle de diferentes domínios proprietários. Enquanto os Web Services (WS) especificam como os serviços (para distribuição dessas competências) devem ser criados e acessados, a SOA define a estratégia para a construção de sistemas distribuídos que entreguem as funcionalidades das suas aplicações como serviços para aplicações clientes ou para a construção de outros serviços (Colan, 2009).

É importante ressaltar que SOA pode ser baseada na tecnologia Web Services, mas ela também pode utilizar outras tecnologias (Corba, EJB, etc.). No entanto, as vantagens oferecidas pelos WS e suas tecnologias viabilizaram a migração dos sistemas para as Arquiteturas Orientadas a Serviços (Service-Oriented Architectures - SOA) (Ma, 2005).

\subsubsection{Propriedades dos Serviços}

Um serviço em uma SOA é uma funcionalidade (de uma aplicação) empacotada como um componente para o uso em um processo de negócio (Colan, 2009). Diferentemente do paradigma de Programação Orientada a Objeto, onde o foco está no empacotamento de dados com operações, o foco central da Arquitetura Orientada a Serviço é a tarefa ou função de negócio - obtendo alguma coisa feita (OASIS, 2007).

Um serviço é oferecido por uma entidade - o provedor de serviço. Ele é uma caixa preta porque sua implementação é oculta ao cliente do serviço, exceto pelos modelos de informação e comportamento que são expostos pela interface do serviço, e pelas informações passadas aos clientes para determinar quando um dado serviço é apropriado para suas necessidades.

Os principais conceitos do paradigma SOA são a visibilidade, a interação e os efeitos dos serviços. Enquanto a visibilidade introduz a possibilidade de compatibilizar as necessidades com as competências (e vice-versa), a interação é a atividade que usa a competência. Tipicamente mediada por troca de mensagens, uma interação prossegue através de uma série de ações de troca de informações e invocações. O propósito de usar as competências é realizar um ou mais efeitos no 
mundo real. Este efeito pode ser o retorno de uma informação ou a mudança no estado de entidades (conhecidas ou desconhecidas) que estão envolvidas na interação (OASIS, 2007).

\subsubsection{Modelo de Referência}

A Organization for the Advancement of Structured Information Standards OASIS (OASIS, 2007) é um consórcio fundado em 1993, mantido por empresas que atuam no setor de TI. O objetivo desta iniciativa é o desenvolvimento, convergência e adoção de padrões do setor, entre eles os que modelam a Arquitetura Orientada a Serviços. Para esta arquitetura, a OASIS define um modelo de referência de base para guiar e promover criações específicas, o OASIS SOA Reference Model.

De acordo com o OASIS, o propósito de um modelo de referência é oferecer um framework conceitual comum que possa ser usado consistentemente através e entre diferentes implementações e na modelagem de soluções específicas.

A Figura 3 mostra como um modelo de referência para SOA se relaciona às outras entradas de arquiteturas de sistemas distribuídos. Os conceitos e relacionamentos definidos pelo modelo de referência têm a intenção de ser base para descrição de arquiteturas de referências e padrões que definem as categorias mais específicas de projetos SOA (OASIS, 2007): 


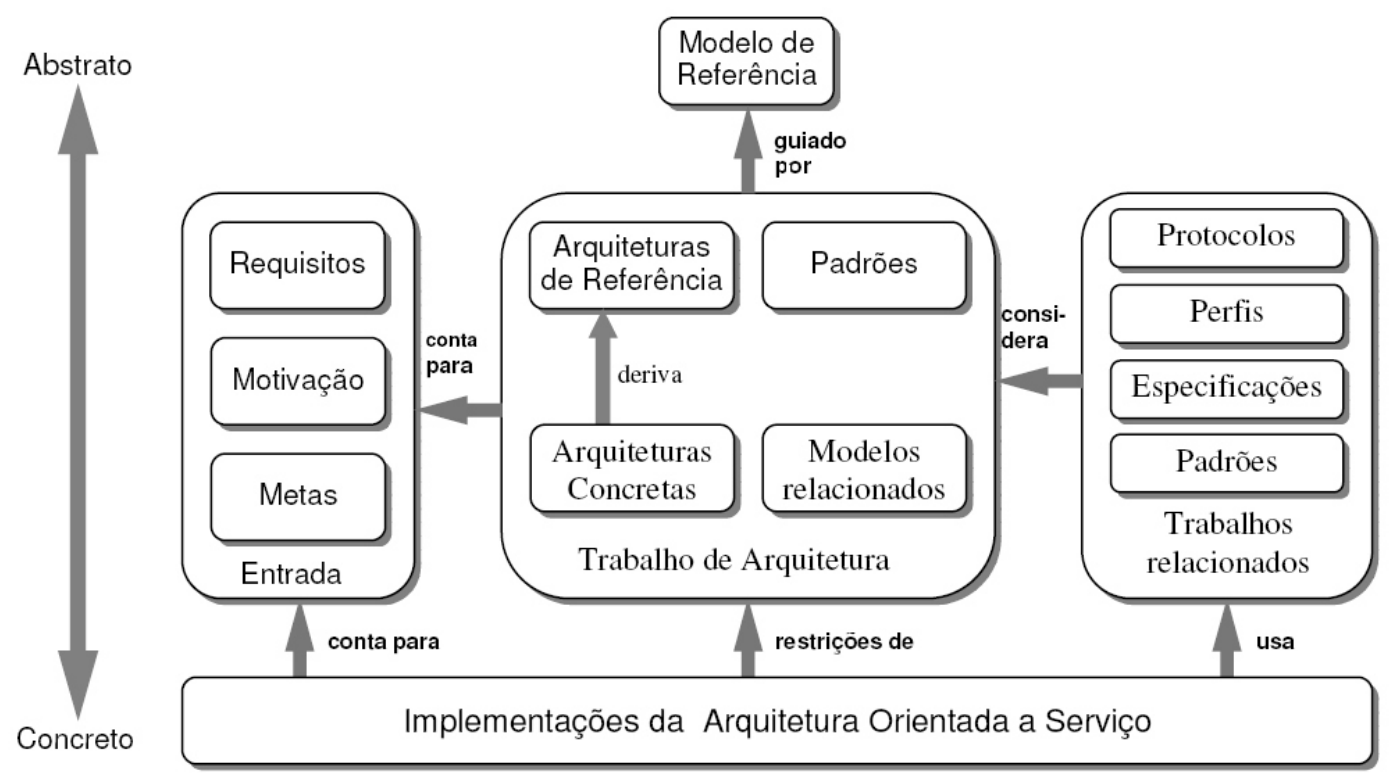

Figura 3 - Framework para implementação de arquiteturas do tipo SOA

Fonte: (OASIS, 2007)

- Enquanto as arquiteturas de referências podem formar as bases de classes de soluções, as arquiteturas concretas irão definir abordagens de soluções específicas.

- As arquiteturas concretas vêm de uma combinação de arquiteturas de referência, padrões de arquitetura e requisitos adicionais, incluindo aqueles impostos pelos ambientes tecnológicos.

- A arquitetura precisa considerar as metas, motivações e requisitos que definem os problemas reais que estão sendo estudados.

- A arquitetura é freqüentemente desenvolvida em um contexto prédefinido: com protocolos, perfis, especificações, e padrões pertinentes.

As implementações SOA combinam todos estes elementos, do princípio arquitetural mais genérico até o mais específico, que define as necessidades atuais, e representa implementações específicas que serão construídas e usadas em um ambiente operacional. Contudo, espera-se que a Arquitetura Orientada a Serviços (OASIS, 2007): 
- Terá entidades que podem ser identificadas como serviços;

- Estará apta a identificar como a visibilidade é estabelecida entre os provedores e consumidores de serviço;

- Estará apta a identificar como a interação será mediada;

- Estará apta a identificar como os efeitos do uso de serviços são compreendidos;

- Terá descrições associadas com serviços;

- Estará apta a identificar o contexto de execução requerido para suportar interações; e

- Possibilitará identificar como as políticas são tratadas e como os contratos podem ser modelados e formados.

\subsubsection{Implementação da Arquitetura}

A SOA fornece os padrões para o projeto, desenvolvimento, implantação e gerenciamento de uma infra-estrutura de aplicações fracamente acopladas (loosely coupled) (Ferreira, 2007). Isto significa que o cliente do serviço não precisa saber os detalhes técnicos da implementação do provedor, como linguagem de programação, plataforma de desenvolvimento, etc. para invocar o serviço (Colan, 2009).

O nível inferior da SOA é composto por serviços básicos e suas descrições e operações primitivas (publicação, descoberta, seleção e utilização). Camadas superiores da arquitetura fornecem os meios para a composição e o gerenciamento desses serviços (Papazoglou; Heuvel, 2007). Cada serviço só precisa saber a forma de transmitir mensagens com base em um pequeno conjunto de interfaces normalizadas. 
Essa abordagem facilita o desenvolvimento de sistemas escaláveis, que permitem adicionar continuamente novos prestadores de serviços, independente das suas implementações (Copp; De Giovanni, 2008).

Existem diversos processos para implementação de arquiteturas SOA. No entanto, grande parte desses processos aplicados por grandes consultorias ou empresas de TI são proprietários e utilizam arquiteturas de referência, arquiteturas concretas e padrões proprietários.

\subsection{Comentário final}

As ferramentas da Informática da Biodiversidade, que possibilitam o avanço da TI no apoio às decisões sobre a conservação e uso sustentável da biodiversidade, utilizam os padrões simples e abertos da Internet para padronizar os seus dados e realizar a comunicação entre os seus sistemas.

A XML traz para o domínio da biodiversidade a tecnologia necessária para a criação de esquemas conceituais que permitem estruturar os dados de forma nãoambígua, com a utilização dos metadados, extensível, e insensível aos problemas de internacionalização/localidade.

A interoperabilidade também é o principal atrativo dos Web Services para que, organizados estrategicamente pelo paradigma de orientação a serviços, permitam às redes de dados sobre biodiversidade uma padronização que independe de plataforma e de linguagem de programação, e da heterogeneidade dos sistemas participantes.

As ferramentas da Informática da Biodiversidade estão intimamente ligadas aos conceitos e tecnologias da computação já apresentados, principalmente, porque enfocam a padronização dos dados e a comunicação entre sistemas de informação sobre a biodiversidade. Elas serão a fonte dos trabalhos relacionados (protocolos, padrões, etc.) do modelo OASIS mencionados na Figura 3. 


\section{CAPÍTULO 3 - INFORMÁTICA DA BIODIVERSIDADE}

Dentro do contexto de integração da Webbee às redes de dados sobre biodiversidade, este capítulo revisa a literatura sobre a Informática da Biodiversidade, procurando enfatizar a padronização dos dados e a comunicação na Internet entre os sistemas de informação sobre a biodiversidade, e as principais ferramentas e serviços da área para catalogar, integrar e publicar dados de espécies e espécimes.

\subsection{Introdução}

A Diversidade Biológica, ou Biodiversidade (Schnase et al., 2007), é definida como "a variabilidade entre os organismos vivos de todas as fontes incluindo, entre outras, ecossistemas terrestres, marinhos e outros ecossistemas aquáticos, e os complexos ecológicos dos quais eles são partes; isto inclui diversidade dentro das espécies, entre espécies e de ecossistemas" (CDB, 2008).

Segundo Stockwell (1997) a Ciência da Biodiversidade é o estudo das tendências históricas e atuais sobre a riqueza e diversidade dos ambientes biológicos. Se, por um lado, ela tem ligações com a pesquisa teórica em biologia evolucionária, taxonomia e ecologia, por outro, ela também está preocupada com a agregação e análise de informações para o gerenciamento científico dos recursos naturais para a sua conservação.

Estas análises consideram que as ações locais sobre a biodiversidade, tanto de conservação quanto de degradação, têm impacto sobre conceitos complexos e de alto nível de organização, tais como biomas, ecossistemas, filos, floras e faunas, cuja interdependência de seus componentes torna os efeitos globais. Por isso, para definir as prioridades de conservação, os pesquisadores precisam agregar e analisar informações que vão além de seus territórios e seus domínios científicos. Além de dados sociais, econômicos e ambientais locais, por exemplo, eles precisam 
considerar a interdependência inerente a diversidade e buscar informações das regiões vizinhas e de terras similares em continentes distantes (Bisby, 2000).

Como conseqüência, para tornar efetivas as decisões sobre conversação e uso sustentável da biodiversidade, é preciso avaliar de forma integrada o status atual do risco da perda de recursos e realizar um monitoramento contínuo com a coleta, armazenamento, análise, simulação, visualização e intercâmbio de um volume expressivo de dados de diversos domínios. No entanto, a quantidade, complexidade e dispersão dos dados tornam as tarefas essencialmente impossíveis de serem realizadas sem o uso das técnicas e tecnologias computacionais e de comunicação modernas. Segundo Steinhage (2008), esta demanda abre precedentes para o surgimento de um novo campo da computação, a chamada Biodiversity Informatics, ou Informática da Biodiversidade (IB).

\subsection{Iniciativas para facilitar o acesso às informações científicas sobre biodiversidade}

Em 1992, na Conferência das Nações Unidas sobre o Meio ambiente e Desenvolvimento, também conhecida como Rio-92, foi assinada a Convenção sobre Diversidade Biológica - CDB. Ela é o primeiro acordo global a cobrir todos os aspectos da biodiversidade biológica: conservação, uso sustentável e compartilhamento dos benefícios dos recursos genéticos (CDB, 2008). Todos os anos os países signatários da CDB encontram-se em uma Conferência das Partes (COP), onde matérias ligadas à Agenda 21, em especial, ao capítulo 15, de Conservação da Diversidade Biológica, são analisadas para deliberação.

Para alcançar seus objetivos, a CDB passou a promover o surgimento de iniciativas, ou o fortalecimento das já existentes, que trabalhem para facilitar o acesso às informações sobre biodiversidade. As iniciativas concentram suas atividades na digitalização (ou seu financiamento), integração e publicação de dados de espécies e espécimes em portais Internet (Canhos et al., 2004). Estes dados podem abranger todas as espécies da Terra: Encyclopedia of Life (EOL), Species 2000, Integrated Taxonomic Information System (ITIS), Global Biodiversity 
Information Facility (GBIF), etc., mas também, podem se especializar em um determinado conjunto de espécies, ou em regiões geográficas, ou ambos: Iniciativa Brasileira dos Polinizadores (IBP), Oceania Pollinator Initiative, Fauna Europea, European Register of Marine Species, Euro-Mediterranean Plant Diversity e InterAmerican Biodiversity Information Network (IABIN), por exemplo.

Segundo Canhos et al. (2004), a digitalização dos dados sobre biodiversidade teve origem no trabalho cooperativo realizado pelos herbários australianos no meio da década de 70. Este trabalho resultou na criação da Environment Resources Information Network (ERIN) em 1989, que serviu de inspiração para que no início dos anos 90, importantes iniciativas, como a Mexico Comisión Nacional para el Conocimiento y Uso de la Biodiversidad (CONABIO) do México e a Costa Rica Instituto Nacional de Biodiversidad (INBio), da Costa Rica, também se envolvessem com a digitalização e a manipulação dos dados sobre biodiversidade, multiplicando as redes de dados sobre biodiversidade.

Desde o surgimento dessas iniciativas, ferramentas de TI foram criadas e evoluídas para digitalizar, manipular e trocar dados sobre biodiversidade, partindo de um ambiente local, para um contexto de rede de dados (Bisby, 2000), impulsionadas pela evolução das redes de comunicação e pela demanda por dados integrados para tomada de decisão. Neste ambiente de integração, foram criadas redes especialistas que adotavam seus próprios padrões, como no caso da ERIN, que ainda em 1989 adotou o HISPID, Herbarium Information Standards and Protocols for Interchange of Data, um padrão para troca de dados eletrônicos. Paralelamente às redes especialistas, ferramentas criadas localmente, pela sua qualidade, praticidade ou identificação (por serem do mesmo domínio de estudos), também se tornaram padrões para outras iniciativas e seus sistemas, principalmente os protocolos de troca de dados e os esquemas conceituais, criando pequenas redes dispersas.

Para melhorar a interoperabilidade entre os sistemas de informação sobre a biodiversidade e aumentar a quantidade de dados integrados com a inclusão de novos colaboradores às redes, foram criadas iniciativas técnicas para viabilizar a padronização das ferramentas da IB. Estes grupos técnicos também são compostos por membros de outras iniciativas, que utilizam aplicativos web de colaboração para concentrar a evolução, criação e validação de padrões. O Biodiversity Information 
Standards (TDWG), anteriormente chamado de Taxonomic Database Working Group, é uma das principais iniciativas que concentram esse tipo de discussão.

No entanto, é importante ressaltar que outras iniciativas, tais como o GBIF, a IABIN e o ITIS, por exemplo, apesar de encaminharem a discussão de seus padrões em ambientes como o TDWG, continuam a criar ferramentas de publicação, análise, simulação e distribuição que também podem ser usadas ou adaptadas pela comunidade.

Como conseqüência do trabalho de todas as iniciativas, os envolvidos com a conservação da biodiversidade têm à sua disposição uma quantidade de dados na Internet cada dia maior associada às ferramentas de digitalização, consulta, análise e simulação, cada vez mais integradas, e que dão suporte as suas decisões de conservação.

Cabe aos interessados: pesquisadores, estudantes, empresas, ativistas, governos, outras iniciativas ou profissionais de TI, dentro de um conceito de rede de dados sobre biodiversidade, utilizar, adaptar e otimizar esses dados e ferramentas para atender as suas necessidades, que podem ser as de um tomador de decisões, ou as de um provedor ou utilizador de dados, que é um dos novos focos a serem adotados pela Webbee.

\subsubsection{Iniciativa Brasileira dos Polinizadores - IBP}

É na visita às flores em busca de recursos alimentares que os polinizadores executam um serviço importante ao meio ambiente (Imperatriz-Fonseca et al., 2000). Neste processo, chamado de polinização, aproximadamente 100.000 espécies de insetos, pássaros e mamíferos mediam a reprodução sexual da maioria das plantas com flores, incluindo $2 / 3$ das plantas comestíveis (FAO, 2005).

Essa interação de mutualismo entre plantas e polinizadores é benéfica aos seres humanos, diretamente, no resultado das colheitas, e indiretamente, na conservação de ecossistemas (Memmott et al., 2007). Estudos mostram que a polinização natural mantém a variabilidade genética e pode melhorar a quantidade e a qualidade da fecundação das flores e da produção de frutos. Estima-se que os 
valores gerados com os serviços de polinização somem mais de 200 bilhões de dólares ao ano (FAO, 2005).

Apesar de sua importância ecológica e econômica, os polinizadores estão em risco crescente de extinção local e global devido à degradação causada pela atividade humana, incluindo a devastação de habitats, o manejo inadequado do solo, a introdução de espécies não-nativas e o impacto no clima (Memmott et al., 2007). Este problema tende a se agravar devido à falta de conhecimento básico dos pesquisadores sobre as necessidades específicas dos polinizadores selvagens, principalmente nos países em desenvolvimento (FAO, 2005).

Em resposta a essa crise de polinização (FAO, 2005), a Convenção sobre Biodiversidade Biológica (CDB) aprovou na COP5, em 2000, a São Paulo Declaration on Pollinators. Esta declaração, escrita por pesquisadores de diversos países, e organizada por brasileiros, culminou na criação de uma Iniciativa Internacional para a Conservação e Uso Sustentável dos Polinizadores, que deve promover, no mundo todo, estudos sobre o declínio e a conservação da diversidade dos polinizadores e o seu impacto econômico na agricultura (Imperatriz-Fonseca et al., 2004).

A partir desta Iniciativa Internacional, diversos projetos de escalas regionais e globais foram criados ou incentivados com intuito de promover acesso às informações sobre biodiversidade dos polinizadores, entre eles, a Iniciativa Brasileira dos Polinizadores (IBP).

A IBP é desenvolvida por vários componentes da sociedade civil, que desenvolvem as bases das atividades para permitirem o uso sustentado e a conservação dos polinizadores e da polinização (IBP, 2007). A Iniciativa desenvolve, financia ou coordena encontros de discussão técnica e política sobre a polinização, livros, artigos, e outros materiais de educação para a sociedade em geral e para os apicultores, além de realizar campanhas de promoção dos polinizadores junto às instituições de diferentes níveis governamentais.

Em relação à Webbee, a IBP tem grande potencial como financiadora e apoiadora. A iniciativa é uma das responsáveis pela projeção nacional e internacional do sistema. Neste sentido, ela também trabalhará para reunir mais grupos de pesquisa para integrar a Webbee, dentro de uma rede de colaboração. resultado direto desta atuação se concretizará em um novo cenário para a Webbee, 
que é o foco da arquitetura de referência proposta por este trabalho: guiar o desenvolvimento de um sistema de informação que é referência sobre os dados de espécies e espécimes de abelhas nativas brasileiras, e de polinização por estas abelhas.

\subsubsection{Inter-American Biodiversity Information Network - IABIN}

A Inter-American Biodiversity Information Network - IABIN é um fórum criado pela OEA (Organização dos Estados Americanos) para promover coordenação e colaboração técnica entre os países da América na coleta, compartilhamento e uso da informação sobre biodiversidade (IABIN, 2007). Desta forma, ela pretende contribuir para a tomada de decisão no manejo e na conservação dos recursos naturais, a educação, e o desenvolvimento sustentável da região.

Entre os seus principais objetivos está a construção de uma infra-estrutura sobre a plataforma Internet para a troca de dados sobre biodiversidade das Américas. A construção desta rede é feita por sub-redes temáticas: Espécies e Espécimes, Áreas Protegidas, Ecossistemas, Espécies Invasoras e Polinizadores. Cada sub-rede possui um grupo de trabalho dedicado, e esses grupos colaboram entre si e coordenam a transferência tecnológica para as bases regionais.

A rede temática dedicada aos polinizadores, a IABIN Pollinators Thematics Network (IABIN-PTN) é coordenada por um consórcio de importantes instituições e programas norte-americanos (Coevolution Institute, National Biological Information Infrastructure e o Integrated Taxonomic Information System) e a Universidade de São Paulo, representada pelo Laboratório de Automação Agrícola (LAA) da Escola Politécnica e o Laboratório de Abelhas do Instituto de Biociências. Nesta parceria, cabe ao LAA a definição dos padrões técnicos e o desenvolvimento das ferramentas da rede: um portal de busca de espécimes adaptado do GBIF (Figura 4), um banco de dados de especialistas, e uma ferramenta de digitalização de dados de espécimes, a Pollinator Data Digitizer - PDD (item 5.2), incorporada da Webbee. Todas essas ferramentas são acessíveis pelo site da IABIN-PTN em http://pollinators.iabin.net. 
O principal diferencial da PTN é a publicação dos dados de interações que envolvem agentes polinizadores (IABIN, 2007). A rede obtém esses dados em chamadas para o financiamento da digitalização ou publicação dos dados de interação de instituições americanas: Brasil, Peru, Colômbia, Chile, entre outras. Todas as ferramentas da PTN estão sendo adaptadas para tratar e integrar esse tipo de dado, que é algo novo entre os sistemas de informação sobre biodiversidade, pois os padrões e ferramentas adotados pela IABIN-PTN para este fim foram desenvolvidos no âmbito deste trabalho.

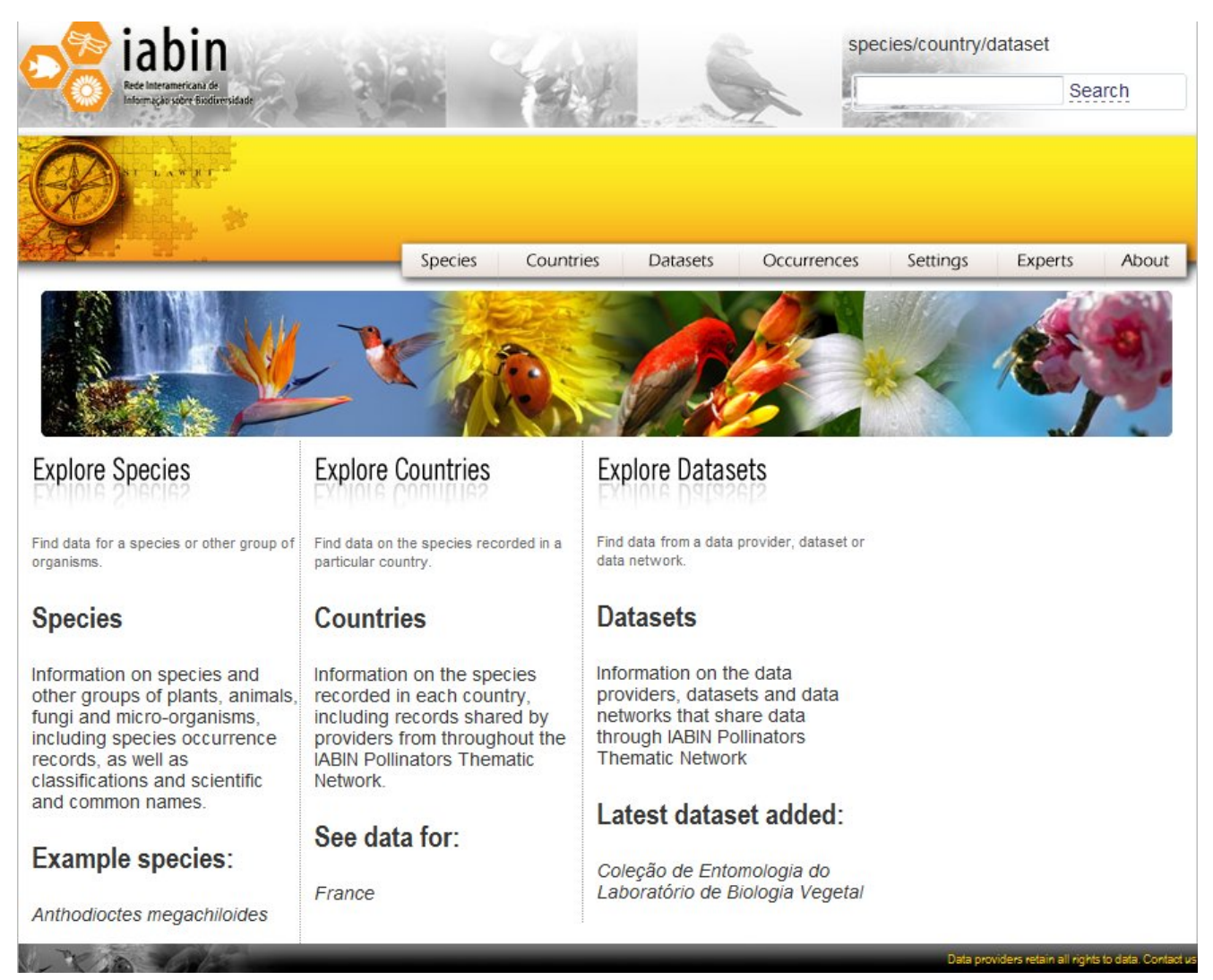

Figura 4 - Página de entrada do Portal da IABIN-PTN

\subsubsection{Integrated Taxonomic Information System}

O objetivo do Integrated Taxonomic Information System - ITIS é criar um banco de dados de referência de nomes e classificações hierárquicas das espécies. 
Este banco de dados é revisado periodicamente para garantir a qualidade, registrando a validação das classificações, revisões, e adições de novas descrições de espécies, da fauna ou flora, no ambiente aquático e terrestre (ITIS, 2008).

O ITIS publica na Internet um arquivo com a lista de todos os nomes de espécies válidos. Atualmente, o ITIS trabalha do desenvolvimento de um Web Service para a validação de nomes taxonômicos pela Internet, que será usado pela nova Webbee.

\subsubsection{Global Biodiversity information Facility - GBIF}

O Global Biodiversity Information Facility (GBIF) surgiu em 1996 de uma recomendação do Fórum de Megaciência da Organização para a Cooperação e Desenvolvimento Econômico (OCDE) (GBIF, 2007). Estes projetos de "megaciência", assim como o Projeto Genoma, têm ações para a resolução de problemas globais com a integração de pesquisadores de diversas áreas e o envolvimento do maior número possível de países, trabalhando de forma cooperativa e integrada (Saraiva, 2003). O principal objetivo do GBIF é coordenar uma rede para integrar e disponibilizar em seu portal Internet, Figura 6, informações de aproximadamente 3 bilhões de espécimes catalogados em coleções biológicas do mundo todo (GBIF, 2007).

Os seus projetos são, em curto prazo, focalizados nos dados de nível de espécies (árvores taxonômicas) e espécimes; em médio prazo, serão concentrados em melhorias de mecanismos de buscas e ferramentas para combinar dados de diferentes fontes; em longo prazo o GBIF proporcionará um portal que habilitará buscas simultâneas em banco de dados sobre biodiversidade, moleculares, genéticos, ecológicos e de ecossistemas (GBIF, 2007).

Para organização das suas atividades, foram definidos 4 comitês de trabalho (Johnson, 2007), (Canhos et al., 2004), (Saraiva, 2003): 
- DADI (Data Access and Database Interoperability): trabalha e colabora na criação de padrões para interoperabilidade de bases de dados;

- ECAT (Electronic Catalogue of Names of Known Organisms): desenvolve um padrão para o catálogo eletrônico de nomes de organismos conhecidos;

- DIGIT (Digitization of Natural History Collection Data): que visa promover a digitalização de coleção de dados de história natural, novas e legadas;

- OCB (Outreach and Capacity Building): responsável pelas atividades de divulgação e formação de recursos.

\subsubsection{Biodiversity Information Standards - TDWG}

A TDWG (International Working Group on Taxonomic Databases) iniciou suas atividades em 1985 como um grupo de trabalho internacional que explorava as idéias sobre padronização e colaboração entre os maiores projetos de base de dados taxonômicos de plantas (Saraiva, 2003). Com o passar dos anos, devido às facilidades promovidas pela Internet, ela passou a desenvolver padrões para a troca de dados biológicos e de biodiversidade, e foi rebatizada para Biodiversity Information Standards (TDWG, 2007).

A iniciativa promove as suas atividades em um ambiente colaborativo e internacional, com a participação de profissionais de diversos domínios: biólogos, zoólogos, entomologistas, ecologistas, geneticistas, cientistas da computação, engenheiros, etc. No portal do TDWG - http://www.tdwg.org, os participantes utilizam ferramentas da Internet 2.0 para interagir, tais como o Wiki (que permite ao usuário final a edição de uma página HTML direto pelo navegador) e o Blog (permite incrementar partes de uma página Internet com o envio de "posts"). 


\subsubsection{Grupos de Trabalho}

As atividades de padronização do TDWG são realizadas por dois tipos de grupos: os Interest Groups (Grupos de Interesse) e os Task Groups (Grupos Tarefa). No primeiro, são discutidos os problemas, objetivos, estratégias, métodos e tecnologias relacionadas com o tratamento de determinado tipo de informação sobre biodiversidade. A partir da definição de um produto especificado por este grupo, uma ferramenta ou um padrão, por exemplo, um Grupo Tarefa é estabelecido para o seu desenvolvimento (TDWG, 2007).

Uma lista com os grupos aprovados pelo TDWG e os assuntos tratados pelos seus colaboradores são listados no Quadro 1. A maior parte dos grupos concentra suas discussões em um espaço dedicado no ambiente Wiki do TDWG, ou em listas de discussões via e-mail. Outros grupos podem existir apenas no ambiente da ferramenta Wiki, mas para se tornarem oficiais, precisam passar por um processo de aprovação coordenado pelo comitê executivo do TDWG.

\begin{tabular}{lllc}
\hline & \multicolumn{1}{c}{ Grupo } & \multicolumn{1}{c}{ Assunto } & Tipo \\
\hline 1 & Biological Descriptions & Dados Biológicos em Geral & IG \\
3 & Geospatial Interest Group & Dados Geospaciais & IG \\
4 & Imaging Interest Group & Informações sobre mídias & IG \\
$\mathbf{5}$ & Multimedia Resources Task Group & Informações sobre fontes multimidias & TG \\
$\mathbf{6}$ & Invasive Species Interest Group & Espécies invasoras & IG \\
7 & Literature Interest Group & Literatura sobre Taxonomia & IG \\
$\mathbf{8}$ & Natural Collections Descriptions IG & Descrições de Coleções & IG \\
9 & Observation and Specimen Records & Espécimes (catalogadas/observadas) & IG \\
10 & Access to Biological Collections Data & Esquema p/ dados de Espécimes & TG \\
\hline 11 & Darwin Core Task Group (DwC) & Esquema p/ dados de Espécimes & TG \\
\hline 12 & Observations Task Group (OBS) & Dados de Observação & TG \\
13 & Process Interest Group & Processos do TDWG & IG \\
\hline 14 & Taxonomic Names and Concepts IG & Nomes e Conceitos Taxonômicos & IG \\
15 & TDWG Architecture Group & Arquitetura dos padrões do TDWG & IG \\
\hline 16 & Globally Unique Identifiers & Identificadores Únicos Globais & TG \\
17 & TAPIR Task Group & Protocolo p/ troca de dados & IG \\
18 & TDWG Infrastructure Project & Infraestrutura do TDWG & IG
\end{tabular}

Quadro 1 - Grupos de Atividades do TDWG 


\subsubsection{Processo de Validação de Padrões}

Da mesma forma, os padrões submetidos ao TDWG precisam passar por um processo de validação antes de se tornarem oficiais. Este processo de validação é definido pelo Process Interest Group. Entre os principais padrões ratificados pela o TDWG, estão o $A B C D$, o Darwin Core e o TAPIR, que serão apresentados nos próximos itens. A definição desses padrões também é fruto de uma relação muito próxima com o GBIF no desenvolvimento da Informática da Biodiversidade (TDWG, 2007).

\subsubsection{Mapeamento da Informática da Biodiversidade}

O TDWG mantém em seu portal uma proposta de mapeamento do desenvolvimento da Informática da Biodiversidade. A partir de um banco de dados é possível listar mais de 600 projetos ligados a IB, classificados pelo TDWG de acordo com os seus objetivos (e cuja classificação também será adotada por este texto) (TDWG, 2007):

- Agregador de Dados (Data Aggregator): recolhe dados de uma variedade de fontes (digital ou impressa) para apresentá-los em um formulário único;

- Indexador de Dados (Data Indexer): fornece listas ou índices de outros sites que fornecem dados;

- Provedor de Dados (Data Provider): fornece dados diretamente a partir de consultas locais ou distribuídas;

- Padronizador de Dados (Data Standards): contribui para a elaboração ou desenvolvimento de padrões de dados; 
- Facilitador (Facilitator): facilita a publicação de dados por outros projetos ou sites;

Algumas das iniciativas apresentadas nos itens anteriores podem ter mais de uma classificação:

- IBP - Facilitator

- IABIN - Data Aggregator (portais de consultas das sub-redes) e Data Standards (padrões de interação);

- ITIS - Data Aggregator (provedores de nomes científicos)

- GBIF - Data Aggregator (dos provedores distribuídos) e Data Standards (definição e validação de importantes padrões);

Outro banco de dados lista aproximadamente 50 redes de informação sobre biodiversidade, formadas por organizações interessadas em trocar determinados dados sobre biodiversidade/biologia.

\subsection{Conceitos básicos da Informática da Biodiversidade}

\subsubsection{Espécimes e Espécies}

Segundo Sarkar (2007), o conhecimento biológico pode ser agrupado em três grupos relacionados às moléculas, aos organismos e aos ambientes. Enquanto a Bioinformática (Bionformatics) foca o desenvolvimento de hipóteses no nível molecular, a Informática da Biodiversidade enfatiza a organização do conhecimento no nível do indivíduo e do ambiente. 


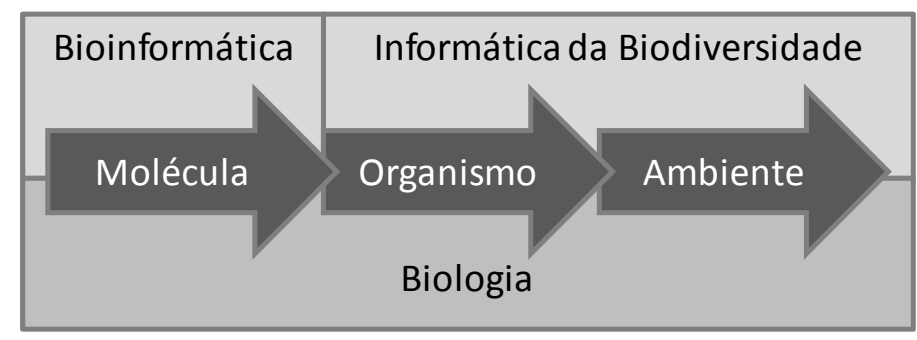

Figura 5 - Divisão de atuação entre Bioinformática e Informática da Biodiversidade Fonte: (Sarkar, 2007)

As iniciativas para facilitar o acesso às informações sobre biodiversidade focam os dados de espécies e espécimes como principal objetivo das redes de dados sobre biodiversidade (Canhos et al., 2004). De forma simplificada, os dados de uma espécie representam uma compilação do conhecimento sobre os indivíduos (espécimes) que têm um grupo comum de características.

Nas redes de dados de espécies, os indivíduos são identificados por um taxa (conjunto de táxons, que são unidades taxonômicas de um sistema de classificação) (Johnson, 2007). Nas redes de dados de espécimes os dados são categorizados em quatro dimensões: identificação do indivíduo (com associação de dados auxiliares: história natural, biologia, fenótipo e genótipo do indivíduo), espaço, tempo e coletor/observador (Graham et al., 2004; Johnson, 2007; TDWG, 2007).

No caso dos espécimes, existe ainda uma classificação dos registros, importante para a organização e, conseqüentemente, o desenvolvimento dos sistemas de informação. O registro do espécime (conjunto dos dados do espécime) pode ser classificado quanto à sua base de observação (anotação).

O Darwin Core2, que é um esquema conceitual utilizado para trocar dados de espécimes (item 3.4.2.1), classifica os seus registros de acordo com a origem dos dados (base de observação), que são provenientes de um objeto, ou de um evento. No caso dos objetos, os dados podem ser obtidos de um indivíduo vivo, preservado ou do seu fóssil, ou então, de uma imagem, um som ou um vídeo deste indivíduo. Os eventos, por sua vez, são classificados como observados por humanos, ou por máquinas (TDWG, 2007).

Em relação aos espécimes, os dados de interesse da Webbee envolvem apenas os preservados e os observados, devido, principalmente, a quantidade de 
dados provenientes dos museus de história natural e dos herbários, e dos trabalhos de campo.

\subsubsection{Dados Primários - Ocorrência de Espécies}

O grupo Observation and Specimen Record do TDWG (TDWG, 2007) define os dados primários sobre biodiversidade como dados observacionais, que consistem na observação (anotação) derivada das medições dos indivíduos no ambiente, ou dos coletados no ambiente e armazenados em coleções de história natural.

Esses dados são considerados primários, pois registram a ocorrência de um indivíduo (identificado) em um determinado espaço e tempo (um espécime). Por isso, também são chamados de ocorrência de espécies (species-occurence) (Chapman, 2005c).

Os dados primários englobam tanto os indivíduos que são capturados e catalogados em museus, quanto os indivíduos observados na natureza, pois o mesmo conjunto básico de dados é aplicado para ambos. As observações têm como desvantagem a dependência do observador para a definição da taxonomia, já que não existe uma evidência física para validação posterior. Por outro lado, os indivíduos catalogados são necessariamente uma foto no tempo de um indivíduo de ontogenia própria (desenvolvimento desde a fecundação do seu óvulo até a morte), que pode não representar a maioria (Johnson, 2007).

Existem diversos usos para os dados primários. Tradicionalmente, museus e herbários utilizam esses dados para o estudo taxonômico, essencialmente, classificar e reclassificar indivíduos e definir novas chaves taxonômicas. Novos estudos utilizam os dados para documentar a biodiversidade e sua distribuição pelo tempo e o espaço com a ajuda da TI, entre eles, a realização de pesquisas biogeográficas, planejamento para conservação de áreas, definição de reservas naturais, desenvolvimento de políticas públicas, estudos de mudança do clima, produção agrícola, manejo florestal, etc. (Chapman, 2005c). 


\subsubsection{Identificadores}

Um pré-requisito para integração de diversas fontes é o uso de um identificador global único para a identificação consistente dos objetos (Page, 2008). As discussões na comunidade da informática da biodiversidade têm focado primariamente em três soluções: HTTP URIs (Uniform Resource Identifiers), Digital Object Identifiers (DOIs) e Life Science Identifiers (LSIDs) (TDWG, 2007).

Um elemento importante dos novos sistemas de informação é o papel principal da taxonomia como indexador dos dados sobre biodiversidade dos organismos e a ligação com outras disciplinas associadas: genômica, biologia, etc. (Bisby, 2000; Page, 2008; Canhos et al., 2004).

\subsubsection{Vocabulário controlado}

Um conceito básico do armazenamento em bancos de dados é o uso de vocabulários controlados para assegurar a recuperação de informações que se referem a uma classe particular. Este conceito parece simples, mas pode ser tornar um problema para os bancos de dados de espécies e espécimes (Canhos et al., 2004).

O uso dos nomes taxonômicos como chave entre diferentes sistemas, pode materializar este problema, já que estes nomes são dinâmicos e são revisados constantemente. Como proposta de solução, o Species2000 (Species2000, 2008) e o ITIS se uniram para formar o EoL com o objetivo de compilar aproximadamente 1,75 milhões de nomes de espécies (Canhos et al., 2004).

\subsubsection{Dados Ambientais Não-Biológicos}

Os dados ambientais têm um importante papel na Informática da Biodiversidade, pois todos os eventos biológicos são diretamente, ou indiretamente relacionados às condições ambientais (Chapman et al., 2005), por isso, estão sendo 
cada vez mais usados na modelagem de padrões de distribuição de espécies e populações (Canhos et al., 2004; Chapman et al., 2005).

Muitos modelos utilizam as informações climatológicas como temperatura, precipitação, radiação, evaporação, umidade do solo, etc. como a base sobre a qual se pode definir o habitat ou o nicho ecológico (Chapman et al., 2005). Um desafio científico e técnico é prover acesso às fontes existentes ou emergentes de dados ambientais, biológicos e socioeconômicos, e prover a integração desses dados como suporte a estes modelos (Canhos et al., 2004). Estes dados estão, em sua grande maioria, em formatos e escalas inapropriados para o uso em diversos estudos da IB (Chapman et al., 2005).

\subsubsection{Redes de dados sobre biodiversidade}

As redes de dados sobre biodiversidade (eventualmente nomeadas neste texto apenas como redes de dados) são compostas por sistemas que utilizam padrões específicos para trocar dados de interesse comum na Internet (Copp; De Giovanni, 2008). Uma rede de dados sobre biodiversidade pode ser nomeada pelos padrões que utiliza. Por exemplo, as redes TAPIR / Darwin Core2 são compostas por sistemas que utilizam o protocolo de comunicação TAPIR (item 3.4.1) e o esquema conceitual de dados Darwin Core2 (item 3.4.2.1).

A utilização de um determinado padrão não impede que um sistema pertença a outras redes de dados. Dizer que um sistema faz parte de uma rede, significa dizer que ele é capaz de trocar mensagens em um determinado conjunto de padrões.

Um passo importante para a definição da arquitetura de referência que guiará o desenvolvimento da nova Webbee é a identificação das redes de dados sobre biodiversidade de interesse, pois algumas especificações técnicas dependem dessas escolhas.

As redes de dados alvo, e os seus respectivos sistemas participantes, devem estar envolvidos com os processos para consumir e prover dados de espécies e espécimes preservados e observados (dados primários) de abelhas e de polinização por abelhas, que é a nova orientação da Webbee. 
Outro aspecto importante das redes de dados sobre biodiversidade é a sua arquitetura. Como discutido anteriormente, essas redes são orientadas pela utilização de serviços na Internet, devido, principalmente, a heterogeneidade da capacidade tecnológica e a distribuição geográfica dos nós. Os principais padrões e ferramentas de comunicação na Internet da Informática da Biodiversidade aproveitam a interoperabilidade, o suporte e a capacidade das tecnologias Web Services para construir seus serviços (Copp; De Giovanni, 2008). Por isso, como será discutido no próximo item, em geral, a arquitetura das redes de dados sobre biodiversidade é construída sobre o paradigma orientado a serviços.

\subsubsection{Arquitetura das redes de dados}

Assim como acontece nos ambientes industriais e financeiros, a dificuldade de acesso aos dados sobre biodiversidade também varia devido às técnicas de coleta, armazenamento e publicação empregadas, que são por sua vez, fortemente dependentes da capacidade de gestão da informação e da tecnologia. No domínio da biodiversidade, esta capacidade varia consideravelmente entre as partes envolvidas, principalmente, pela oferta de recursos financeiros.

Como conseqüência direta, nas redes de dados sobre biodiversidade, os dados armazenados em máquinas de diferentes capacidades (de computadores pessoais a supercomputadores da NASA). Eles também podem ser gerenciados por softwares de complexidades distintas (de blocos de notas a gerenciadores de coleções). Por fim, estes dados são manipulados por diversos usuários (dos iniciantes aos mais experientes). Estas propriedades demandam o compartilhamento em um canal que supere estas diferenças. Este canal deve prever a comunicação entre distâncias, freqüentemente, intercontinentais. Outro desafio é a evolução do número de participantes das redes, que surgem em maior número a cada ano.

Por estes motivos, as ferramentas da Informática da Biodiversidade precisam adotar padrões para garantir a comunicação efetiva entre todos esses participantes, em meios heterogêneos e geograficamente distribuídos (Copp; De Giovanni, 2008). Neste contexto, existe uma ressonância entre as necessidades da IB e as 
oportunidades de globalização e interoperabilidade oferecidas pela Internet (Bisby, 2000), particularmente, pelos Web Services, e pelas arquiteturas orientadas a serviços, que em seu paradigma escalável faz a menor suposição possível sobre a rede e também minimiza quaisquer suposições de confiança que são freqüentemente feitas em sistemas de escala menor.

Existem três estratégias básicas para a arquitetura dos sistemas de informação sobre biodiversidade, que se diferenciam pela execução da consulta aos dados: local, distribuída ou mista (Copp; De Giovanni, 2008). Entretanto, a maior parte das soluções se baseiam na arquitetura orientada a serviços implementada sobre Web Services. Também existem serviços típicos das redes de dados sobre biodiversidade, como descrito nos próximos itens, mas todos eles se enquadram nos conceitos dos elementos básicos dos Web Services: um provedor de serviços, um provedor de registro e um cliente do serviço.

\subsubsection{Componentes básicos dos sistemas}

\section{Interfaces e Portais Internet}

Um portal é uma página Internet que provê uma interface para que os usuários cheguem até diversas páginas distribuídas, serviços ou aplicações. Ao contrário dos portais mais simples, os portais dos sistemas de informação sobre biodiversidade são mais do que seções de notícias, fóruns, diretório de arquivo e diretório de páginas Internet.

Em uma perspectiva de rede de dados sobre biodiversidade, eles são clientes ou provedores de serviços para a manipulação, validação e distribuição de dados, que são a sua maior funcionalidade, agindo sempre de forma transparente para o usuário final.

No caso da pesquisa de dados em provedores distribuídos (Data Aggregator), cabe ao visitante apenas a tarefa de indicar as chaves de consultas (nomes taxonômicos ou populares, de coleções, de pesquisadores, etc) e navegar pelos 
registros do portal (Figura 6), sem perceber a complexidade dos serviços de busca de dados, manipulação e apresentação envolvida na consulta.

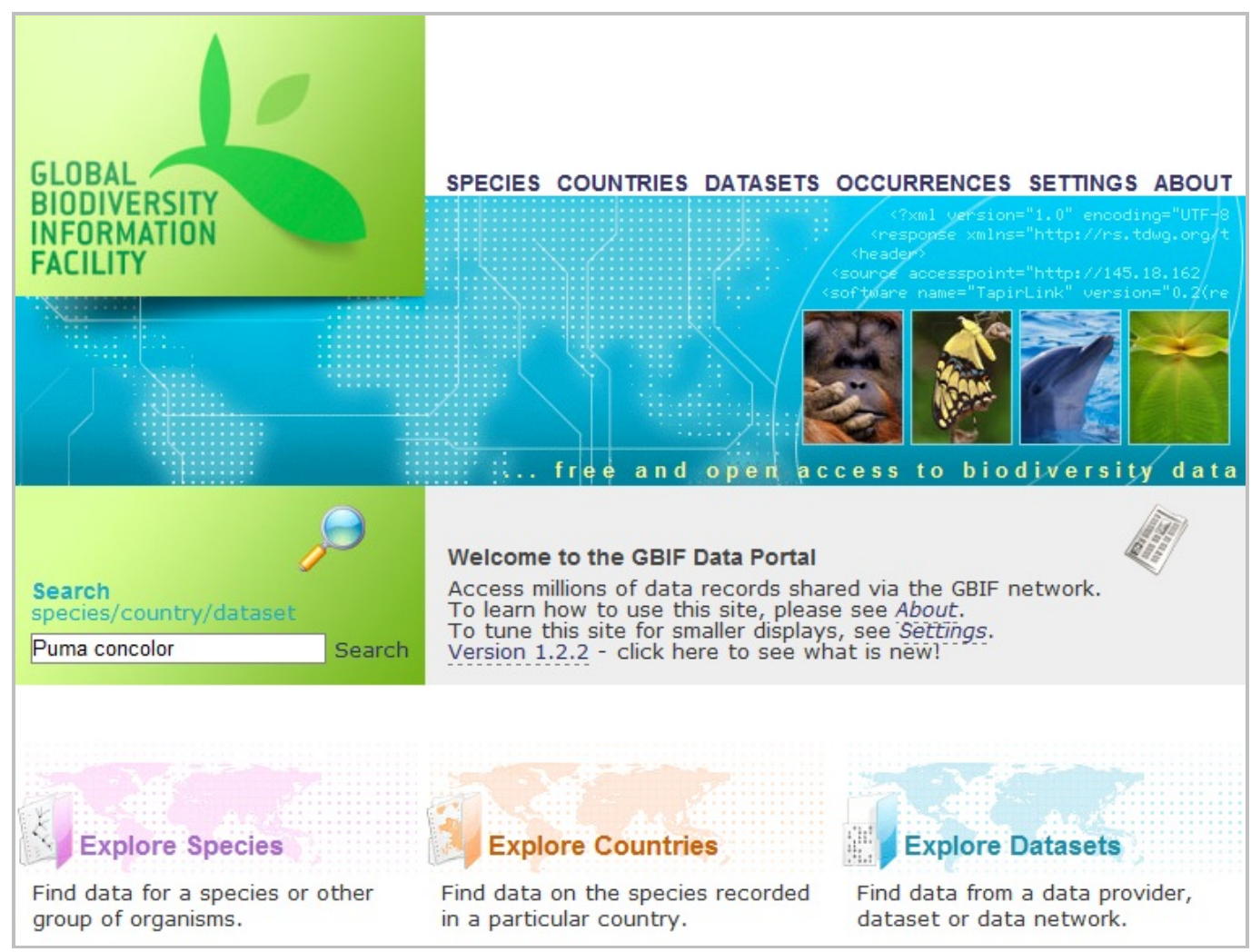

Figura 6 - Portal do Global Biodiversity Information Facility - GBIF

\section{Message Brokers}

Message Brokers são usados como elemento chave para estabelecer a integração de dados em redes heterogêneas. Eles são softwares do tipo middleware (que conectam softwares entre si), trabalhando usualmente como um concentrador entre muitas aplicações e clientes.

Nos sistemas de informação sobre biodiversidade, o papel do message broker é ser basicamente um meio para transmitir um pedido de busca, de um software cliente para uma ou mais aplicações. No caso dos portais de informações, busca nos bancos de dados; já no caso dos softwares de análise, busca pelos serviços de transformação de coordenadas, por exemplo. 


\section{Agregadores de Dados e Harvesters}

Os agregadores de dados são programas ou serviços que coletam e integram informações para depois serem entregues aos clientes. Este tipo de software pode realizar transformações ou aplicar serviços externos de análise (como validadores de coordenadas geográficas, por exemplo) aos dados consultados, para resolver eventuais diferenças contextuais entre as fontes. Um exemplo deste tipo de software são os portais que buscam preços de um mesmo produto em diversos sites na Internet e apresentam um relatório comparativo ao cliente (Copp; De Giovanni, 2008).

Nos sistemas de informações sobre biodiversidade, um Data Harvester realiza a coleta de dados em sistemas distribuídos para guardá-los em um repositório comum, que pode ser atualizado constantemente, publicado em portais ou ser diretamente consultado. Por acessar sistemas heterogêneos, este software faz a função de message broker e agregador de dados nas arquiteturas que compõe (Copp; De Giovanni, 2008).

\section{$\underline{\text { Diretório de Serviços }}$}

Os diretórios de serviços são componentes chaves das redes de dados sobre biodiversidade. Eles guardam informações de contatos de organizações e serviços disponíveis na Internet, e também armazenam metadados que descrevem a abrangência dos dados oferecidos. Estas informações são usadas para que os sistemas decidam em que provedores farão suas consultas. Por exemplo, uma consulta por uma espécie de mamífero será improdutiva se realizada em um provedor de dados de insetos (Copp; De Giovanni, 2008).

Este diretório pode ser implementado como uma base de dados no próprio sistema, dando aos usuários detalhes sobre as fontes utilizadas. Pode-se inclusive permitir acesso a essa base para que os provedores atualizem seus metadados, ou então, pesquisá-los em outros bancos de dados (Copp; De Giovanni, 2008).

Devido à adoção dos Web Services como motor das redes de dados sobre biodiversidade, o UDDI (item 2.2.3) tornou-se uma alternativa para esta solução 
caseira. No entanto, em redes de menor complexidade, com poucos nós bem definidos, a utilização do UDDI pode comprometer a desempenho da rede por ser mais uma etapa no processo, além de introduzir um novo componente com um protocolo diferente. Por isso, a utilização do UDDI deve ser analisada caso a caso, considerando principalmente o crescimento e a consistência dos nós da rede (Copp; De Giovanni, 2008).

\section{Provedores de Dados}

Os dados sobre biodiversidade são armazenados por centenas de indivíduos e organizações, cada um com suas necessidades específicas, suas capacidades tecnológicas e sua gestão dos dados. Nas últimas décadas, esforços foram concentrados para integrar esses dados, com o objetivo de facilitar o acesso às informações em uma rede de dados sobre biodiversidade. (Copp; De Giovanni, 2008).

Para colocar os dados dispersos, ou isolados, nessas redes, portais de dados criaram ferramentas Internet de digitalização e análise de banco de dados. A digitalização dos dados mostrou-se muito eficiente, pois permite a entrada dos dados em um formato já pré-determinado para integração na rede de dados. No entanto, a entrada dos dados na rede, via análise de arquivos enviados pela Internet, permaneceu restrita aos formatos de banco de dados determinados pelos portais.

Para contornar esta restrição, foi criado um novo tipo de ferramenta da Informática da Biodiversidade, os provedores de dados, que realizam a tarefa de ler os dados arquivados em um determinado formato (de banco de dados), para depois disponibilizar o conteúdo em outro formato padrão (que determina o tipo do provedor) para a rede de dados. Essa ponte é realizada com o mapeamento de conceitos, a transformação de dados e a transformação de consultas (Copp; De Giovanni, 2008). 


\subsubsection{Arquitetura de Consultas Distribuídas}

$\mathrm{Na}$ arquitetura de consultas distribuídas, os comandos de consulta aos registros são definidos pelos usuários finais (End users) e repassados pela aplicação cliente (Client application) aos provedores de serviços (Provider service) utilizando o Message broker. Os provedores se encarregam de processar essas requisições e consultar os provedores de dados (Provider database) para devolver os resultados. Neste processo, também é possível consultar o endereço do Provedor de serviços utilizando um serviço especializado, o serviço de registros (Registry service), Figura 7

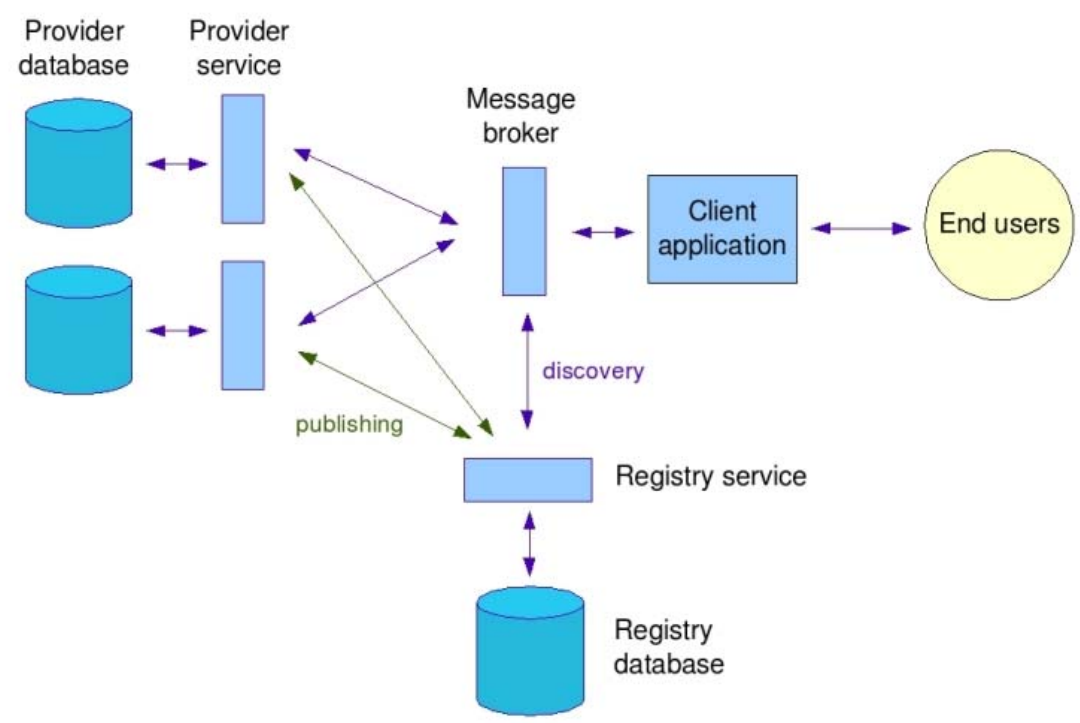

Figura 7 - Exemplo de Arquitetura de Consultas Distribuídas

Fonte: (Copp; De Giovanni, 2008)

\section{Principais Vantagens da Arquitetura de Consultas Distribuídas}

- O controle de acesso aos dados é feito direto pelo provedor. Devido à ameaça da biopirataria e do contrabando de espécies nativas em extinção, informações sensíveis como localização geográfica, por 
exemplo, devem ser tratadas com segurança. Nesta arquitetura, o provedor decide a quantidade e que tipos de dados devem ser entregue a aplicação cliente.

- Serviços personalizados de acordo com a Aplicação Cliente. Os provedores podem ter interfaces customizadas com diversos clientes e oferecer os mesmos dados, ou parte deles, de acordo com a necessidade do parceiro.

- Garantia de informações atualizadas. Na estratégia de consultas distribuídas os registros consultados são resgatados diretamente dos seus provedores de dados. Sendo assim, estarão sempre atualizados em relação a sua fonte.

\section{$\underline{\text { Principais Desvantagens da Arquitetura de Consultas Distribuídas }}$}

- Não há garantia de disponibilidade do provedor. Por ser dependente da resposta do provedor, não há garantia de acesso aos dados nesta estratégia. Quando uma consulta é disparada pelo portal, é preciso que o provedor esteja disponível para processar e responder a requisição. Este é um ponto crítico quando se considera a distância da capacidade tecnológica entre provedores, principalmente, dos recursos para assegurar a disponibilidade dos equipamentos e da rede de comunicação. Para evitar o atraso causado pelas consultas a provedores indisponíveis, é possível verificar de tempos em tempos o status dos provedores. Esta solução pode consumir um tempo de processamento importante do portal se for considerado a periodicidade e o número de provedores a serem consultados.

- Atraso no tempo de resposta das consultas. Dependendo da natureza da aplicação cliente, a quantidade de provedores a serem consultados pode impactar no tempo de resposta do sistema. $\mathrm{Na}$ 
arquitetura de consultas distribuídas, portais de dados de coleções e observações, por exemplo, disparam uma mesma consulta para diversos provedores. Nela, cada requisição estará sujeita ao tempo do tráfego na Internet e ao tempo de processamento de cada provedor, dependentes respectivamente, da qualidade da rede de comunicação entre portal e provedor, e da qualidade dos equipamentos e da organização dos dados. Ainda neste tipo de arquitetura, a cada consulta o agregador fará o tratamento dos dados antes de entregá-los aos clientes, diferentemente da arquitetura de consulta locais que fará esse tipo de tratamento apenas uma vez durante o harvest.

\subsubsection{Arquitetura de Consultas Locais}

A alternativa estratégica à arquitetura de consultas distribuídas é a utilização de uma base de dados local (Cache database). Esta base de dados incremente a solução de consultas distribuídas (Figura 8). Ela é a responsável por agregar os dados dos provedores de dados da aplicação cliente em um único repositório.

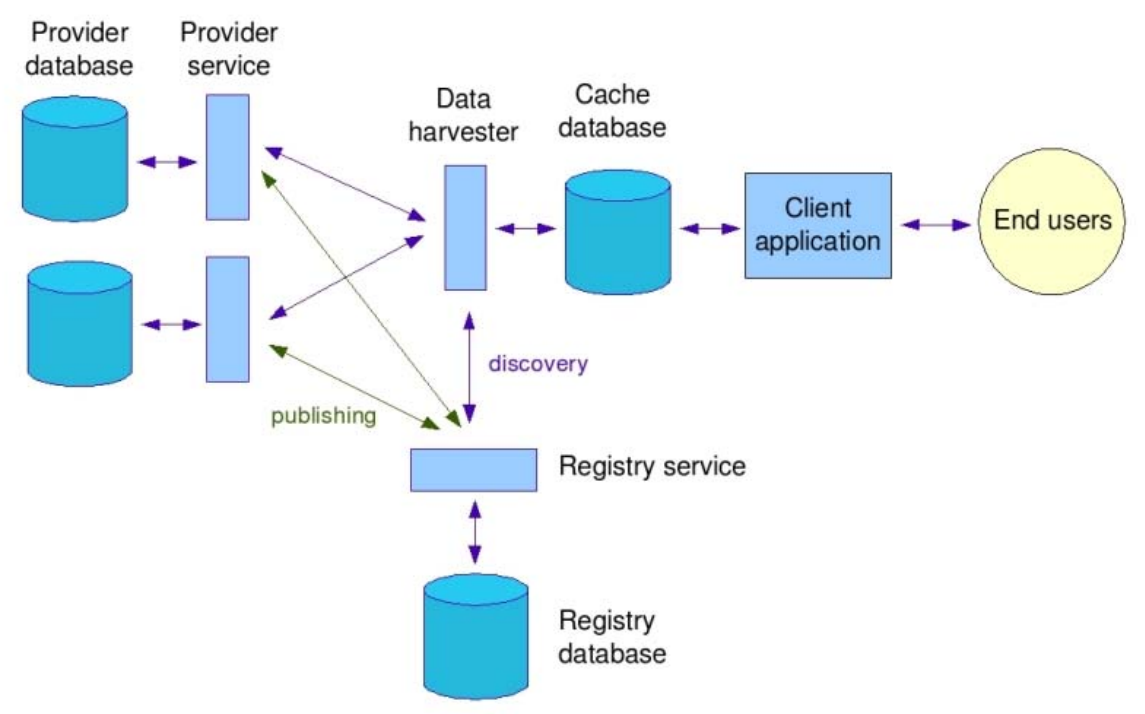

Figura 8 - Arquitetura baseada em Armazenamento temporário de Dados Fonte: (Copp; De Giovanni, 2008) 


\section{$\underline{\text { Principais Vantagens da Arquitetura de Consultas Locais }}$}

- Estrutura direcionada para a consulta. O trabalho de transformação e adequação dos dados realizado pelo harvest, cria uma estrutura simples e otimizada para a consulta dos dados. Além do tempo economizado na busca das informações em provedores remotos, essa organização agiliza a consulta e o processamento dos dados, já que permite a criação de visões específicas, e o pré-tratamento e préanálise de dados, tornando-se o principal atrativo da estratégia local.

- Diversas formas de atualizar o repositório central. Nesta estrutura os provedores podem atualizar seus dados diretamente no cache utilizando interfaces específicas, ou então, restringir, quando conveniente, a publicação de dados sensíveis. Um processo automático também pode ser criado para atualizar os dados periodicamente (em períodos de menor tráfego, por exemplo).

- Mapeamento da rede de dados sobre biodiversidade. Ao buscar os dados nos provedores, o Data harvest também obtém os metadados atualizados dos provedores e do conteúdo armazenado. Estas informações permitem ao portal mapear a rede de dados sobre biodiversidade, apontado quais provedores estão ou não ativos, os dados publicados, os contatos de suporte, etc., agilizando e otimizando as consultas dos sistemas clientes.

\section{Principais Desvantagens da Arquitetura de Consultas Locais}

- Possibilidade de dados desatualizados. Por não estarem conectadas diretamente aos provedores de dados, as aplicações clientes podem apresentar informações desatualizadas em algumas buscas. A solução que atualiza periodicamente o cache pode ser cara se considerada a freqüência de atualização dos dados, que em 
algumas aplicações, pode ser maior que a de buscas no portal (como no monitoramento de espécimes, por exemplo).

- Falta de controle sobre os dados. A falta de controle sobre os dados é considerada uma das principais desvantagens da estratégia. Apesar da possibilidade de restringir remotamente o acesso aos dados de um repositório central, os provedores de dados não têm garantias (além das contratuais) da utilização (ou não) dos dados. Essa falta de garantia pode ser prejudicial na relação com os investidores que mantém os provedores, principalmente na utilização indevida de dados sensíveis (localização de plantas medicinais, por exemplo), ou então, na comprovação de abrangência dos dados providos (é importante estimar o público dos dados para justificar financeiramente os gastos com o provedor).

- Recursos para manutenção do repositório central. Se o número de provedores e de registros armazenados no repositório central for demasiadamente grande, a gestão física passa a exigir mais recursos financeiros, e a complexidade da manutenção lógica (criação de visões e espelhos especializados do banco, por exemplo) pode comprometer a agilidade da consulta.

\subsubsection{Arquitetura Mista de Consultas}

Outra solução pode adotar uma abordagem mista, que permite a análise das vantagens e desvantagens de cada arquitetura caso a caso. Provedores que exigem o controle de seus dados serão abordados com a estrutura distribuída, já os provedores que não tem condições para garantir a disponibilidade de seus dados, serão abordados com o harvest em horários pré-estabelecidos, por exemplo. Esta abordagem mista tem estrutura similar à arquitetura de consultas locais, considerando que determinados provedores ignoram a passagem pelo banco de dados cache. 


\subsection{Ferramentas e serviço da Informática da Biodiversidade}

\subsubsection{Protocolos de Troca de Dados sobre biodiversidade}

O modelo de arquitetura orientado a serviços adotado pelas redes de dados sobre biodiversidade é baseado no envio de requisições aos provedores de serviços, que devolvem as respostas com base em protocolos de mensagens. Muitas vezes, esses protocolos de mensagens são construídos sobre outros protocolos. No caso da Internet, o SOAP sobre o HTTP é amplamente usado como nas aplicações de dados e serviços distribuídos, principalmente nos Web Services (Louridas, 2006).

No domínio da biodiversidade, além do SOAP, outros protocolos específicos para a troca de mensagens XML sobre HTTP são amplamente utilizados, tais como o DiGIR e o BioCASE, específicos para a troca de dados de espécimes (Copp; De Giovanni, 2008, Canhos et al., 2004). Eles são utilizados por sistemas de grande porte, como GBIF (GBIF, 2007) e a IABIN, e são desenvolvidos no âmbito do TDWG (TDWG, 2007). Recentemente, um novo protocolo foi desenvolvido pelo TDWG para unificar as duas soluções, o TAPIR.

O TDWG Access Protocol for Information Retrieval - TAPIR é um protocolo recente que foi criado para substituir, ou trabalhar em conjunto com outros protocolos de redes de dados sobre biodiversidade (TDWG, 2007). Ele especifica um protocolo padronizado de requisições e respostas baseado em mensagens XML, que transitam sobre o protocolo HTTP e é independe de estados (Copp; De Giovanni, 2008).

Ao contrário do DiGIR e do BioCASE, o TAPIR é independente de esquemas federados, por isso, tanto o Darwin Core, como o $A B C D$ são suportados pelo protocolo (Canhos et al., 2004). Esquemas conceituais de espécies, tais como o Plinian Core, também podem ser associados ao protocolo TAPIR (Plinian Core, 2007). Analogamente aos outros protocolos, uma "rede de dados TAPIR" é definida pelo uso do protocolo por sistemas de informação para a comunicação entre os provedores. 
A seguir, são apresentadas as mensagens oferecidas pelo TAPIR, e que ilustram a especialização desse tipo de protocolo (Copp; De Giovanni, 2008):

- Metadata: operação padrão usada para recuperar informações básicas sobre o serviço;

- Capabilities: Usada para recuperar as definições essenciais sobre como interagir adequadamente com o serviço;

- Inventory: Usado para recuperar valores distintos de um ou mais conceitos (elementos de um esquema conceitual);

- Search: Usado para procurar e recuperar um dado;

- Ping: Usado para monitorar a disponibilidade do serviço.

Diversas aplicações foram criadas para este protocolo (TDWG, 2007), tais como servidores: PyWrapper, TapirLink, TapirDotNET, clientes: TapirChirp, TapirJChirp e outros softwares de apoio, como o testador de mensagens TapirTester e o criador de mensagens: TapirBuilder, e estão disponíveis no portal do TDWG.

\subsubsection{Esquemas conceituais de dados}

Os esquemas conceituais podem ser vistos como modelos de dados com uma definição formal de classes (entidades), suas características (atributos) e como estas classes se relacionam umas com as outras (relacionamento). Eles podem ser usados para o desenho de banco de dados, modelagem de classes e troca de dados, mas para as redes de dados sobre biodiversidade, eles também permitem que os provedores heterogêneos sejam vistos como um único e extenso banco de dados (Copp; De Giovanni, 2008). 
Os esquemas federados controlam essa heterogeneidade entre os participantes ao definir uma semântica para a rede, ou seja, eles definem os tipos de dados (conceitos) trocados na rede, independente do protocolo de mensagens.

Esta semântica é realmente aplicada quando os provedores mapeiam os conceitos do esquema federado no banco de dados local. A partir daí, quando um provedor recebe uma consulta, ele a transforma para o padrão do gerenciador de banco de dados local, analisa o mapeamento de campos, para então executar a consulta. Depois, o caminho inverso é feito, e a resposta à consulta é formatada de acordo com um modelo de saída antes de ser enviada.

É possível que o modelo de saída (output model) coincida com o esquema conceitual e, neste caso, diz-se que o modelo canônico foi adotado. Isto acontece quando o esquema (que define os conceitos) foi escrito em XML Schema, que é a linguagem utilizada para descrever o output model. Todavia, é importante considerar a possibilidade de ter diferentes modelos de saídas a partir de um mesmo esquema conceitual (Copp; De Giovanni, 2008).

No caso das redes DiGIR e BioCASE, apenas um esquema canônico é suportado, o Darwin Core e o ABCD, respectivamente (Canhos et al., 2004 ) (Copp; De Giovanni, 2008). Já o TAPIR, pode trabalhar com qualquer esquema federado (TDWG, 2007).

\subsubsection{Darwin Core}

O esquema conceitual Darwin Core (DwC) foi originalmente criado para ser usado pelo protocolo DiGIR (Copp; De Giovanni, 2008). Ele foi projetado para facilitar a troca de informações sobre ocorrências geográficas de organismos e a existência física de espécimes em coleções (TDWG, 2007). Ele é um XML Schema simples com um número pequeno de elementos que cobrem as informações básicas de registros biológicos de todos os grupos taxonômicos (Canhos et al., 2004, Johnson, 2007). Os elementos da versão 1.4 do esquema contêm informações sobre a taxonomia do espécime, a localização geográfica da ocorrência e os elementos de referência (TDWG, 2007). Esta versão não é a recomendada para uso 
pelo TDWG, pois está em validação, no entanto, ela já é usada pelo GBIF em seu portal.

Atualmente, o Darwin Core é tratado como um vocabulário de termos, que podem ser referenciados para compor esquema, tais como o Simple Darwin Core, que é uma versão que engloba os 45 elementos do DwC. Não existe uma estrutura de agregação entre os elementos do Simple Darwin Core, todos os elementos estão no mesmo nível hierárquico. Efetivamente, como XML Schema, ele não pode ser usado como estrutura de troca de dados, porque apenas um elemento raiz é permitido em uma instância XML. Por isso, é preciso definir outro XML Schema (application schema) referenciando os elementos do Darwin Core dentro de um ou mais grupo de elementos (Copp; De Giovanni, 2008).

\section{Extensões}

Um esquema Darwin Core permite a extensão do seu esquema para usos específicos, não tratados naturalmente pelo esquema padrão (TDWG, 2007). Nesta extensão, ele é acrescido de novos elementos (Cartolano-Júnior et al., 2007). Para serem consideradas extensões oficiais, as novas propostas devem ser submetidas ao TDWG (item 3.2.5) para validação da comunidade científica.

A criação de extensões para $o$ DwC deve seguir recomendações e procedimentos definidos no Darwin Core Namespace Policy (TDWG, 2007) que, basicamente, instrui o desenvolvedor a considerar se os novos termos podem ser acomodados com uma simples revisão da descrição ou comentário de um termo já existente, antes de criar um novo termo.

\subsubsection{2. $\quad A B C D$}

O Access to Biological Collection Data - ABCD é um esquema complexo para acesso e troca de dados sobre espécimes e observações (ou seja, dados primários de biodiversidade) (ABCD, 2008). O ABCD é mantido por um grupo do TDWG que 
trabalha em conjunto com o Committee on Data for Science and Technology CODATA e é utilizado principalmente na Europa, em conjunto com o protocolo BioCASE (Copp; De Giovanni, 2008, Canhos et al., 2004). A versão atual do esquema (v2.06) contém tipos de dados reutilizáveis e elementos específicos de cada disciplina da biologia, que vão desde coleções paleontológicas até coleções de organismos vivos (ABCD, 2008).

O ABCD é um esquema complexo, que comparado com o Darwin Core, agrega outros dados relevantes ao estudo da biodiversidade, tais como biologia, comportamento, literatura, produtos de análises, ou arquivos multimídia, por exemplo.

Ambas as abordagens têm as suas vantagens e desvantagens: os esquemas normalizados oferecem as vantagens da abrangência, flexibilidade e integridade, enquanto podem ser penalizados pela dificuldade de serem manipulados, criados, consultados e enviados, comprometendo o desempenho e os custos; por outro lado, os esquemas simples são facilmente manipulados (até mesmo em uma planilha de dados), mas deixam a desejar quanto à integridade e qualidade dos dados (Johnson, 2007).

\subsubsection{Plinian Core e SPM}

O Plinian Core (PliC) é um conjunto de conceitos que definem atributos para integrar e recuperar informações sobre espécies (Plinian Core, 2007). Ele é um esquema conceitual extenso que carrega diversos tipos de dados: identificação do registro, taxonomia da espécie, ciclo de vida, comportamento, conservação e demografia, distribuição, uso, referências e até folclore (Cartolano-Júnior et al., 2007).

O PliC, entre outros esquemas de dados de espécies, é base para a criação de um novo modelo de dados de espécies organizado pelo grupo Species Profile Model (SPM) do TDWG (TDWG, 2007). Este padrão será complementar aos esquemas de espécimes $A B C D$ e Darwin Core na identificação das espécies dos indivíduos. 
O desenvolvimento do Plinian Core é coordenado pelo Instituto Nacional de Biodiversidad (INBio) da Costa Rica.

\subsubsection{Arquivos de Autoridade de Dados}

Apesar do nome, o arquivo de autoridades não é autoritário, ele fornece um padrão de nomes que podem ser selecionados ou comparados. Dentre todos os arquivos de autoridades existentes, são considerados os mais relevantes os de nomes taxonômicos (Johnson, 2007). Como visto no item 3.3.3, essa importância é atribuída ao fato de ela ser base para a comunicação de conceitos biológicos, apesar de ela não ser definitiva, e poder ser revisada de tempos em tempos (Soberon, 2004).

O armazenamento e recuperação desses dados biológicos requerem altaqualidade, boa documentação, e fontes continuamente atualizadas (Canhos et al., 2004). Ainda existe pouca padronização para as interfaces eletrônicas deste tipo de estrutura. Agregadores de dados como o Integrated Taxonomic Information System (ITIS), o Species2000, o Universal Biological Indexer and Organizer (uBIO) e o Electronic Catalogue of Names of Known Organisms (ECAT) do GBIF têm trabalhado para prover mecanismos para unir esses esforços em um conjunto harmonioso (Johnson, 2007).

\subsubsection{Georreferenciamento}

O georreferenciamento dos dados sobre biodiversidade é necessário para os estudos de biogeografia, tais como o de distribuição de espécies (Canhos et al., 2004), por exemplo, e diversos outros estudos que utilizem dados primários (item 3.3.2). Este processo significa a conversão da localização de cada espécime em um sistema de coordenadas conhecido (Johnson, 2007). 
Ele é um conceito simples, mas é uma tarefa difícil (Chapman et al., 2005). Erros neste campo reduzem o valor dos registros, pois a localização, exata ou estimada (assegurada por valores de incerteza), é essencial para a composição dos dados primários de biodiversidade. Esquemas em que este campo não é obrigatório, como no Darwin Core, por exemplo, tratam os registros sem georreferenciamento como identificadores de espécimes, e não podem ser usados em estudos com análises e simulações de distribuição (Johnson, 2007).

\subsubsection{Limpeza de Dados}

Quando se digitalizam os dados de espécies e espécimes, considerações sobre a qualidade dos dados incluem erros em identificação taxonômica, georreferenciamento e a transcrição dos dados por si só. Erros são comuns e esperados, mas não podem ser ignorados (Canhos et al., 2004). Novas ferramentas na internet têm surgido para a validação de dados de identificação taxonômica, datas e georreferenciamento e podem ser associadas aos arquivos de autoridade de dados em suas tarefas.

\subsubsection{Análise e Modelagem}

Em geral, os dados sobre biodiversidade existentes não provêm segurança para decisões ambientais diretas e detalhadas. Modelagem, ou alguns passos de inferência, são necessários para identificar e preencher lacunas de dados, planejar pesquisas futuras, avaliar as prioridades de conservação, e prover informação para decisões ambientais (Canhos et al., 2004). Em especial, a modelagem de nichos ecológicos para predição de distribuições geográficas de espécies é um campo em crescimento na Informática da Biodiversidade (Soberon, 2004)

A idéia geral da modelagem de nicho ecológico envolve o uso da informação primária da biodiversidade (ocorrência de espécies) para caracterizar as 
necessidades ecológicas da espécie (nicho ecológico) (Canhos et al., 2004). Integrando os dados primários da biodiversidade com as informações ambientais, os pesquisadores podem predizer os impactos das mudanças climáticas na biodiversidade marinha e terrestre; os conservacionistas podem encontrar lacunas nas redes de sistemas de conservação; os pesquisadores agrícolas e especialistas em saúde podem predizer a duração e a abrangência das pestes e doenças; ou então, analisar o impacto positivo ou negativo da introdução de uma espécie (Johnson, 2007).

Em geral, as ferramentas utilizam diferentes algoritmos de modelagem, baseados em árvores de classificação, regressões, redes neurais, algoritmos genéticos, entre outros (Johnson, 2007; Santana et al., 2008).

\subsection{Comentário final}

A conservação e o uso sustentável das espécies ameaçadas dependem do monitoramento contínuo de diversos tipos de dados sobre biodiversidade, principalmente os dados primários (de ocorrência de espécies) associados aos dados ambientais. A manipulação e a análise deste grande e complexo volume de dados dependem da TI, em particular, da evolução da Informática da Biodiversidade, um novo campo da computação.

As Iniciativas apresentadas neste capítulo facilitam o acesso aos dados sobre biodiversidade ao apoiar, manter ou financiar sistemas de informação ou redes de dados. Elas também contribuem com a criação de ferramentas e padrões para viabilizar a interoperabilidade entre as diversas redes especializadas e o crescimento do número de participantes destas redes.

Entres os sistemas e redes que compartilham dados de espécimes (dados primários) e de espécies de abelhas, destacam-se o GBIF e a IABIN-PTN, que também são importantes na padronização da IB junto com o TDWG, e na adoção de modelos de arquiteturas orientadas a serviços, que se tornaram padrões para os sistemas da área. 
Os serviços de georreferenciamento, limpeza e análise de dados, e de vocabulário controlado, comuns entre redes de dados sobre biodiversidade, e que têm evoluído rapidamente devido à importância da qualidade dos dados para a tomada de decisões, assim como os componentes básicos das arquiteturas dos sistemas de informação da área (Portal, Message Broker, Agregadores e Harvesters, Diretórios de Serviços e Provedores de dados), são base para a análise dos requisitos da arquitetura de referência no próximo capítulo. 


\section{CAPÍTULO 4 - ESPECIFICAÇÃO E PROPOSTA DE ARQUITETURA DA SERVICE-ORIENTED WEBBEE}

Este capítulo apresenta as etapas de especificação e análise dos requisitos que levaram à definição da arquitetura de referência, chamada de Service-Oriented Webbee - SOWB, que guiará a evolução da Webbee. Como ponto de partida, um levantamento do status atual da Webbee (stand-alone) foi realizado para compreender a sua aderência aos novos requisitos apresentados pela comunidade. Apenas parte do levantamento é apresentada neste capítulo, o texto completo compõe o Apêndice A do texto.

O texto prossegue com a apresentação dos requisitos da nova versão da Webbee e a análise dos principais requisitos para a arquitetura de referência: a orientação a serviços, a definição de interação entre espécimes e a proposta de um esquema de banco de dados de espécimes. Por fim, a proposta de arquitetura de referência é descrita, com seus padrões, serviços e modelos.

\subsection{Webbee - versão stand-alone}

\subsubsection{Introdução}

A Webbee é um projeto multidisciplinar construído para reunir em um único sistema, diversos tipos de informações sobre a biodiversidade brasileira em espécies de abelhas nativas (Saraiva; Cartolano-Júnior 2003). O objetivo desta concentração e organização de informações é contribuir para o mapeamento e quantificação da biodiversidade brasileira em abelhas, cujo público alvo é formado por pesquisadores, alunos de pós-graduação e de graduação nas áreas de biologia, ecologia e agronomia; e apicultores e agricultores. 


\subsubsection{Arquitetura do Sistema}

O foco estratégico da Webbee é a cooperação entre vários centros de pesquisa via Internet, seja na realização de experimentos, ou na contribuição com informações sobre espécies: textos, imagens, vídeos, etc. (Saraiva; ImperatrizFonseca, 2002). A arquitetura da Webbee reflete esta estratégia e integra ao mesmo tempo um sistema de instrumentação, um sistema de informação e uma rede de informações.

O sistema de instrumentação da Webbee compreende a monitoração de colônias de abelhas localizadas no Laboratório de Abelhas. Neste sistema, uma placa de aquisição de dados colocada num computador pessoal recebe sinais de sensores de temperatura e de umidade relativa do ar colocados dentro de uma colônia, e de um sensor de fluxo de abelhas, colocado na entrada da colônia. Fora do âmbito da colônia, uma estação meteorológica coleta dados sobre o ambiente. Esses dados coletados são enviados na forma de arquivos, via Internet, para outro computador, onde são armazenados no banco de dados (Figura 9).

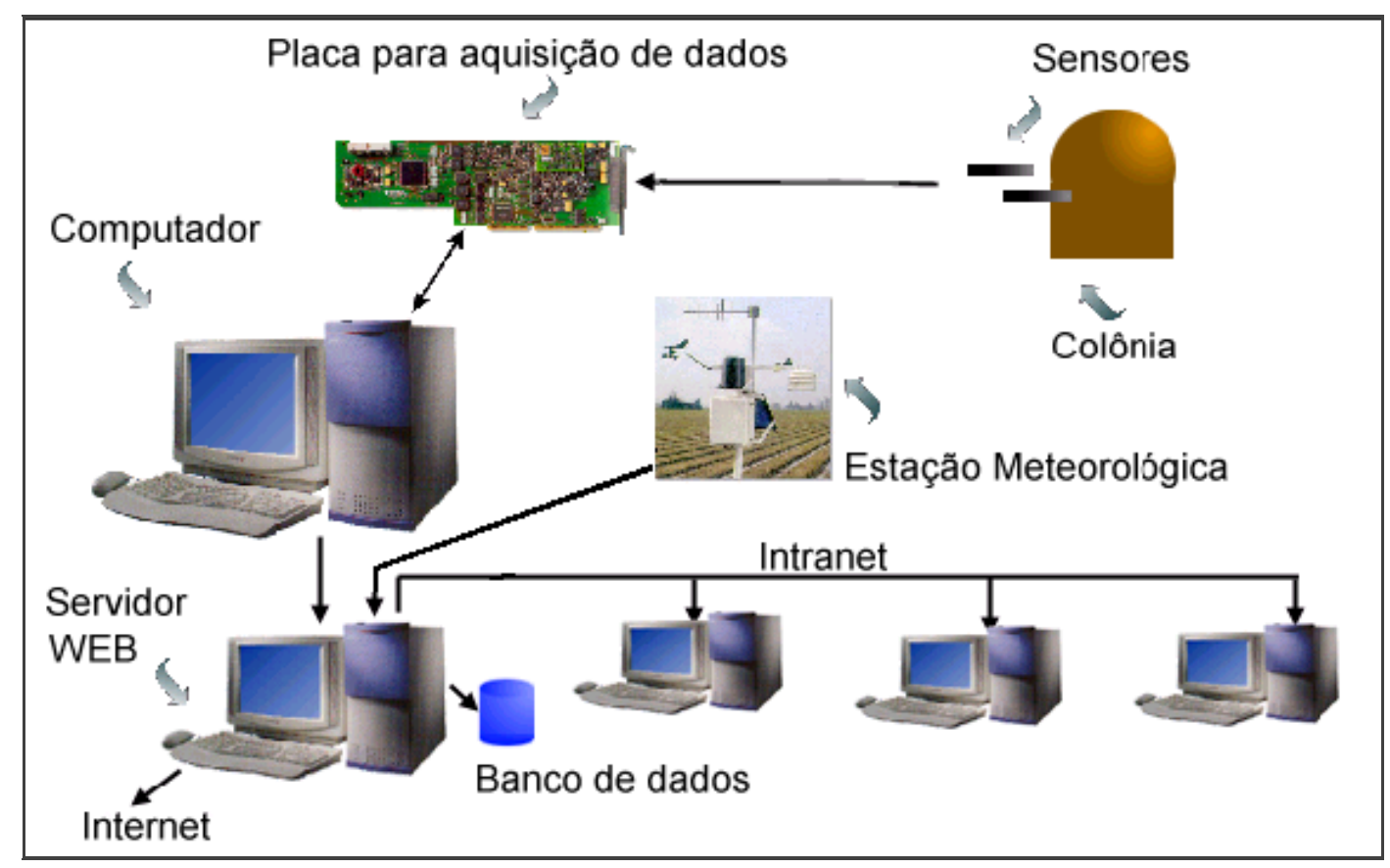

Figura 9 - Arquitetura e Principais Componentes da Webbee

Fonte: (Cunha, 2001) 


\subsubsection{Arquitetura de Software}

O sistema de informação é o núcleo da Webbee, pois é ele que recebe os dados automaticamente coletados e permite disponibilizá-los na rede (Cunha, 2001).

O sistema está dividido em três módulos:

- Módulo de Serviços, composto pelos programas servidores de banco de dados SQL (Structured Query Language) e Web (HTTP), e uma linguagem de programação interpretada;

- Módulo de Manutenção, composto pelo programa de manutenção; que é utilizado pelo administrador e pelos pesquisadores para inserção de dados;

- Módulo Web, composto pelo Navegador Web. É a interface do usuário com o sistema em qualquer ponto da Internet;

O banco de dados foi estruturado para organizar e conter dados sobre as espécies de meliponíneos, bem como diversos outros dados de interesse relacionados, como espécies de plantas visitadas, distribuição geográfica, entre outras. O banco foi modelado tendo por base as informações coletadas para o banco de dados do projeto BIOTA-SP FAPESP (BIOTA, 2007), e inúmeras outras solicitações dos especialistas consultados. A Figura 10 apresenta um diagrama simplificado do banco de dados, com as suas principais entidades de dados (retângulos). 


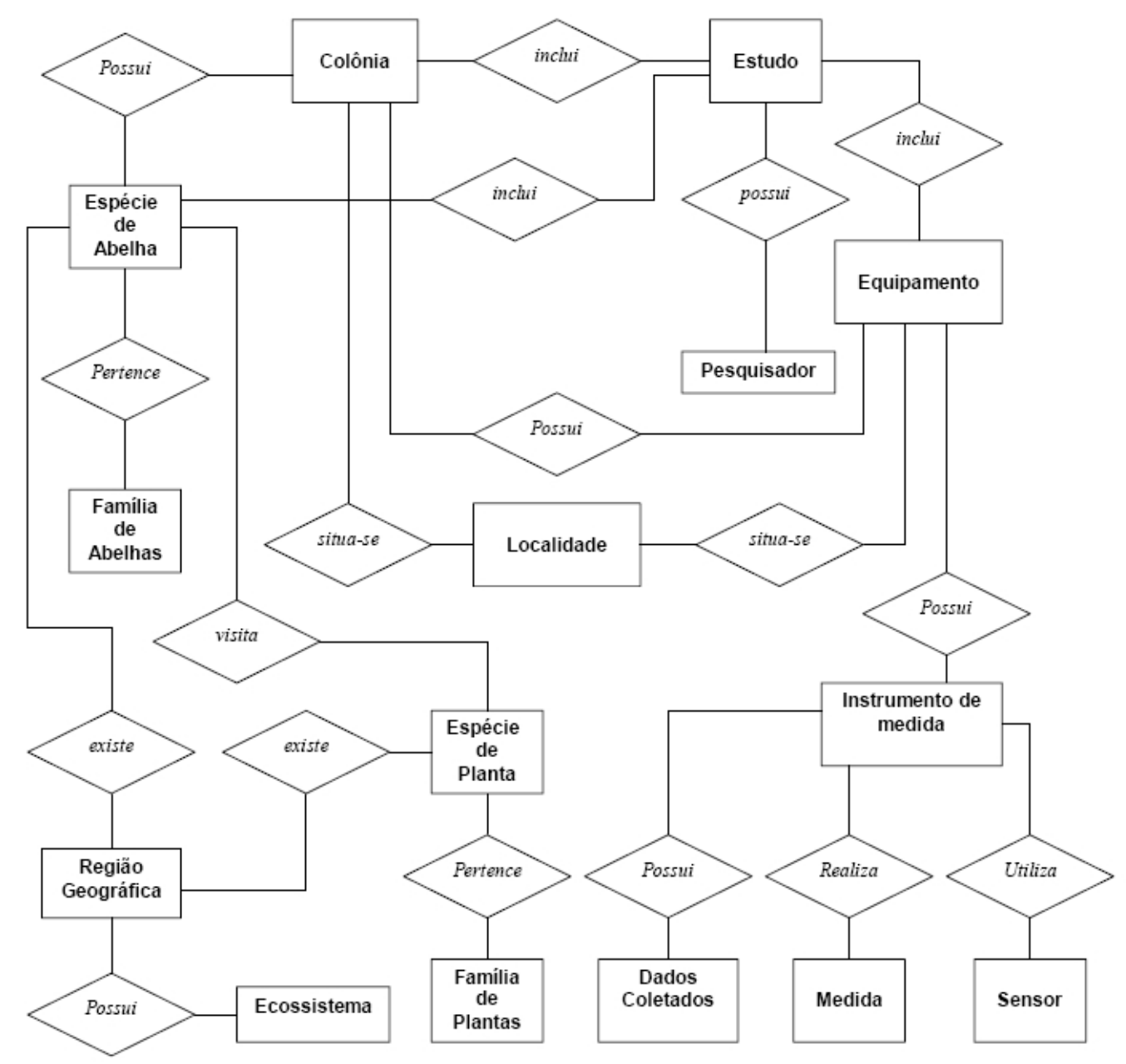

Figura 10 - Diagrama de Entidade-Relacionamento mínimo (sem atributos)

Fonte: (Cunha, 2001)

\section{$\underline{\text { A interface de operação via Internet }}$}

A definição das formas de exibição do conteúdo do banco de dados da Webbee foi feita em parceria pelos pesquisadores Laboratório de Automação Agrícola e do Laboratório de Abelhas e foi implementada como parte de um trabalho de iniciação científica (Saraiva; Cartolano-Júnior 2003).

Optou-se pela distribuição das espécies de abelhas e plantas em fichas com imagens e textos específicos sobre cada espécie Figura 11. Estas fichas contêm imagens sobre diferentes vistas das espécies e textos que fornecem dados sobre cada imagem. A partir da ficha de uma abelha é possível listar as plantas visitadas 
por ela e a partir dessa lista, abrir a ficha das plantas (Figura 12). O mesmo acontece na ficha das plantas, onde é possível listar as espécies de abelhas visitantes.

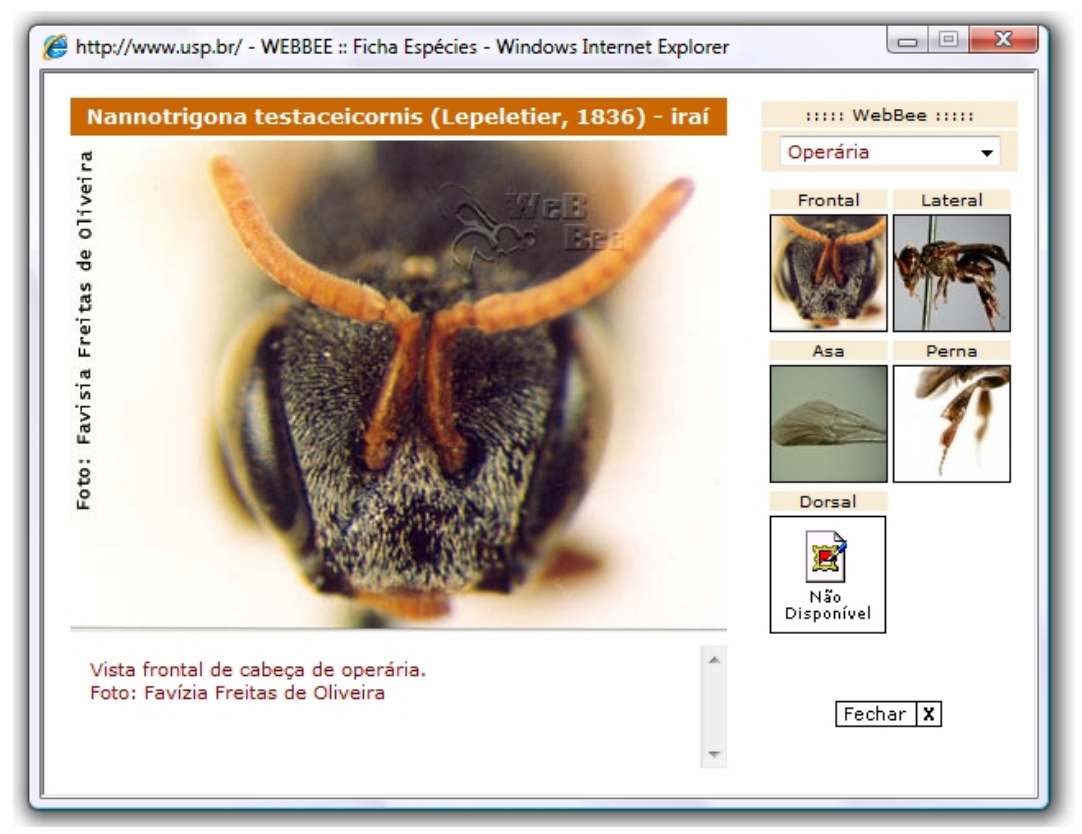

Figura 11 - Imagens de Fichas de Espécies

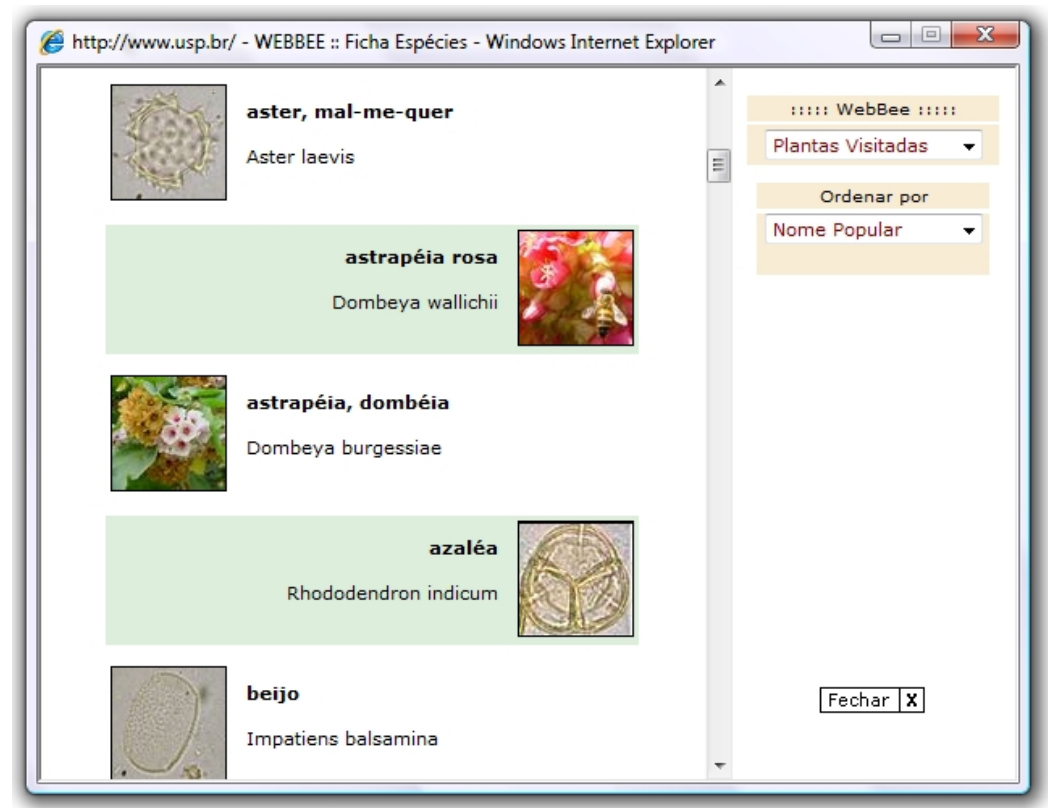

Figura 12 - Lista de Espécies de Plantas visitadas pela Espécie de Abelha. 


\subsection{Especificação dos Requisitos da nova versão da Webbe}

A Webbee desperta grande interesse na comunidade científica, e as discussões sobre o seu papel têm convergido para uma rede de dados nacional, para auxiliar a tomada de decisões em nível local e ser referência em dados de abelhas nativas brasileiras para outras redes de dados sobre biodiversidade.

Esta proposta considera um novo cenário, que vem se fortalecendo nos últimos anos com uma maior importância dada aos agentes polinizadores, com a organização da comunidade científica brasileira em torno desse tema e com o amadurecimento e o desenvolvimento da Informática da Biodiversidade, que impulsionam o acesso aos dados sobre biodiversidade.

Neste cenário, a nova versão da Webbee passa a concentrar iniciativas brasileiras (para facilitar o acesso às informações) e se a integrar a rede de dados sobre biodiversidade de espécies e espécimes de abelhas nativas brasileiras, e de polinização por estas abelhas.

\subsubsection{Integração com as redes de dados sobre biodiversidade}

Desde a época de sua criação, a Webbee se restringe à catalogação de espécies de abelhas nativas e a automatização da coleta de dados ambientais e de movimento em experimentos com colônias no Laboratório de Abelhas. Esses dados são armazenados em um banco de dados central e publicados na Internet.

A integração das diversas fontes de dados brasileiras é feita pelo cadastro de informações pelo usuário, no banco de dados, via aplicativo de manutenção, ou seja, não existe uma integração automática, pois a Webbee não publica e tão pouco consome dados ou serviços de outros sistemas.

Essa estrutura é muito bem sucedida e atende a demanda inicial pela qual foi criada (item 4.1.1). Entretanto, a qualidade dos serviços prestados levou a Webbee a um novo patamar de sistema de informação. Ela deve passar a oferecer conteúdo 
e serviços a outros sistemas de biodiversidade e, eventualmente, consumir conteúdo e serviços de outros sistemas.

Também se espera que a Webbee seja um portal que concentre e indexe as informações sobre abelhas nativas brasileiras nas redes de dados sobre biodiversidade. Além de prover conteúdo próprio, este portal deve funcionar como um Data Indexer (item 3.2.5.3), que seja a porta de entrada do usuário para outros sistemas.

Essa atuação orientada a consumir e prover serviços para outros sistemas não é suportada hoje pelo sistema. Apesar de já trabalhar no modelo clienteservidor, as solicitações não atuam como serviços e têm apenas abrangência local. As interfaces de programação usadas no sistema de informação não estão preparadas para o acesso remoto e dinâmico a outros sistemas, e nem estão escritas dentro dos padrões de comunicação entre sistemas da Informática da Biodiversidade.

Uma solução adequada para este novo e importante requisito recai na utilização de um dos modelos de arquitetura orientada a serviços apresentados no Capítulo 3, e das ferramentas e padrões de comunicação entre sistemas da Informática da Biodiversidade (tais como TAPIR e Darwin Core).

\subsubsection{Concentração de provedores locais}

Outro papel importante destinado à Webbee é a de concentrar as iniciativas locais para facilitar o acesso às informações sobre biodiversidade. Este requisito está intimamente ligado a atuação da Webbee como referência em informações sobre espécies e espécimes de abelhas nativas brasileiras, e de polinização por estas abelhas.

Assim como ocorre com outros sistemas, no SpeciesLink (CRIA, 2008) por exemplo, fontes de dados locais deverão utilizar a infra-estrutura e a capacidade tecnológica da Webbee para manter on-line os seus dados.

Por falta de recursos tecnológicos ou de mão de obra especializada, importantes fontes de dados não têm condições de criar ou manter um provedor 
online. Seus dados continuam armazenados em planilhas eletrônicas, blocos de notas ou softwares especializados que não atendem os padrões da Informática da Biodiversidade. Existem ainda os casos em que os dados não estão digitalizados, e permanecem em teses e dissertações, diários de campo, anotações de experimentos e outros manuscritos, longe do alcance da comunidade.

Para aqueles que já têm uma estrutura organizada, a adoção de uma base de dados única também pode ser considerada uma vantagem estratégica. Por conveniência um provedor pode utilizar a Webbee como ponte para publicar seus dados em um número maior de sistemas de informação. Já para a Webbee, a concentração dos dados é uma vantagem estratégica do ponto de vista técnico (no tratamento e análise dos dados) e político (na qualidade e quantidade dos dados) frente aos outros sistemas. Entretanto, questões relacionadas à propriedade e atualização dos dados podem impedir a migração de alguns provedores.

A hospedagem dos provedores será viabilizada com a adoção de uma arquitetura mista de consultas (item 3.3.7). Nesta estrutura a Webbee será capaz de manter os dados de seus provedores locais, originados do harvest de provedores menores, da carga local por outras estruturas (planilhas eletrônicas, arquivos de texto, etc.) ou de uma ferramenta local de digitalização, e ao mesmo tempo, poderá consultar provedores de dados externos de forma distribuída, abrangendo um número maior de fontes.

\subsubsection{Utilização de dados de espécimes no sistema}

A introdução dos dados de espécimes na Webbee é justificada pela importância e quantidade de dados primários de abelhas brasileiras que não são publicados. Sistemas como o SpeciesLink (CRIA, 2008) têm contribuído para o armazenamento e busca de espécimes preservados e observados, inclusive de abelhas. No entanto, não existe um sistema que concentre suas buscas em abelhas e que publique os dados das coleções e observações de médio e pequeno porte.

A solução para a integração desses dados pode contar com o conjunto de ferramentas bem sucedidas já utilizadas pelos principais sistemas de informação 
sobre a biodiversidade, como o GBIF e a IABIN, por exemplo, que têm os dados primários como foco.

\subsubsection{Utilização de dados de interação entre espécimes}

A interação é o elemento básico do processo de polinização por abelhas, por isso, esse tipo de dado tem de grande importância comercial e científica. Ao conhecer as condições (climáticas, geográficas, biológicas, etc.) que favorecem determinadas interações, entre determinadas espécies, pode-se compreender melhor o processo a ponto de otimizá-lo ou reproduzi-lo com maior eficiência, por exemplo. Em outro exemplo, a reprodução das condições favoráveis pode viabilizar pesquisas de distribuição/migração de espécies, ou então, de introdução de uma nova espécie em uma cultura comercial.

Dados de interação entre abelhas e plantas já são publicados pela Webbee na ficha de espécies (Figura 12), e o seu banco de dados já comporta o relacionamento entre as entidades espécies de abelhas e espécies de plantas (Figura 10). Entretanto, estes dados são uma generalização de diversas observações de campo dos pesquisadores do Laboratório de Abelhas, e o agrupamento omite dados de cada observação: localidade, tempo, observador, etc., restando apenas uma descrição das espécies e do tipo da interação.

Existe uma demanda para que, além dos dados de interação entre espécies, os dados da observação da interação, ou seja, a ocorrência de fato, também seja publicada. Estes dados são fonte para a realização de análises e modelagens de distribuição/migração de espécies polinizadoras, e de estudos relacionados. Esperase que a Webbee se torne uma referência dos dados de interação com abelhas, fornecendo este tipo de dado aos usuários finais via portal, e aos outros sistemas de informação via ferramentas de integração de sistemas.

Particularmente, a Rede de Polinizadores da IABIN tem grande interesse neste tipo de dado que, dentro do seu escopo, tem maior valor agregado que apenas os dados de espécimes (preservados e observados) de polinizadores. 


\subsubsection{Facilidade para integrar novas aplicações}

Muitas ferramentas evoluíram da versão atual da Webbee, ou tiveram o sistema como modelo para abordagem de novos temas. Entretanto, elas não puderam ser integradas à Webbee devido, principalmente, às novas tecnologias utilizadas por essas ferramentas, e a descentralização do desenvolvimento. Esperase que sistemas de informação e de instrumentação relacionados às abelhas possam ser facilmente integrados à Webbee.

Como discutido no Capítulo 2, a adoção de uma arquitetura orientada a serviços facilita a escalabilidade, já que a comunicação entre os sistemas é independente da organização individual, e depende apenas da localização e definição de serviços cujas interfaces são construídas e acessadas com a utilização de padrões.

No domínio da instrumentação eletrônica, a principal contribuição das novas ferramentas está ligada à realização de experimentos remotos. Neste novo conceito, o usuário deixa de ter acesso apenas aos dados dos experimentos já realizados, e passa a realizá-los remotamente pela Internet, para depois colher os resultados. As estruturas que possibilitam este tipo de operação são chamadas de weblabs (Ferreira, 2007).

O Virtual Network Center of Ecosystem Services - VINCES (VINCES, 2008), TIDIA-FAPESP, é um projeto coordenado pelo LAA para a criação de aplicações para a Internet Avançada, e tem como foco weblabs de serviços ambientais, tais como a fotossíntese e a polinização. Os weblabs destinados aos polinizadores, principalmente os de monitoração de colméia, já têm uma proposta de arquitetura orientada a serviços (Ferreira, 2007) e podem ser integrados a nova Webbee:

- Monitoração de Colméia: monitoração de uma colméia de abelha sem ferrão (Meliponini) com câmera de vídeo, microfone e sensores de movimento, temperatura e umidade relativa do ar, que são ligados a nós de uma rede de controle do tipo LON (Ferreira, 2007) (Figura 13). 


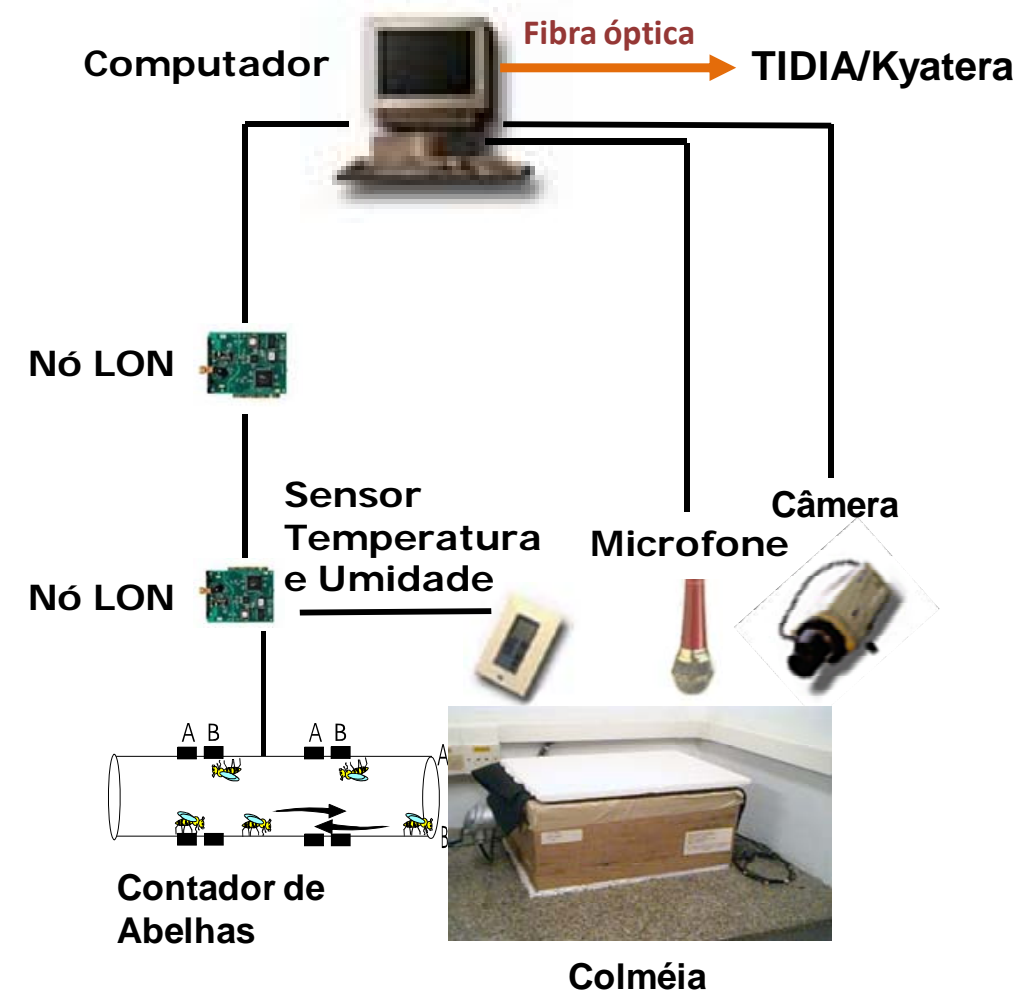

Figura 13 - Estrutura do weblab de monitoração de variáveis em colméias Fonte: (Ferreira, 2007)

Entre os sistemas de informação, a principal ferramenta a ser integrada é o mecanismo de busca do novo portal. Ele deverá buscar todos os dados da Webbee, independente do tipo: espécies, espécimes, experimentos, pesquisadores, etc. De uma maneira geral, a partir de uma busca do usuário, a Webbee exibirá as ocorrências do termo de busca nos provedores de dados (de diversos tipos de dados). Graças à organização orientada a serviços, o Portal da Webbee deve se resumir a um motor de buscas, que para o usuário, deve ser visto como um "guardachuva de aplicações".

Os sistemas legados da Webbee (catálogo e ficha de espécies, e gráficos da estação meteorológica) e as novas ferramentas criadas pelo LAA deverão ser tratados como aplicações "locais" que, assim como os outros sistemas na Internet, prestarão serviços a nova Webbee. Caberá a nova Webbee hospedar apenas as páginas de conteúdo didático, de pesquisadores associados e da IBP. 


\subsubsection{Segurança, créditos e qualidade dos dados}

A Webbee é uma oportunidade de coordenação de esforços, de padronização de conteúdos e de divulgação de resultados numa plataforma comum e de propriedade e responsabilidade compartilhada pela comunidade (Saraiva, 2003). No entanto, essa oportunidade também deve ser um ponto de atenção, que pode trazer impactos negativos em relação à segurança, autoria e qualidade dos dados.

A autoria dos dados é um dos principais entraves para a entrada de novos participantes. Para garantir a autoria das informações, a Webbee deve prever a informação da autoria de todo o material exibido. Textos, fotos, imagens devem ser creditados ao autor que será devidamente identificado.

$\mathrm{Na}$ nova arquitetura orientada a serviços, a segurança dos dados será responsabilidade dos provedores de dados e serviços. Eles devem decidir quais informações devem ou não ser publicadas. A responsabilidade da Webbee ficará restrita a segurança dos dados dos provedores locais. Neste caso, cada provedor decidirá quais dados ficarão ou não disponíveis ao público.

Nas aplicações "locais" (como a ficha de espécies), quando conveniente, e de forma independente, níveis de privilégio irão garantir a segurança na manipulação dos dados, e também servirão de base para um sistema de validação de dados. Neste sistema, pesquisadores mais experientes validarão os dados cadastrados por outros pesquisadores. Os dados serão publicados durante o processo, indicando quando uma informação estiver "em validação". Esta medida de validação irá privilegiar a qualidade dos dados ao criar um processo de verificação durante o cadastro.

\subsection{Análise dos requisitos da arquitetura de referência}

Os objetivos de negócio da Webbee são bem definidos: concentrar as iniciativas regionais e se integrar às redes de dados sobre biodiversidade como 
referência em informações sobre espécies e espécimes de abelhas nativas brasileiras, e de polinização por estas abelhas.

Sobre estes objetivos, uma análise foi orientada para identificar as principais lacunas entre a estrutura stand-alone do sistema (item 4.1) e os requisitos da nova versão da Webbee, apresentados nos itens anteriores (item 4.2). Esta análise foi utilizada para que pudessem ser identificados os padrões e as ferramentas da Informática da Biodiversidade, apresentadas no Capítulo 3, utilizados pelas redes de interesse da Webbee.

Dentre os diversos padrões, comuns a estas redes, destacam-se o protocolo de comunicação TAPIR, e o esquema de dados Darwin Core, especializados na troca de dados de espécimes. No entanto, devido à especialização da rede Webbee, fez-se necessário definir padrões para estruturar e trocar dados de interação entre espécimes, essenciais para o estudo de polinizadores, e que não eram encontrados entre os padrões utilizados pelas redes de interesse ou, pelo menos, não atendiam os requisitos da Webbee.

Os itens seguintes apresentam os dois principais pontos de análise da arquitetura de referência da nova Webbee, a identificação das redes de interesse e a definição do tratamento computacional dos dados de interação.

\subsubsection{Identificação das redes de dados e sistemas de interesse}

Como discutido no item 3.3.6 a definição dos sistemas de informação sobre a biodiversidade que são de interesse da Webbee para a integração dos seus dados, é um passo importante para a definição da arquitetura de referência que guiará a evolução da Webbee, pois influenciam nas suas especificações técnicas.

As redes de dados de interesse e, consequentemente, os seus sistemas de informação, devem estar envolvidos com os processos para consumir e prover dados de espécies e espécimes (preservadas e observadas) de abelhas nativas brasileiras e de polinização por estas abelhas, que é a nova orientação da Webbee. Eles não precisam ser especializados nestes tipos de dados, na verdade, não os 
são, pois esse é o papel da nova Webbee, mas, de uma forma generalizada, eles devem tratar os dados de abelhas nativas.

As redes (e os sistemas de informação) de interesse da Webbee trocam dados primários padronizados pelo esquema Darwin Core2 (v1.4) e suas extensões, e dados de espécies padronizados pelo Species Profile Model, nos dois casos, trocados com o protocolo TAPIR. Ao adotar o TAPIR, a Webbee pode utilizar quaisquer esquemas conceituais sobre a biodiversidade que se adequem às mensagens trocadas pelo TAPIR.

A seguir, são apresentados os principais sistemas de interesse e sua arquitetura, que inspiraram a definição da arquitetura de referência deste trabalho, por utilizarem padrões bem-definidos e serem referências em seus domínios.

\section{Global Biodiversity Information Facility - GBIF}

O portal GBIF é o principal participante da rede de dados primários sobre a biodiversidade. Ele utiliza e define padrões da Informática da Biodiversidade para catalogar, indexar e publicar os seus dados, que somam mais de 177 milhões de registros de espécimes (preservadas e observadas), incluindo as abelhas, e mais de 294 provedores distribuídos pelo mundo.

A arquitetura de software do Portal incorpora os elementos da arquitetura mista (Figura 14) para interagir com outros sistemas. Como discutido no item 3.3.7, este tipo de arquitetura pode realizar consultas distribuídas (direto no provedor) ou em uma base local (com uma cópia dos dados do provedor).

O módulo do portal chamado Index é o responsável por realizar o harvest dos provedores de nomes taxonômicos e de dados de espécimes, que são agregados e armazenados em uma base local (cache). Tanto o harvest como as consultas diretas aos provedores de dados são feitos com os serviços disponibilizados pelos provedores com o protocolo TAPIR. As consultas que não envolvem dados sobre biodiversidade, tais como publicação e consulta sobre serviços, utilizam protocolos comuns entre os Web Services, o SOAP. 


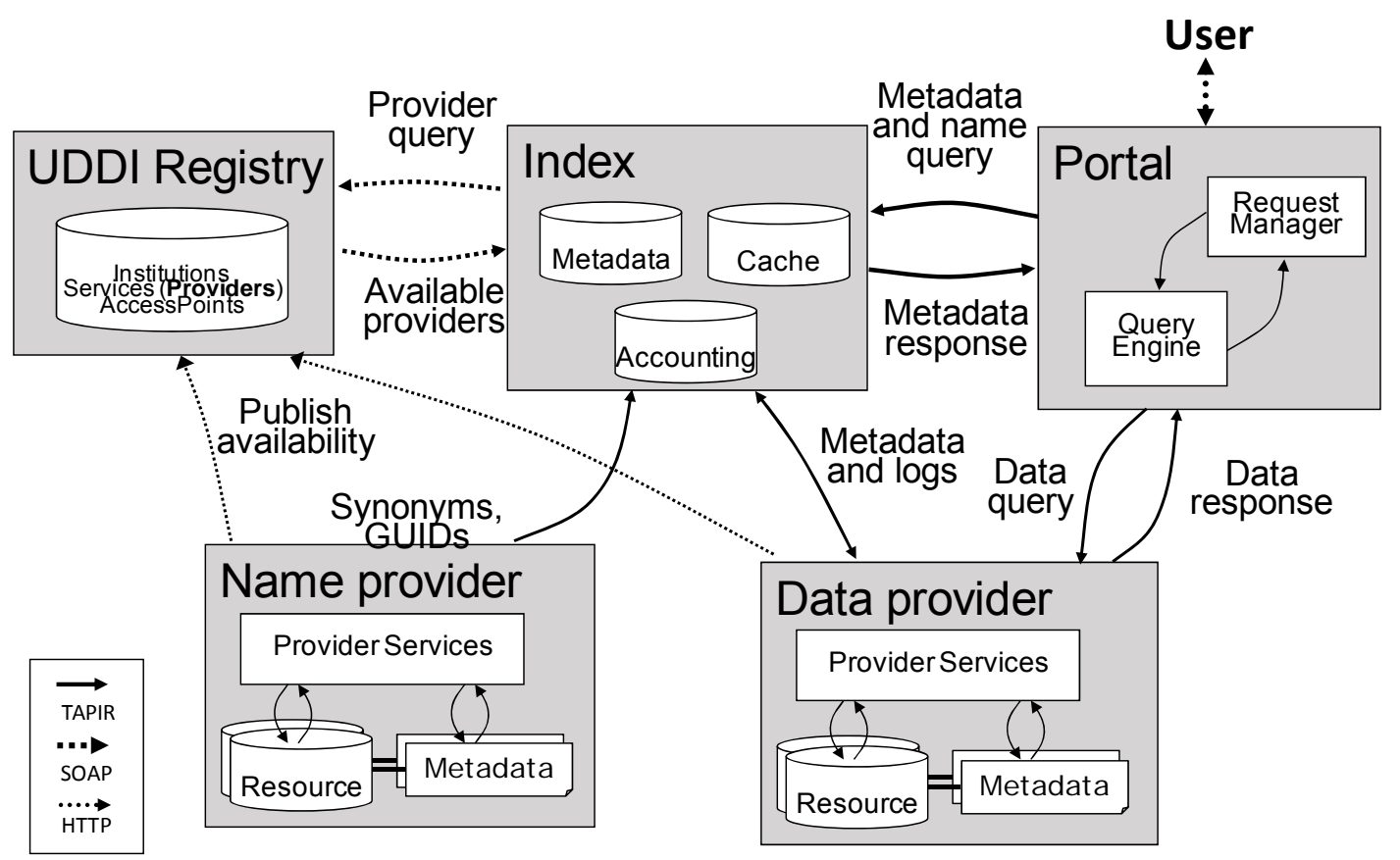

Figura 14 - Arquitetura de software do Portal GBIF

Fonte: (GBIF, 2007)

\section{IABIN-Pollinators Network - PTN e SSTN}

As 6 redes temáticas da IABIN seguem uma orientação sobre protocolos e padrões de dados. Para os dados de espécimes e espécimes, são utilizados os esquemas conceituais Darwin Core2 (v1,4) e Plinian Core, respectivamente, trocados com o protocolo TAPIR.

Duas redes temáticas da IABIN são de interesse da Webbee, a Pollinators Network (Figura 15), que concentra os dados de polinizadores de toda a rede, e a Species \& Specimens, que trata os dados de espécies e espécimes em geral. 


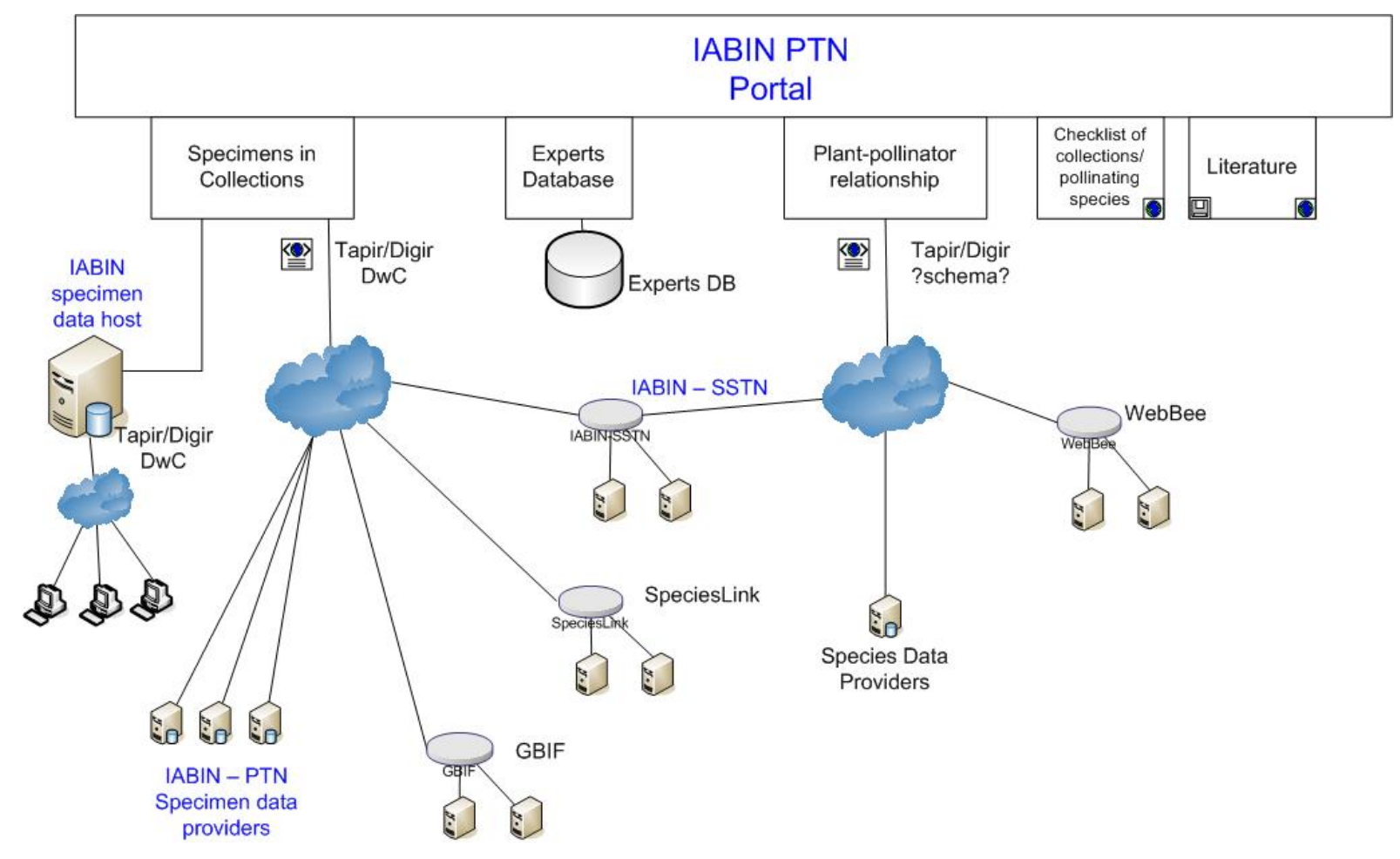

Figura 15 - Arquitetura da Rede Temática de Polinizadores - IABIN-PTN Fonte: (IABIN, 2007)

Ambas as redes temáticas utilizam uma versão customizada do Portal do GBIF, portanto, também atuam com uma arquitetura mista de consultas. A diferença de customização entre os portais está relacionada à especialização das redes. Enquanto a PTN adaptou o portal para tratar dados de interações entre espécimes, a SSTN incorporou os dados de espécies em todos os processos do Portal.

\subsubsection{Definição do tratamento computacional dos dados de Interação}

\subsubsection{Conceito de Interação}

Nas fontes de dados sobre biodiversidade avaliadas: coleções, planilhas de anotações e referências bibliográficas, uma interação é sempre descrita como um evento do tipo "espécime $x$ espécime" ou "espécie $x$ espécie". No primeiro tipo de 
interação, pode-se precisar como o evento (particular) aconteceu, pois envolve dois espécimes (indivíduos reais). Já na interação entre espécies, ocorre uma generalização do primeiro tipo.

Essa diferença entre os dados de interação pode ser analisada de forma semelhante à diferença entre "espécies" e "espécimes". Os dados de uma espécie representam uma generalização do conhecimento sobre os indivíduos que têm um grupo de características em comum, os espécimes, que por sua vez, foram observados ou catalogados por alguém em um espaço e tempo definidos (item 3.3). De forma análoga, podemos dividir as interações entre:

- Atômicas: que é um evento observado por alguém em um espaço e tempo definidos e que, por isso, é único, ou seja, não pode se repetir. Neste caso, existem, necessariamente, dois espécimes reais envolvidos, que de fato foram observados pela pessoa. Posteriormente, esses espécimes podem ser coletados e registrados como espécimes preservados em museus, ou podem permanecer intocados na natureza e serem registrados como observações.

- Generalizadas: que é uma generalização de inúmeras interações atômicas e que, por isso, só pode ser descrita no nível de espécies. Se este tipo de interação envolvesse pelo menos um indivíduo real, passaria a determinar um fato único, caracterizando o outro indivíduo, o observador, o espaço e o tempo, ou seja, uma interação atômica.

Foram consideradas no escopo do trabalho apenas as interações "atômicas", ou seja, aquelas envolvem apenas espécimes (observados ou catalogados), principalmente, porque este tipo de interação representa a maior parte dos dados coletados em campo, importantes para os modelos de distribuição e podem, no limite, gerar as interações generalizadas. O Quadro 2 lista os atributos obrigatórios de uma interação atômica que, a partir deste ponto, será chamada apenas de "interação". Por dependência conceitual, a interação exige a identificação unívoca dos espécimes que, junto com a identificação do evento, compõe um registro unívoco de interação. 


\begin{tabular}{|c|}
\hline Interação \\
\hline $1^{\circ}$ Espécime \\
\hline Identificação (espécie) \\
\hline Espaço \\
\hline Tempo \\
\hline Observador/Coletor \\
\hline Interação \\
\hline Identificação (evento) \\
\hline Espaço \\
\hline Tempo \\
\hline Observador \\
\hline $2^{\circ}$ Espécime \\
\hline Identificação (espécie) \\
\hline Espaço \\
\hline Tempo \\
\hline Observador/Coletor \\
\hline
\end{tabular}

Quadro 2 - Campos de uma interação atômica

A seguir, são apresentados os tipos de interações tratadas pela Webbee com base nos tipos dos espécimes.

- Indivíduos Coletados. Exemplo: na Fazenda Passos (espaço), o pesquisador Diogo Fernandes (oletor) presenciou no dia 12/05/2009 (tempo) a visita de uma jataí (Tetragonisca Angustula) a uma jabuticabeira (Myrciaria trunciflora), que posteriormente foram coletadas e encaminhadas para serem preservadas em coleções (Quadro 3).

\begin{tabular}{lll} 
& \multicolumn{1}{c}{ Abelha } & Planta \\
\hline Indivíduo & & \\
\hline Espécime & Preservado em Coleção & Preservado em Coleção \\
\hline Identificação & & \\
\hline Nome Científico & Tetragonisca Angustula & Myrciaria trunciflora \\
\hline Espaço & & \\
\hline Local & Fazenda Passos & Fazenda Passos \\
\hline
\end{tabular}




\begin{tabular}{|c|c|c|}
\hline Coordenadas & (longitude $\mathrm{X}$, latitude $\mathrm{Y}$ ) & (longitude $\mathrm{X}$, latitude $\mathrm{Y}$ ) \\
\hline \multicolumn{3}{|l|}{ Tempo } \\
\hline Data & 12/05/2009 13:34:00 & $12 / 05 / 2009$ 13:34:00 \\
\hline \multicolumn{3}{|c|}{ Observador I Coletor } \\
\hline Nome & Diogo Fernandes & Diogo Fernandes \\
\hline
\end{tabular}

Quadro 3 - Exemplo de dados de interação entre espécimes preservados em coleções

- Indivíduo Coletado e Indivíduo Observado. Exemplo: na Fazenda Passos (espaço) o pesquisador Diogo Fernandes (observador/coletor) presencia no dia 12/05/2009 (tempo) a visita de uma jataí (Tetragonisca Angustula) a uma jabuticabeira (Myrciaria trunciflora). Apenas a abelha é coletada e encaminhada para ser preservada em uma coleção. A planta permanece intocada (Quadro 4).

\begin{tabular}{lcc} 
& \multicolumn{1}{c}{ Abelha } & Planta \\
\hline Indivíduo & & \\
Espécime & Preservado em Coleção & Observado \\
\hline Identificação & & \\
\hline Nome Científico & Tetragonisca Angustula & Myrciaria trunciflora \\
Espaço & & \\
\hline Local & Fazenda Passos & Fazenda Passos \\
Coordenadas & (longitude X, latitude Y) & (longitude X, latitude Y) \\
Tempo & & \\
\hline Data & $12 / 05 / 2009$ 13:34:00 & $12 / 05 / 2009$ 13:34:00 \\
Observador / Coletor & & \\
\hline Nome & Diogo Fernandes & Diogo Fernandes \\
\hline
\end{tabular}

Quadro 4 - Exemplo de dados de interação entre espécime preservado em coleção e espécime observado em campo

- Indivíduos Observados. 
Exemplo 1: na Fazenda Passos (espaço) o pesquisador Diogo Fernandes (observador) presencia no dia 12/05/2009 (tempo) a visita de uma jataí (Tetragonisca Angustula) a uma jabuticabeira (Myrciaria trunciflora). Ambos permanecem intocados e não são coletados (Quadro 5).

\begin{tabular}{lcc} 
& \multicolumn{1}{c}{ Abelha } & Planta \\
\hline Indivíduo & & \\
Espécime & Observado & Observado \\
\hline Identificação & & \\
\hline Nome Científico & Tetragonisca Angustula & Myrciaria trunciflora \\
Espaço & & \\
\hline Local & Fazenda Passos & Fazenda Passos \\
Coordenadas & (longitude X, latitude Y) & (longitude X, latitude Y) \\
\hline Tempo & & \\
\hline Data & $12 / 05 / 2009$ 13:34:00 & $12 / 05 / 2009$ 13:34:00 \\
\hline Observador / Coletor & & \\
\hline Nome & Diogo Fernandes & Diogo Fernandes
\end{tabular}

Quadro 5 - Exemplo de dados de interação entre espécimes observados em campo

Exemplo 2: um pesquisador localiza em uma referência bibliográfica a descrição do espaço e tempo de uma interação entre dois indivíduos, que pode ser descrita por "na Fazenda Passos (espaço), o pesquisador Diogo Fernandes (observador) observou em 12/05/2009 (tempo) que duas abelhas jataí (Tetragonisca Angustula) visitaram uma jabuticabeira (Myrciaria trunciflora)" (Quadro 6). 


\begin{tabular}{|c|c|c|}
\hline & Abelha & Planta \\
\hline \multicolumn{3}{|l|}{ Indivíduo } \\
\hline Espécime & Observado & Observado \\
\hline \multicolumn{3}{|l|}{ Identificação } \\
\hline Nome Científico & Tetragonisca Angustula & Myrciaria trunciflora \\
\hline \multicolumn{3}{|l|}{ Espaço } \\
\hline Local & Fazenda Passos & Fazenda Passos \\
\hline Coordenadas & (longitude $\mathrm{X}$, latitude $\mathrm{Y}$ ) & (longitude $\mathrm{X}$, latitude $\mathrm{Y}$ ) \\
\hline \multicolumn{3}{|l|}{ Tempo } \\
\hline Data & 12/051979 13:34:00 & $12 / 05 / 1979$ 13:34:00 \\
\hline \multicolumn{3}{|c|}{ Observador / Coletor } \\
\hline Nome & Diogo Fernandes & Diogo Fernandes \\
\hline \multicolumn{3}{|c|}{ Informações Relacionadas } \\
\hline Referência & (Fernandes, 1979) & (Fernandes, 1979) \\
\hline
\end{tabular}

Quadro 6 - Exemplo de dados de interação entre espécimes observados em referências bibliográficas

Se em alguns dos casos fossem relatadas interações do tipo: "a abelha jataí interage com a planta jabuticabeira", ela não seria considerada, pois não trata a interação entre indivíduos, e sim, entre espécies, pois não tem indicações do observador, do espaço e do tempo. 


\subsubsection{Modelo de interação entre espécimes}

O modelo de interação atômica detalhado no Quadro 2 pode ser representado graficamente pela Figura 16.

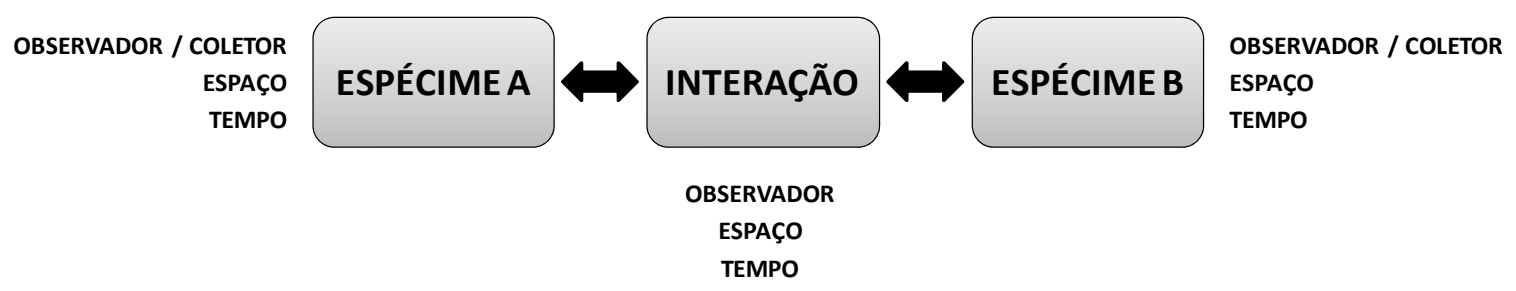

Figura 16 - Representação gráfica do Modelo de Interação entre espécimes

Os dados do observador ou coletor, do espaço e do tempo são obrigatórios para os três elementos. Dependendo do tipo dos espécimes envolvidos, os itens obrigatórios podem, ou não, ser compartilhados com a interação:

- Indivíduos Coletados: Os dados do observador da interação e do coletor dos espécimes; e da data da observação e da data da coleta, não são necessariamente os mesmos. Exemplo: um pesquisador faz uma observação entre uma abelha e uma planta, mas outros pesquisadores podem coletá-las em tempos diferentes (Quadro 7).

\begin{tabular}{|c|c|c|c|}
\hline & Abelha & Planta & Interação \\
\hline \multicolumn{4}{|l|}{ Espaço } \\
\hline Local Coleta & Local A & Local A & \\
\hline Local Observação & & & Local A \\
\hline \multicolumn{4}{|c|}{ Coletor I Observador } \\
\hline Coletor & Coletor A & Coletor B & \\
\hline Observador & & & Observador $\mathbf{C}$ \\
\hline \multicolumn{4}{|l|}{ Tempo } \\
\hline Coleta & Tempo A & Tempo B & \\
\hline Observação & & & Tempo C \\
\hline
\end{tabular}

Quadro 7 - Exemplo de dados de atributos de interação de indivíduos coletados 
- Indivíduo Coletado e Indivíduo Observado: Os dados do observador da interação e do coletor do indivíduo; e da data da observação e da data da coleta, não são necessariamente os mesmos. Mas, neste caso, o observador e o data são os mesmos para a interação e o indivíduo observado. Exemplo: um pesquisador faz uma observação entre uma abelha e uma planta determinada, mas outro pesquisador coleta a abelha em outro tempo (Quadro 8).

\begin{tabular}{|c|c|c|c|}
\hline & Abelha & Planta & Interação \\
\hline \multicolumn{4}{|l|}{ Espaço } \\
\hline Local Coleta & Local A & & \\
\hline Local Observação & & Local A & Local A \\
\hline \multicolumn{4}{|c|}{ Coletor I Observador } \\
\hline Coletor & Coletor A & & \\
\hline Observador & & Observador C & Observador $\mathbf{C}$ \\
\hline \multicolumn{4}{|l|}{ Tempo } \\
\hline Coleta & Tempo A & & \\
\hline Observação & & Tempo C & Tempo C \\
\hline
\end{tabular}

Quadro 8 - Exemplo de dados de atributos de interação de um indivíduo coletado e um observado

- Indivíduos Observados: Os dados do observador e da data são necessariamente os mesmos para a interação e os indivíduos (Quadro 9).
Abelha
Planta
Interação

Espaço

Local Coleta

Local Observação

Local A

Local A

Local A

Coletor / Observador

Coletor

Observador

Observador C

Observador C

Observador C

Tempo

Coleta 
Os locais das observações e da coleta dos indivíduos (dois primeiros casos) também podem ser diferentes, por exemplo: uma abelha pode interagir com uma planta e ser coletada em outra, a metros de distância. No entanto, essa variação tem pouco impacto na precisão (de georreferenciamento) dos dados, já que a variação geralmente ocorre em uma mesma localidade (uma fazenda, por exemplo). Por isso, o modelo foi simplificado, e considerou o mesmo espaço para todos os envolvidos.

Como atributos complementares aos dados obrigatórios, podem ser agregados dados que detalhem o evento de interação (direção, clima, anotações, subclassificações do evento, referências, etc.) ou a classificação dos espécimes (taxonomia, comportamento, etc.).

\subsubsection{Avaliação dos esquemas conceituais disponíveis sobre dados de interação entre espécimes}

Definido o modelo de interação, era preciso avaliar quais dos principais esquemas conceituais disponíveis (e usados pelas redes de interesse) era o mais adequado para representar essas informações.

- Darwin Core2 v1.4 (DwC) - O esquema mantido pelo TDWG não oferece suporte a dados de interação. Até o início do trabalho, também não existia uma extensão que desse suporte a esses dados (TDWG, 2007).

- Access to Biological Collection Data v2.06 (ABCD) - O esquema $A B C D$ trata os dados de interação entre espécimes (item 4.3.2.1) de forma estruturada dentro de um elemento complexo, o Associations (ABCD, 2008): 
Posição do elemento Associations na estrutura do esquema:

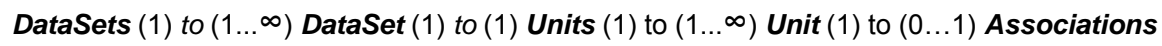

Partindo do pressuposto que uma instituição pode possuir muitas coleções, cada uma com seus respectivos indivíduos que, por sua vez, podem ter associações com indivíduos da mesma coleção, ou, até mesmo, de coleções de outras instituições, podemos interpretar a estrutura da seguinte maneira:

- Na estrutura, um Associations pode existir em uma Unit, que representa um indivíduo de uma coleção;

- A Unit, por sua vez, faz parte de um conjunto de Unit associado a um DataSet, que representa a coleção;

- Por fim, o esquema agrupa todos os DataSet em uma estrutura maior, que representa a instituição com todas as suas coleções;

O Associations associa o registro ABCD do indivíduo (Unit) a um ou muitos registros com o elemento UnitAssociation:

Posição do elemento UnitAssociation na estrutura do esquema:

Associations (1) to $(1 \ldots \infty)$ UnitAssociation

No UnitAssociation, os elementos suficientes para identificar globalmente um registro $A B C D$ de forma unívoca (que já existem no elemento Unit), também são usados para identificar os registros associados (em outras coleções). Esses elementos de identificação são acrescidos do prefixo "Associated": UnitSourcelnstitutionCode, UnitSourceName e UnitID; e agrupados com a descrição da associação (AssociationType). Um elemento opcional de comentário também é disponibilizado, o Comment, (Figura 17). 


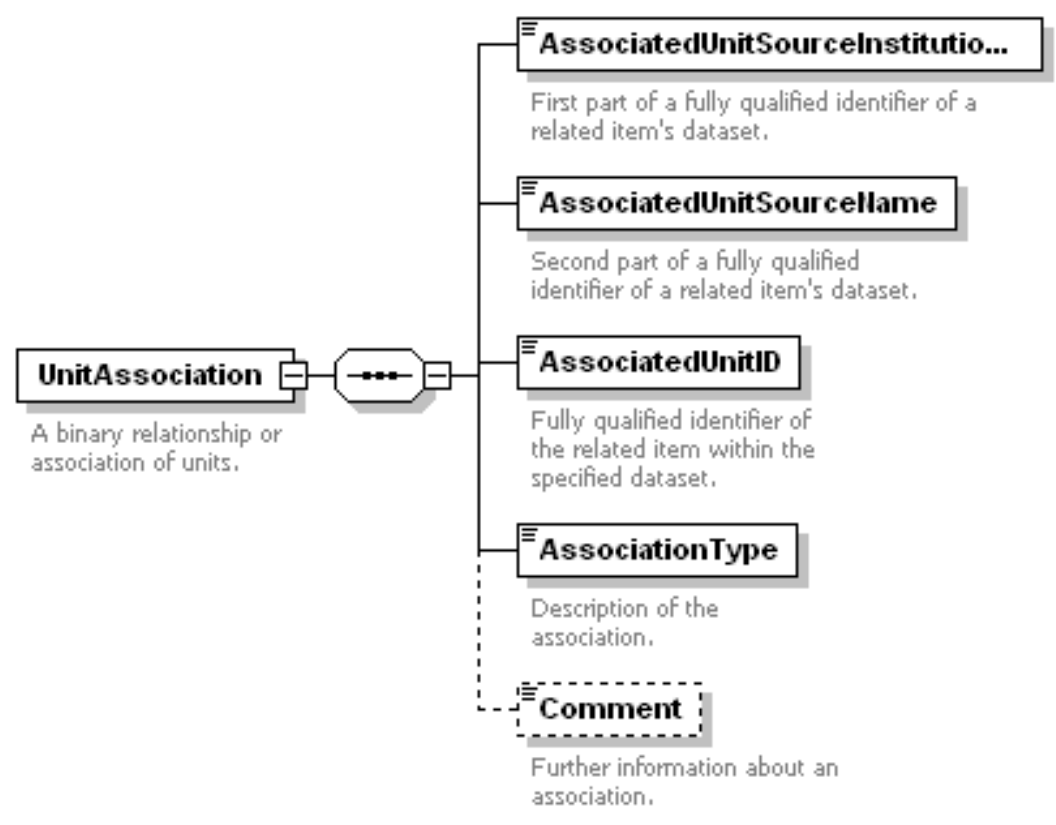

Figura 17 - Estrutura do elemento de interação do esquema $A B C D$ Fonte: (ABCD, 2008)

A descrição da interação limita-se a identificação do tipo, sendo assim, no caso dos indivíduos coletados, deve-se assumir que a interação aconteceu no mesmo momento da coleta.

- $\quad$ Plinian Core v2.0 (PliC) - Na versão 1.0 do PliC (setembro de 2005), o elemento Relationships, uma cadeia de caracteres, era responsável pelas observações obtidas em campo ou nas bibliografias sobre as interações entre espécies (item 4.3.2.1). Já a versão 2.0, lançada em Abril de 2007, utiliza uma forma estruturada de tratar os dados de relacionamento, e passou a adotar o termo "interação" para descrever o evento.

Os dados de interação são acomodados em um elemento complexo chamado Interaction, que pode ocorrer inúmeras vezes no esquema. Nele, são tratadas dados sobre o tipo da interação (InteractionType), o identificador Plinian Core da espécie (InteractionSpecies), um elemento único e opcional de comentários (InteractionComments) e um ou mais elementos opcionais de bibliografia (References): 


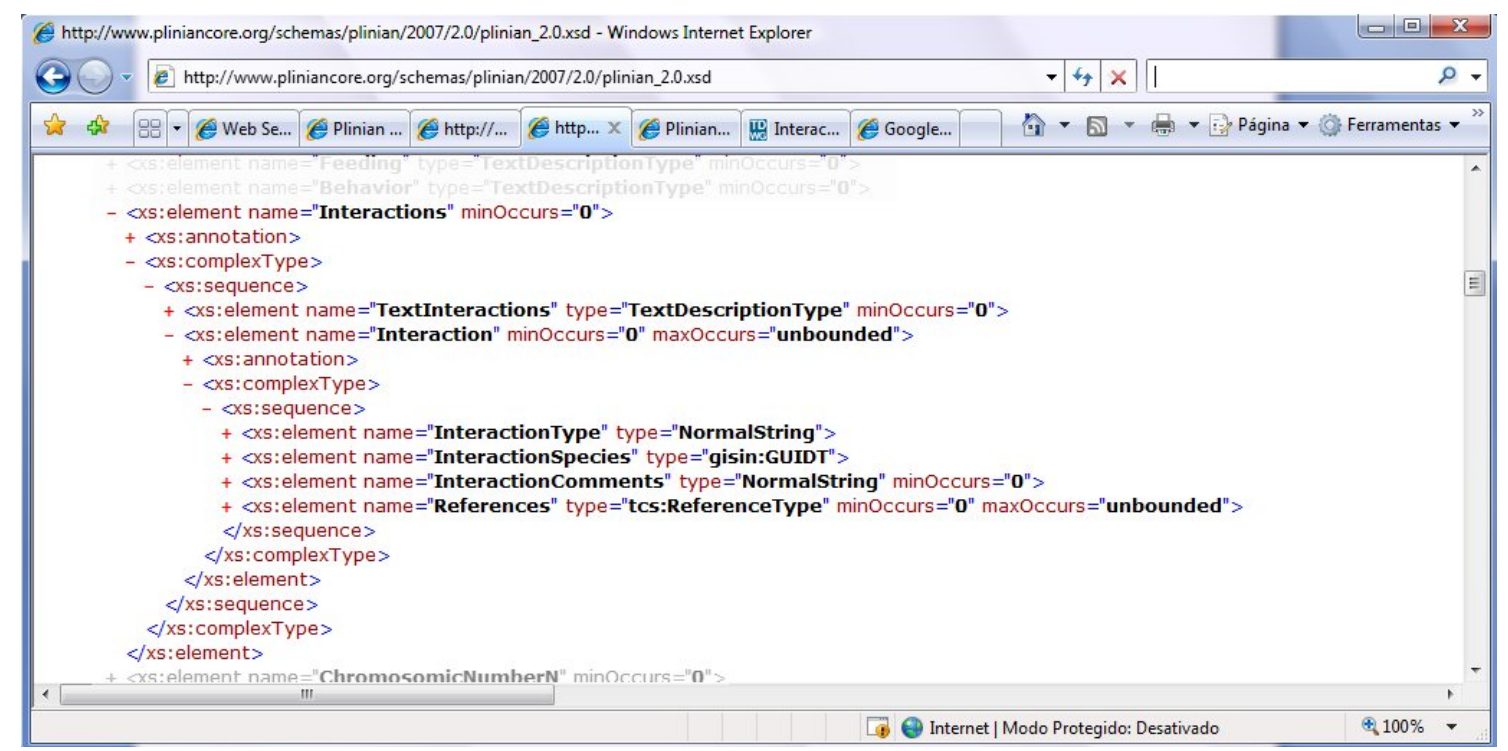

Figura 18 - Estrutura do elemento Interactions do esquema Plinian Core v2.0

Posição do elemento Interaction na estrutura do esquema:

DataSet (1) to (1...) TaxonRecord (1) to (0..1) NaturalHistory (1) to (0...1) Interactions (1) to $(0 \ldots \infty)$ Interaction

O Plinian Core trata a interação "generalizada", em que apenas espécies são envolvidas, sem descrição de espaço, tempo e observador para todos os dados (indivíduos e interação).

A avaliação dos esquemas conceituais disponíveis indicou que não existia uma solução disponível que fosse aderente a estrutura do modelo definido no item anterior. O esquema Darwin Core2 (versão 1.4, mais recente) não considera esses dados, nem mesmo em suas extensões. O ABCD considera a interação entre espécimes, não traz entre seus conceitos os dados de espaço, tempo e observador da interação, perde em performance pelo tamanho do esquema. Já o Plinian Core trata apenas das interações generalizadas. 


\subsection{Proposta da Arquitetura da SOWB}

O modelo de implementação de arquiteturas do OASIS, o SOA Reference Model, representado pela Figura 3 (item 2.3.2), foi utilizado para criar a arquitetura de referência da nova Webbee, a SOWB (Service-Oriented Webbee).

Os itens deste modelo foram definidos a partir das análises apresentadas no item 4.3, evidenciando:

- Os objetivos da Webbee (Capítulo 1);

- As ferramentas da Informática da Biodiversidade (Capítulo 2 e 3);

- A distância entre a versão atual e a evolução da Webbee (item 4.1);

- Os requisitos da nova versão da Webbee (item 4.2);

- Os requisitos da arquitetura de referência, considerando a especialização da Webbee na troca de dados de interação (item 4.3);

Como resultado, foi proposta uma arquitetura de referência (Figura 19) para guiar o desenvolvimento da nova Webbee, em que os principais itens do modelo OASIS foram definidos como:

- Motivação: Integrar a Webbee às redes de dados sobre biodiversidade como referência em digitalização, catalogação e publicação de dados de espécies e espécimes de abelhas nativas brasileiras, bem como de dados de interação abelha-planta.

- Metas: Realizar troca de dados com os sistemas de interesse da Webbee, principalmente o GBIF e a IABIN-PTN, e permitir a escalabilidade de aplicações. 
- Requisitos: Integração com redes de dados sobre biodiversidade, concentração de provedores locais, utilização de dados de espécimes e de interação entre espécimes, facilidade para integrar novas ferramentas ao sistema e segurança, qualidade e crédito dos dados. Estes itens foram discutidos nos itens 4.2 e 4.3 .

- Protocolos: TAPIR para a troca de dados com outros sistemas, Darwin Core2 e SPM para definir os dados de espécimes e espécies, respectivamente, a serem trocados, e o protocolos padrões dos Web services (SOAP, XML e HTTP) para a troca de dados (que não são de biodiversidade) na Internet.

- Padrões: Os serviços considerados padrões para os sistemas de informação sobre biodiversidade, apresentados no Capítulo 3, foram incorporados à arquitetura sob o nome de "qualidade dos dados" (limpeza, georreferenciamento e validação de nomes), "controle e permissão" (segurança e crédito dos dados) e "provedores de dados" (publicação de dados). 


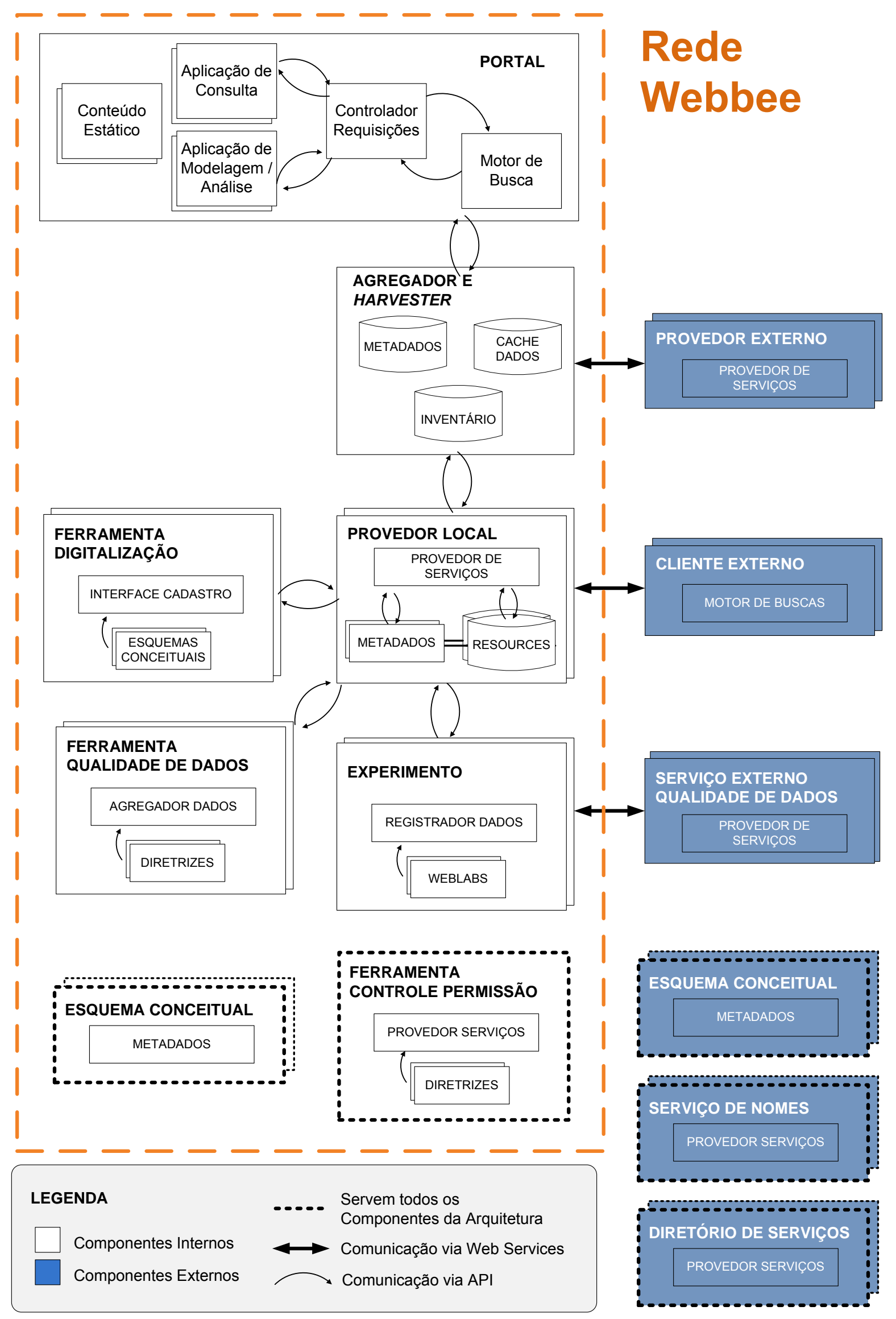

Figura 19 - Proposta de arquitetura de referência para o desenvolvimento da nova Webbee. 


\subsubsection{Portal}

O portal da SOWB é a interface do sistema com o usuário final. Por ele o usuário terá acesso a todos dados e metadados do sistema, independente do tipo, utilizando diversas aplicações de consulta, modelagem e análise. Cada aplicação pode referenciar um tipo específico de dado: ficha de espécies, catálogo de espécimes, mapas de ocorrências de espécies, modelagem de distribuição geográfica, etc. Mas a principal aplicação de consulta do Portal será a ferramenta de pesquisa geral, que fará uma busca em todos os tipos de dados e metadados armazenados no sistema, retornando um resultado consolidado.

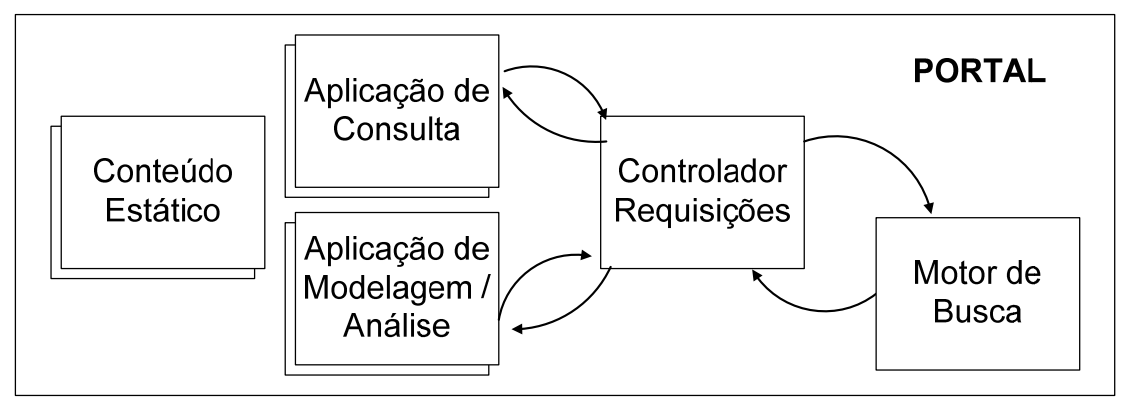

Figura 20 - Arquitetura do Portal da proposta para a SOWB.

Independente da aplicação, todas as consultas de dados e metadados serão processadas por um controlador de requisições, que oferecerá acesso personalizado a todos os tipos de dados e metadados: registros para fichas de espécies, pacotes de dados para modelagem, status e inventário dos provedores, etc.. O controlador será responsável pela composição e interpretação das mensagens trocadas pelo motor de buscas via Web Services.

\subsubsection{Agregador e Harvester}

O papel do Agregador na arquitetura é indexar todos os provedores do sistema - locais e externos - agregando os seus metadados e o inventário dos seus 
recursos (Figura 21). Essa tarefa é executada pelo acesso aos serviços dos provedores de dados.

Além disso, para os provedores que permitem o harvest dos seus dados, módulo faz uma cópia dos dados no banco de cache. Para os provedores locais, o harvest não é necessário.

Quando o motor de busca do Portal (Figura 20) requisita acesso aos dados do registro (e não apenas aos metadados ou inventário dos provedores) ele faz acesso direto aos provedores locais e externos (que permitem apenas as consultas distribuídas), ou então, à base de dados cache, no caso das consultas locais.

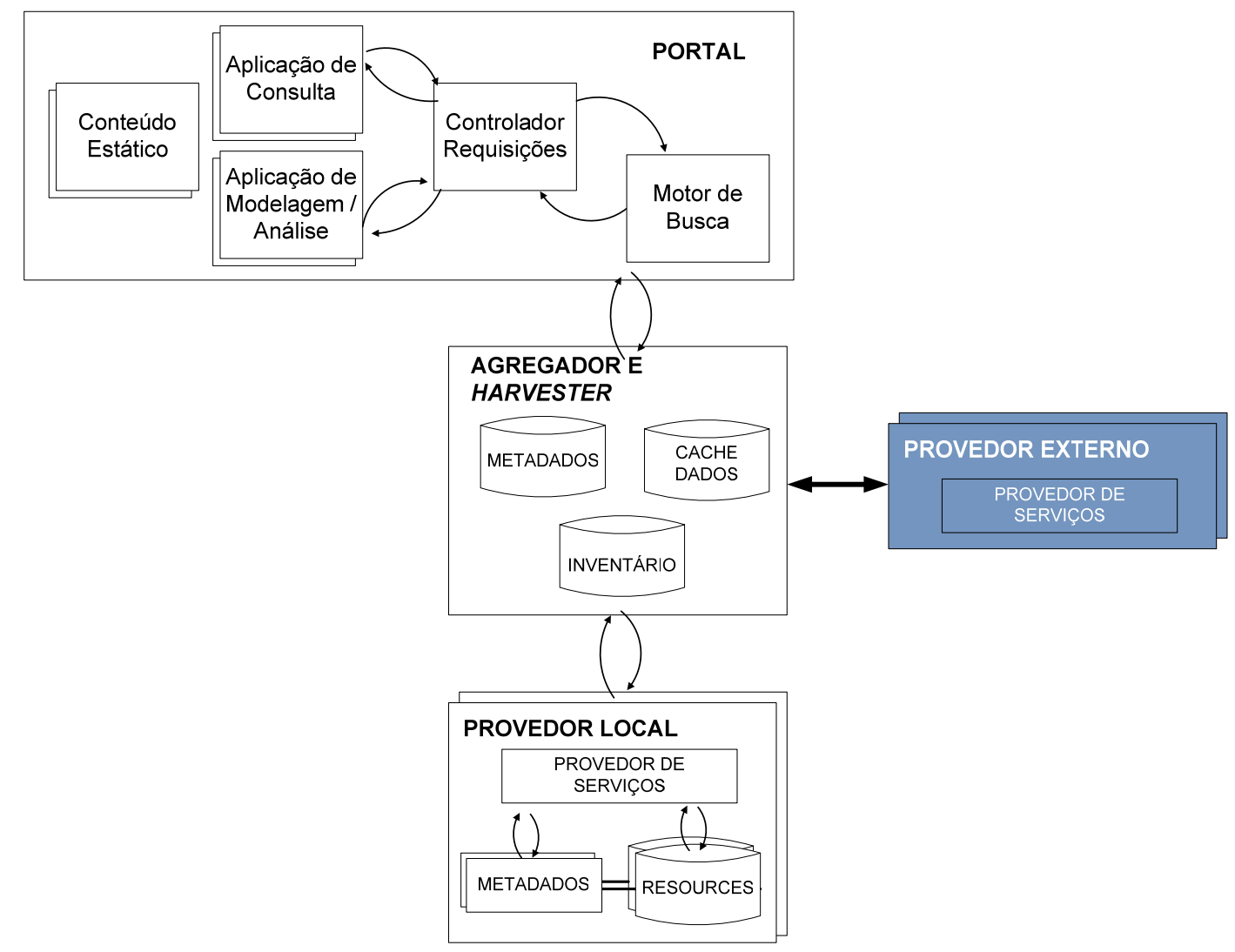

Figura 21 - Estrutura de operação do Agregador de dados da SOWB 


\subsubsection{Entrada e manipulação dos dados locais}

Os provedores de dados locais devem ser consultados de acordo com o tipo dos seus dados: espécies, espécimes, interações entre espécimes, dados experimentais, medidas ambientais, etc.

Estes dados poderão ser digitalizados por ferramentas específicas, ou então, armazenados diretamente no banco de dados pelos weblabs. Em ambos os casos, o tipo dos dados dependerá da aplicação de digitalização ou medição (no caso dos weblabs).

Uma vez salvos nos bancos de dados dos provedores locais, estes dados poderão ser agregados ou transformados por ferramentas de qualidade e limpeza de dados. Estas ferramentas, por sua vez, farão uso de serviços disponíveis na Internet para executar suas tarefas de georreferenciamento, validação de nomes científicos, limpeza de dados, etc.

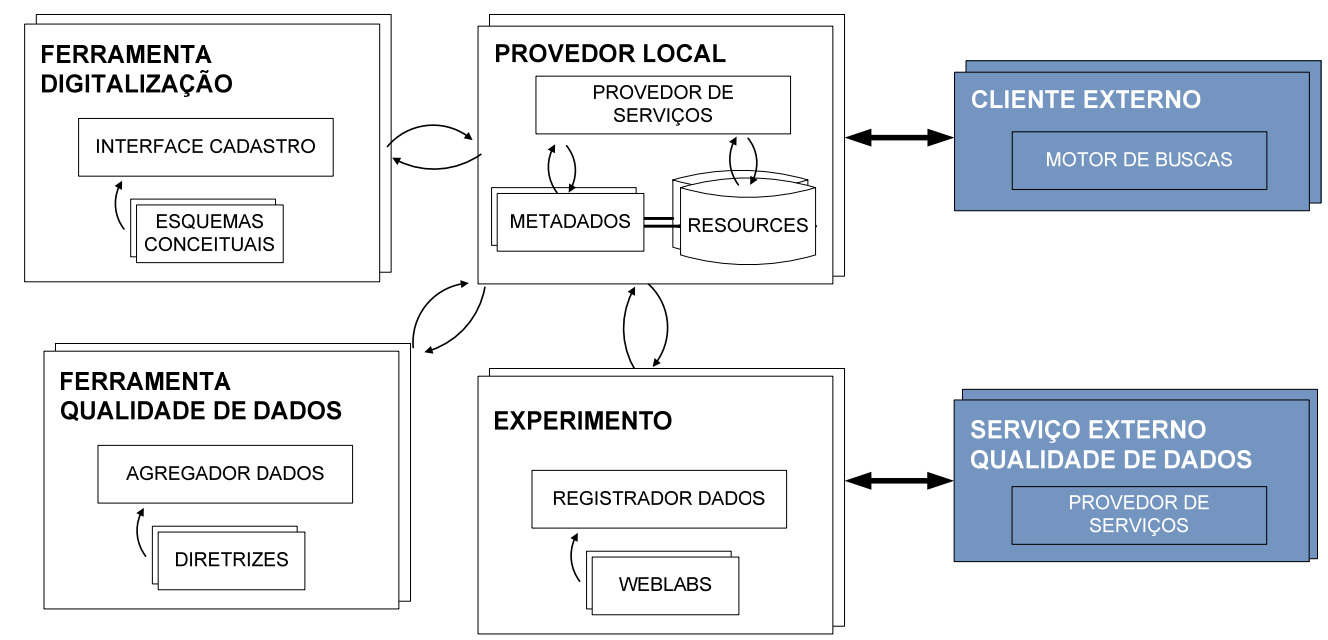

Figura 22 - Arquitetura de entrada e manipulação de dados na Webbee

Sistemas clientes também poderão acessar os dados dos provedores locais diretamente via Web Services, desde que utilizem os padrões destinados a determinado tipo de dado: espécimes, Darwin Core, espécies, SPM, etc. 


\subsubsection{Esquemas conceituais}

O componente de esquemas conceituais da arquitetura de referência (Figura 23) representa os esquemas que podem estruturar os dados da Webbee. Para os dados de espécimes é definido o Darwin Core 2 (v1.4) e para o dados de espécies, o SPM. Também é representado por este componente o esquema que irá estruturar os dados de interação entre espécimes, definido no item 4.3.2

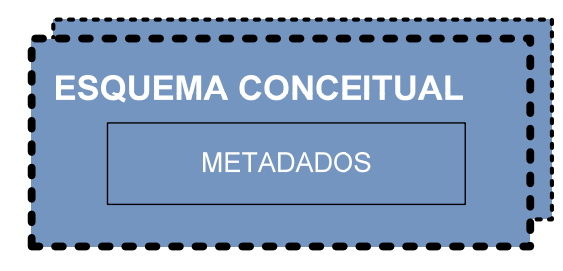

Figura 23 - Componente de esquemas conceituais da arquitetura de referência.

\subsection{Comentário final}

Quando da sua construção em 2001, a Webbee pretendia ser um sistema de informação stand-alone sobre a biodiversidade brasileira em abelhas nativas, no nível de espécies. No entanto, a importância dos dados primários, sobretudo de interação entre espécimes (base para a polinização), e a evolução da IB e das iniciativas da área, influenciaram na decisão para que a Webbee fosse reconstruída, para agregar mais ferramentas e concentrar os dados regionais, permitindo a integração com outros sistemas de outras redes de dados sobre biodiversidade.

A análise dos padrões para a troca de dados de interação (em geral) encaminhou uma discussão sobre a importância e a qualidade dos dados de interação, originando um modelo de interação específico para os espécimes e um novo padrão para troca desse tipo de dado.

A proposta de arquitetura apresentada segue o modelo de arquitetura e os padrões (do TDWG) adotados pelos principais sistemas da área que trocam dados 
sobre biodiversidade de espécies e de espécimes, em especial, o GBIF e a IABIN (itens 3.3.7 e 4.3.1).

Nesta arquitetura, um portal centraliza as consultas dos usuários finais, e as redistribui para os provedores locais e distribuídos, via TAPIR e Darwin Core2 ou SPM na Internet. Serviços de qualidade, segurança e validação dos nomes também foram agregados à arquitetura, considerando os principais serviços já disponíveis e citados no capítulo anterior.

No próximo capítulo são apresentadas implementações para as provas de conceito, que envolvem a criação de um esquema de interação entre espécimes, que é a principal especialização da Webbee em relação aos sistemas das redes de interesse, e uma ferramenta de digitalização de dados de espécimes e interação entre espécimes, para validar esse esquema. 


\section{CAPÍTULO 5 - IMPLEMENTAÇÕES PARA PROVAS DE CONCEITOS}

Após a definição da arquitetura da SOWB foram realizadas provas de conceitos com intuito de avaliar a maturidade dos padrões e ferramentas adotados: comportamento em operação, suporte, restrições técnicas, etc., e validar as premissas adotadas na análise de requisitos.

A implementação das provas de conceito envolveu a criação do esquema conceitual de dados de interação entre espécimes, definido no item 4.3.2. Esta implementação foi base para a criação da primeira aplicação da SOWB envolvendo os dados de espécimes e de interação entre espécimes, a Pollinator Data Digitizer PDD.

$\mathrm{Na}$ arquitetura de referência da Figura 19, o esquema de interação é representado pelo componente "esquema de interação" e é utilizado por outros componentes que precisam estruturar os dados: ferramenta de digitalização, provedores de dados, portal, etc.

A PDD é composta por um banco de dados, uma ferramenta para a digitalização de dados e um provedor, que por sua vez, foram utilizadas para avaliar o comportamento do esquema Darwin Core2, do protocolo TAPIR e do provedor Tapirlink na comunicação com outro sistema, o Portal da rede IABIN-PTN.

\subsection{Esquema Conceitual de Dados de Interação entre Espécimes - Interaction Extension}

A avaliação dos esquemas conceituais apresentada no item 4.3.2.3 descartou a utilização dos esquemas Darwin Core2, ABCD e Plinian Core para a padronização dos dados de interação entre espécimes. No entanto, a vantagem em utilizar um padrão comum às principais redes de dados primários sobre biodiversidade (inclusive as de interesse da Webbee) e as experiências bem-sucedidas hospedadas pelo TDWG, tais como a Geospatial Extension e a Curatorial Extension 
(item 3.4.2.1), determinaram uma solução com a extensão do esquema Darwin Core2 (versão 1.4).

Em um processo iterativo de desenvolvimento, foram definidas três versões para o esquema conceitual de interação entre espécimes. Este processo iterativo partiu das especificações do negócio levantadas e das diretrizes técnicas para criação de extensões do DwC, para definir e publicar a primeira versão do esquema no TDWG para validação da comunidade científica. Paralelamente, o esquema foi implementado e testado operacionalmente na Pollinator Data Digitizer - PDD (item 5.2).

As críticas feitas na ferramenta de colaboração do portal do TDWG e os resultados das provas de conceito na PDD foram analisados e realimentaram o processo com novas especificações em três rodadas.

\subsubsection{Primeira Versão}

A primeira versão do esquema conceitual de dados de interação de espécimes foi publicada no TDWG em 16 de Maio de 2007. Ela foi desenvolvida em um trabalho conjunto com o Eng. Renato De Giovanni, do Centro de Referência em Informações Ambientais - CRIA, e a bióloga Tereza Giannini, do Laboratório de Abelhas do Instituto de Biociências da Universidade de São Paulo. Esta versão foca os dados específicos de polinização, e adota uma estratégia modular com três extensões do esquema Darwin Core2 (versão 1.4): Interaction Extension, Pollination Extension e Environmental Measurements Extension (INBI, 2007; TDWG, 2007).

Esta estratégia assume que os dados da Interaction Extension podem se referir a interação entre qualquer espécime, e não apenas a interação plantapolinizador. No entanto, quando uma determinada interação estiver no contexto da polinização, a Pollination Extension pode ser usada para tratar os dados mais específicos. Da mesma forma, quando a interação vier acompanhada de medidas ambientais, a Environment Measurements Extension pode ser usada para tratar estes dados. 


\subsubsection{Interacion Extension}

A Interaction Extension (Extensão de Interação) trata os dados de interação entre espécimes de forma generalizada. Ela define apenas um novo elemento, o RelationshipType (Tipo do Relacionamento), e utiliza os 45 elementos que compõe o DwC2 para identificar o segundo espécime (Figura 24).

Interaction Extension Concept List

\begin{tabular}{|c|c|}
\hline \multirow[t]{2}{*}{ Element } & Description \\
\hline & Interaction Elements \\
\hline \multirow[t]{5}{*}{ RelationshipType? } & $\begin{array}{l}\text { A descriptive term indicating the type of relationship between an organism represented with DarwinCore? and the } \\
\text { related organism represented with this extension. Examples: } \\
\text { VisitedFlowerOf - FlowerVisitedBy?, PreyedUpon? - PreyedUponBy?, DispersedSeedOf? - } \\
\text { SeedWasDispersedBy?, HostOf? - ParasiteOf?, ExtractedResinFrom? - ResinExtractedBy?, NestedIn? - } \\
\text { UsedAsNestBy?, PathogenOf? - InfectedBy? }\end{array}$ \\
\hline & Record-level Elements \\
\hline & Taxonomic Elements \\
\hline & Identification Elements \\
\hline & Biological Elements \\
\hline
\end{tabular}

Figura 24 - Esquema conceitual de interação publicado no TDWG - Interaction Extension Adaptado de TDWG (2007)

\subsubsection{Pollination Extension}

A Pollination Extension (Extensão de Polinização) define cinco novos elementos que evidenciam ações que podem ocorrer durante o processo de polinização: Pollination Evidence (Evidência de Polinização), PollenRemoval (Remoção de Pólen), NectarRemoval (Remoção de Néctar), OilRemoval (Remoção de Óleo) e FlowerPredation (Predação da Flor). Todos os elementos são do tipo probabilityType, que indicam a probabilidade de tal ação ter realmente acontecido. 


\begin{tabular}{|c|c|c|}
\hline Element & Description & Type \\
\hline PollinationEvidence? & $\begin{array}{l}\text { Indicates if pollination occurred. Use " } 1 \text { " if the event happened, " } 0 \text { " if the event did not happen and " } 0.5 \text { " to } \\
\text { indicate uncertainty. NULL should be used if there was no attempt to obtain this information. }\end{array}$ & probabilityType \\
\hline PollenRemoval? & $\begin{array}{l}\text { Indicates if pollen was removed. Use " } 1 \text { " if the event happened, " } 0 \text { " if the event did not happen and " } 0.5 \text { " to } \\
\text { indicate uncertainty. NULL should be used if there was no attempt to obtain this information. }\end{array}$ & probabilityType \\
\hline NectarRemoval? & $\begin{array}{l}\text { Indicates if nectar was removed. Use " } 1 \text { " if the event happened, " } 0 \text { " if the event did not happen and " } 0.5 \text { " to } \\
\text { indicate uncertainty. NULL should be used if there was no attempt to obtain this information. }\end{array}$ & probabilityType \\
\hline OilRemoval? & $\begin{array}{l}\text { Indicates if oil was removed. Use " } 1 \text { " if the event happened, " } 0 \text { " if the event did not happen and " } 0.5 \text { " to } \\
\text { indicate uncertainty. NULL should be used if there was no attempt to obtain this information. }\end{array}$ & probabilityType \\
\hline FlowerPredation? & $\begin{array}{l}\text { Indicates if at least part of the flower was consumed. Use " } 1 \text { " if the event happened, " } 0 \text { " if the event did not } \\
\text { happen and " } 0.5 \text { " to indicate uncertainty. NULL should be used if there was no attempt to obtain this } \\
\text { information. }\end{array}$ & probabilityType \\
\hline
\end{tabular}

Figura 25 - Esquema conceitual de especialização em polinização publicado no TDWG - Pollination Extension

Extraído de TDWG, 2007

\subsubsection{Environment Measurements Extension}

A Environment Measurements Extension (Extensão de Medidas Ambientais) propõe 4 novos elementos para armazenar as medidas ambientais associadas à interação: Temperature (Temperatura) em graus Celsius, RelativeHumidity (Umidade Relativa), Luminosity (Luminosidade) em Lux e WindSpeed (Velocidade do Vento) em metros por segundo.

\begin{tabular}{|c|c|c|}
\hline Element & Description & Type \\
\hline Temperature? & Air temperature in Celsius degrees. & double \\
\hline RelativeHumidity? & Relative humidity. & double \\
\hline Luminosity? & Luminosity in Lux. & double \\
\hline WindSpeed? & Wind speed in meters per second. & double \\
\hline
\end{tabular}

Figura 26 - Esquema conceitual de especialização em medidas ambientais publicado no TDWG Environment Measurements Extension

Extraído de TDWG, 2007 


\subsubsection{Considerações sobre a primeira versão}

As considerações sobre a primeira versão feitas pela comunidade científica na ferramenta de colaboração do TDWG e pelos parceiros do Laboratório de Abelhas pontuaram:

- Interação entre Espécimes: O termo "relacionamento" entre espécimes não identifica, necessariamente, um contato direto. Um relacionamento pode ser indireto, e não exigir o contato, ou então, pode descrever algo generalizado, já o termo "interação" descreve uma "ação recíproca de dois ou mais corpos uns nos outros" (MICHAELLIS, 2009).

- Padronização dos tipos de interação: Os termos que descrevem o tipo da interação entre os espécimes são importantes para a análise qualitativa dos dados. A padronização pode evitar os problemas associados à utilização de idiomas regionais e de sinônimos para o mesmo tipo de evento. Foi recomendada a utilização de um vocabulário controlado para designar os tipos de interação entre espécimes.

- Direção da Interação: $\mathrm{Na}$ versão 1, a direção da interação está embutida no tipo da interação: FlowerVisitedBy (Flor Visitada Por) e VisitedFlowerOf (Flor Visitada De). Uma solução alternativa foi discutida e envolvia a utilização de um campo de direção da interação. No entanto, esta solução foi descartada devido à adição de um campo a mais no esquema, e porque ele não resolvia completamente a ambigüidade na leitura, pois dependia do termo usado como tipo de interação. Como os termos para designar os tipos de interação seriam padronizados, optou-se por manter a direção embutida no tipo de interação. 
- Sobrecarga de Elementos: A utilização de um esquema Darwin Core2 completo para identificar o espécime na Interaction Extension foi criticada por tirar uma das principais características do DwC, a simplicidade do esquema. A cada interação, podem ser repetidos os 45 elementos do DwC. Como solução, foi proposta a utilização apenas no Global Unique Identifier - GUI (Identificador Global Único) do espécime relacionado. No entanto, esta solução requer que uma nova consulta seja feita para colher os demais elementos de cada espécime (a partir do GUI).

- Multiplicidade de Interações: O registro de interações na PDD indicou que um mesmo espécime pode ter mais de uma interação com um mesmo espécime. Por exemplo: uma mesma abelha pode visitar uma jabuticabeira e também, pode recolher néctar dela, neste caso, são dois registros de interação para o registro da jabuticabeira, ou então, uma mesma jabuticabeira é visitada por $\mathrm{N}$ abelhas, que resulta em $\mathrm{N}$ registros de interação para o registro DwC da jabuticabeira (Figura 27). Essa multiplicidade incorre na repetição de muitos elementos entre os espécimes envolvidos, o que prejudica a sua atualização e a performance dos sistemas. Por isso, uma nova estrutura do esquema de interação foi criada, tratando os dados de interação de forma independente do registro dos espécimes.

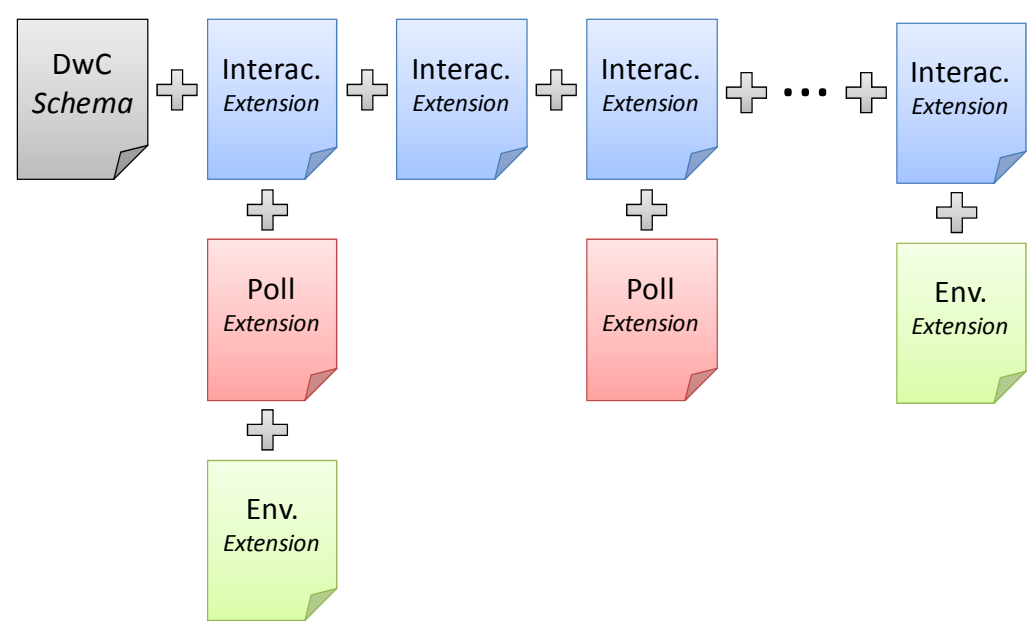

Figura 27 - Agregação dos esquemas de interação em um registro Darwin Core 


\subsubsection{Segunda Versão}

A segunda versão do esquema considera a multiplicidade de interações, e por isso, troca apenas o registro da interação entre espécimes. Esta solução está de acordo com o padrão DwC, pois, assim como o Simple Darwin Core, ele é uma especificação para uma maneira particular de utilizar os seus termos. As interações auxiliares (Pollination Extension e Environment Measurements Extensions) permanecem inalteradas e podem ser incorporadas a nova versão do esquema, quando conveniente. A versão 2 do esquema foi implementada, e está sendo utilizada na versão atual da PDD (item 5.2.2), mas ela não chegou a ser publicada.

\subsubsection{Interaction Extension}

Para a segunda versão, foi definido um vocabulário controlado de termos, usados para definir os tipos das interações, que por sua vez, não são mais chamadas de "relacionamentos". Estes termos preenchem o elemento Interaction do segundo esquema de interação (Quadro 10). Nele, os espécimes passam a ser identificados apenas pelos seus respectivos Identificadores Globais Únicos (Global Unique Identifier - GUI): GlobalUniqueldentifier1 e GlobalUniqueldentifier2. Ao invés de criar estes dois novos termos, estes identificadores não poderiam ser apenas substituídos pelo termo GlobalUniqueldentifier, pois haveria uma duplicidade de termos.

\begin{tabular}{lcc}
\hline \multicolumn{2}{c}{ Interaction Extension v2 } \\
\hline \\
InteractionGlobalUniqueldentifier & Texto & Obrigatório \\
\hline DateLastModified & DataHora & Obrigatório \\
\hline GlobalUniqueldentifier1 & Texto & Obrigatório \\
\hline Interaction & Texto & Obrigatório \\
\hline GlobalUniqueldentifier2 & Texto & Obrigatório \\
\hline RelatedInformation & Texto & Não Obrigatório \\
\hline
\end{tabular}

Quadro 10 - Elementos da segunda versão do esquema conceitual de interação entre espécimes 
O registro DwC de interação, assim como o registro DwC de espécime, precisa ser univocamente identificado. Sem esta identificação, não é possível indexar os dados de um provedor de dados em um processo de harvest. O elemento Interaction Global Unique Identifier, foi criado para este fim, e tem função semelhante ao GUI, no entanto, ele é uma concatenação dos GUI dos espécimes relacionados e o tipo da interação:

\section{GlobalUniqueldentifier1+ Interaction+ GlobalUniqueldentifier2}

Outros dois termos do vocabulário original do Darwin Core foram importados: o DataLastModified e o RelatedInformation. O primeiro indica a data e a hora em que um ou mais dados do registro foram modificados em relação a uma versão prévia. Já o segundo, permite armazenar referências, tais como publicações, referências bibliográficas, URLs e etc.

\subsubsection{Considerações sobre a segunda versão}

- Interpretação dos dados de campo: O conceito de interação atômica foi definido durante a avaliação da segunda versão do esquema conceitual de interação na PDD. Os dados de interação disponibilizados para cadastro pelos pesquisadores, em sua grande maioria, consideravam a interação entre espécimes (preservados ou observados) e espécies. Este erro de interpretação era fruto da preocupação do pesquisador em identificar apenas a "taxonomia" (espécie) que se relacionava com determinado espécime. Ele não considerava que esta "taxonomia" era, na verdade, um indivíduo (identificado por uma taxonomia, um espaço e um tempo), ou seja, um espécime, no caso, observado. A partir desta definição, os registros disponibilizados de interações entre espécimes (preservados ou observados) e "espécies", passaram a ser considerados como interações entre espécimes (preservados ou observados) e espécimes 
observados, e uma segunda versão da PDD (atual, item 5.2.2), foi adaptada para encaminhar este tipo de interpretação por parte do usuário.

\subsubsection{Terceira Versão}

A última versão do esquema de interação utiliza o conceito de interação atômica apresentada no Quadro 2 (item 4.3.2.1) e do modelo de interação da Figura 16 (item 4.3.2.2). No esquema, a interação, assim como acontece com os espécimes, deve ser identificada, localizada no tempo e no espaço, e ter o seu observador definido (Quadro 11). Em alguns casos, descritos no item 4.3.2.2, os espécimes e a interação podem compartilhar dados (espaço, tempo e observador) que, por isso, não são obrigatórios.

\begin{tabular}{|c|c|c|}
\hline \multicolumn{3}{|c|}{ Interaction Extension v3 } \\
\hline InteractionGlobalUniqueldentifier & Texto & Obrigatório \\
\hline DateLastModified & DataHora & Obrigatório \\
\hline GlobalUniqueldentifier1 & Texto & Obrigatório \\
\hline InteractionType & Texto & Obrigatório \\
\hline GlobalUniqueldentifier2 & Texto & Obrigatório \\
\hline RelatedInformation & Texto & Não Obrigatório \\
\hline LocalityElements & & Não Obrigatório \\
\hline CollectingElements & & Não Obrigatório \\
\hline
\end{tabular}

Quadro 11 - Elementos da terceira versão do esquema conceitual de interação entre espécimes.

Os termos dos elementos de Locality (localidade) e Collecting (Coleta, mas que no DwC pode ser interpretada como Observação) foram utilizados do vocabulário padrão do DwC. Estes termos são os mesmo do esquema Simple Darwin Core (TDWG, 2007). 
Esta proposta de esquema ainda está em fase de conclusão, para que depois possa ser implementada e testada na PDD. As mudanças em relação à segunda versão são menores do que as realizadas da primeira para a segunda versão. Isto porque não há uma mudança estrutural, apenas um acréscimo de campos para adequação ao modelo de interação definido.

\subsection{Pollinator Data Digitizer - PDD}

A Pollinator Data Digitizer (PDD) é uma aplicação Internet da SOWB criada como prova do Interaction Extension, apresentado no item anterior. Como prova de conceito, o desenvolvimento desta aplicação pretende:

1. Testar os padrões Darwin Core2 e TAPIR em operação;

2. Contar com a participação direta do usuário para avaliar os termos do Interaction Extension;

3. Permitir o harvest dos dados de interação utilizando o Interaction Extension;

\subsubsection{Implementação relacional do Simple Darwin Core e das extensões Interaction e Geospatial}

Para implementação do banco de dados da PDD, foram utilizados como ponto de partida os esquemas Simple Darwin Core, Interaction Exension e Geospatial Extension. Como não existe uma estrutura agregadora (item 3.4.2.1) entre os elementos do Simple Darwin Core e suas extensões - todos estão no mesmo nível hierárquico - um esquema relacional foi criado (Figura 28). 
Neste esquema relacional, todos os elementos dos esquemas (Kingdom, InstitutionCode, Collector, etc.) foram considerados atributos de uma das entidades representadas no esquema por retângulos. Vale ressaltar que estas entidades não existem nos esquemas originais (não existe um elemento Locality Elements, nos esquemas). Os nomes em inglês foram mantidos para facilitar o mapeamento com os esquemas conceituais. A entidade Record-Level Elements (elementos do registro) foi utilizada como entidade raiz, já que todas as outras são complementares ao registro do espécime.

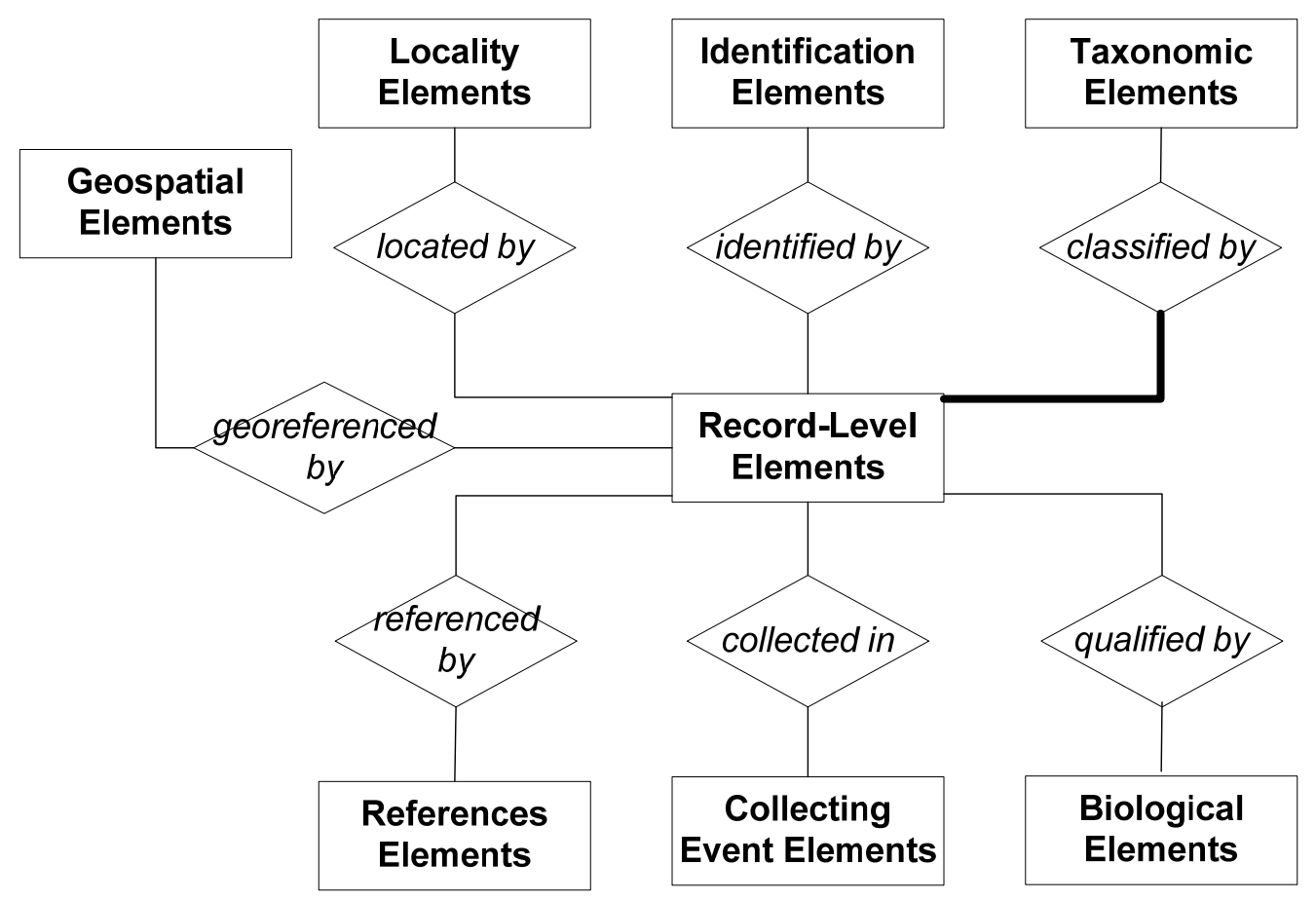

Figura 28 - Diagrama de Entidade-Relacionamento (sem atributos) do núcleo 
A Figura 29 apresenta a implementação da abordagem relacional da entidade Taxonomic Elements.

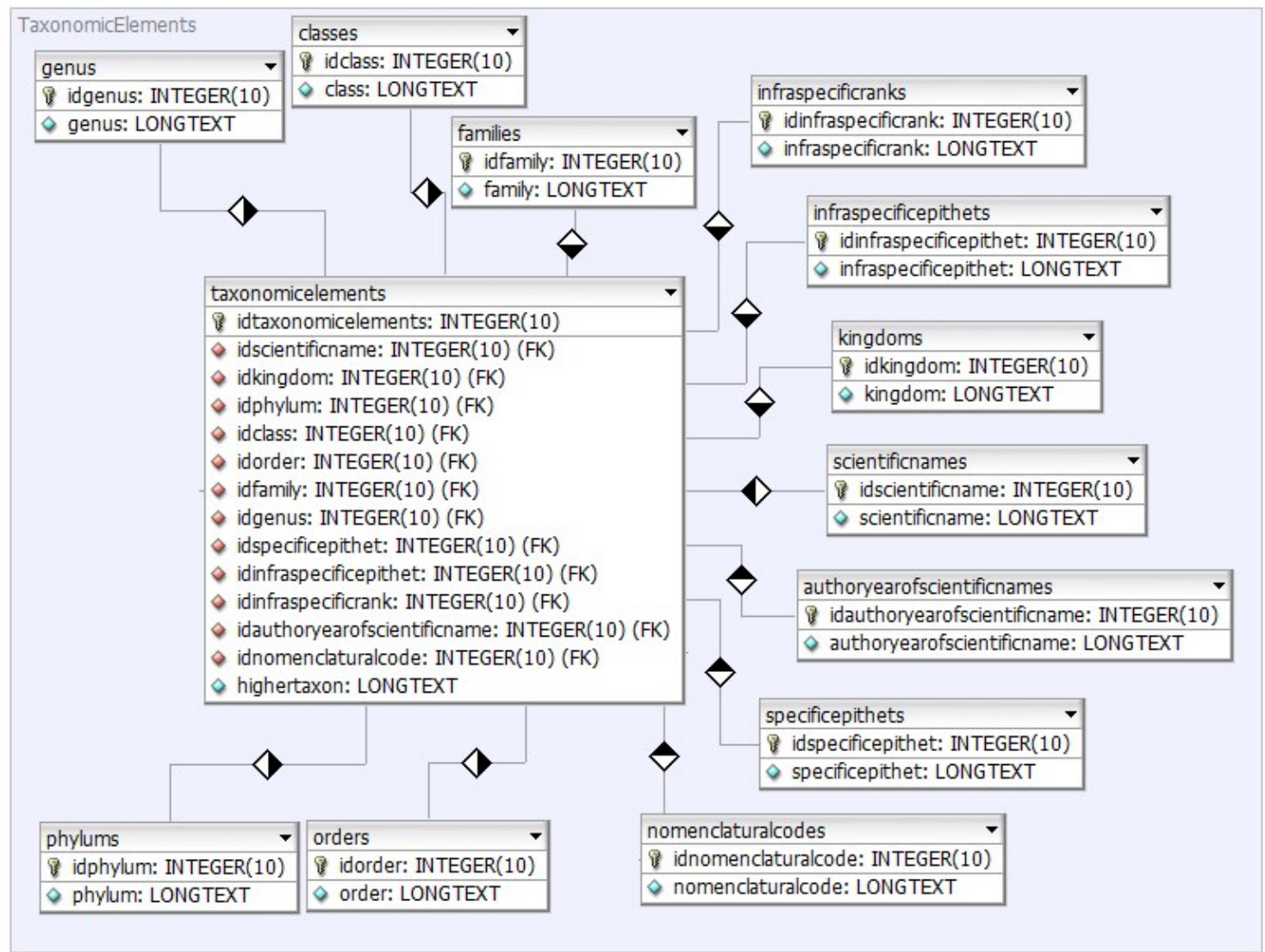

Figura 29 - Implementação relacional da entidade Taxonomic Elements do Darwin Core2

\subsubsection{Arquitetura de software}

A estrutura da PDD é baseada em um conjunto de páginas Hypertext Preprocessor - PHP, (PHP, 2007), que utilizam arquivos de configuração escritos em XML para compor formulários HTML e consultas em Structured Query Language - SQL. Estes arquivos XML refletem a implementação relacional do esquema Simples Darwin Core e suas extensões Geospatial e Interaction (5.2.1), que também dá origem ao banco de dados MySQL (MySQL, 2007) da PDD. 
A Figura 30 ilustra o tratamento de um dos campos oriundo da implementação relacional, o campo idkingdom da tabela taxonomicElements (elementos taxonômicos):

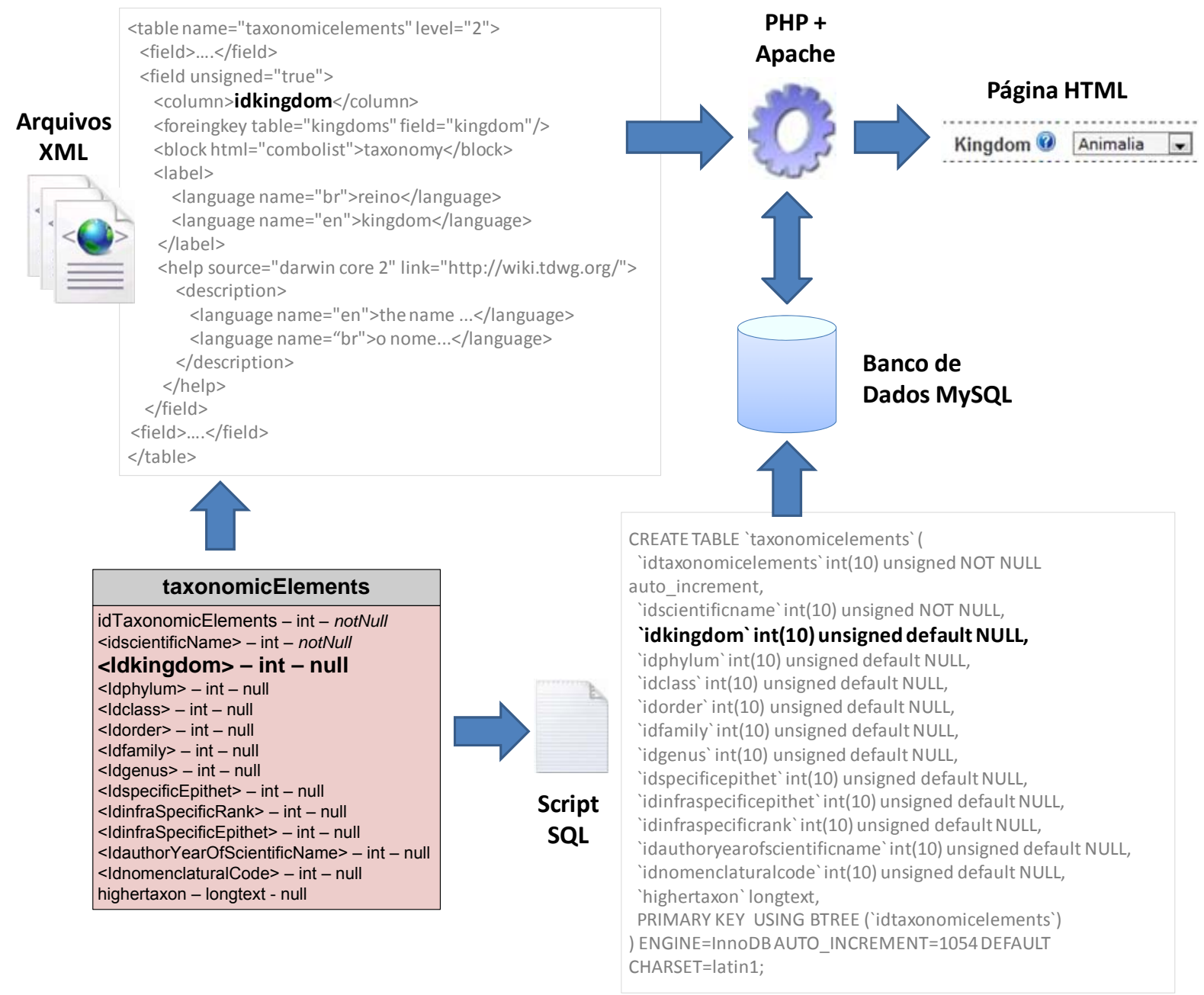

Figura 30 - Esquema da arquitetura de software da PDD

- A partir da implementação relacional do esquema Simple Darwin Core e suas extensões, um script SQL é escrito para criar o campo em um banco de dados SQL; 
- Esta mesma definição também cria o campo em um arquivo de configuração XML, que reflete o banco de dados, e associa diversos metadados ao campo: rótulos em diferentes línguas, texto de descrição, o tipo de elemento no formulário (caixa de seleção, caixa de texto, etc.), se ele pode ser nulo, etc.;

- Quando o usuário acessa a PDD, o PHP lê os arquivos de configuração XML e monta a página com os formulários.

- Ao executar uma ação (cadastro, consulta, etc.), o PHP também utiliza os arquivos de configuração XML para montar as consultas SQL e enviar ao banco de dados, para depois receber o resultado e compor novamente o formulário com dados.

Esta estrutura flexível, que permite a configuração dos campos da PDD por arquivos XML, foi implementada para facilitar a prova de conceito, por agilizar a modificação dos campos de entrada.

\subsubsection{Provedor de dados de Espécimes e de Interação entre Espécimes}

A solução para o provedor de dados de espécimes e de interação da PDD deveria testar a utilização do protocolo TAPIR para se comunicar com as redes de dados primários de interesse, em especial, com a IABIN-PTN. Ela também deveria avaliar o comportamento do novo esquema conceitual de dados de interação entre espécimes em operação na troca de dados.

Uma lista de softwares servidores baseados no protocolo TAPIR está disponível no portal do TDWG, entre eles estão o PyWrapper (escrito em Python), o TapirLink (PHP) e o TapirDotNET (Microsoft .Net C\#). A linguagem de programação no qual ele é escrito, que é a mesma da PDD, e o fato dos desenvolvedores serem os mesmos que mantém o protocolo TAPIR, influenciaram na escolha do TapirLink para a PDD. 
O TapirLink integra as redes de dados sobre biodiversidade oferecendo um serviços de publicação de dados aos sistemas. A interação com este serviço segue as mensagens do protocolo TAPIR (item 3.4.1): ping, metadata, capabilities, inventory e search. Metadados são utilizados para identificar o provedor e os seus resources (recursos). Internamente, o software faz acesso direto aos resources, que podem ser bancos de dados, arquivos, planilhas, etc., orientado pelos seus metadados (Figura 31).

O provedor oferece ao usuário final uma área administrativa amigável para o cadastro dos metadados do provedor e dos resources. Nela é possível fazer o mapeamento dos campos nos esquemas conceituais. Na Figura 32, a lista de conceitos do Darwin Core da v1.4 (concept), é mapeada (mapping) em uma tabela do banco de dados (view_dwc_1_4) e seus campos.

Também é possível carregar esquemas adicionais (como o de interação entre espécimes, por exemplo) com novos conceitos.

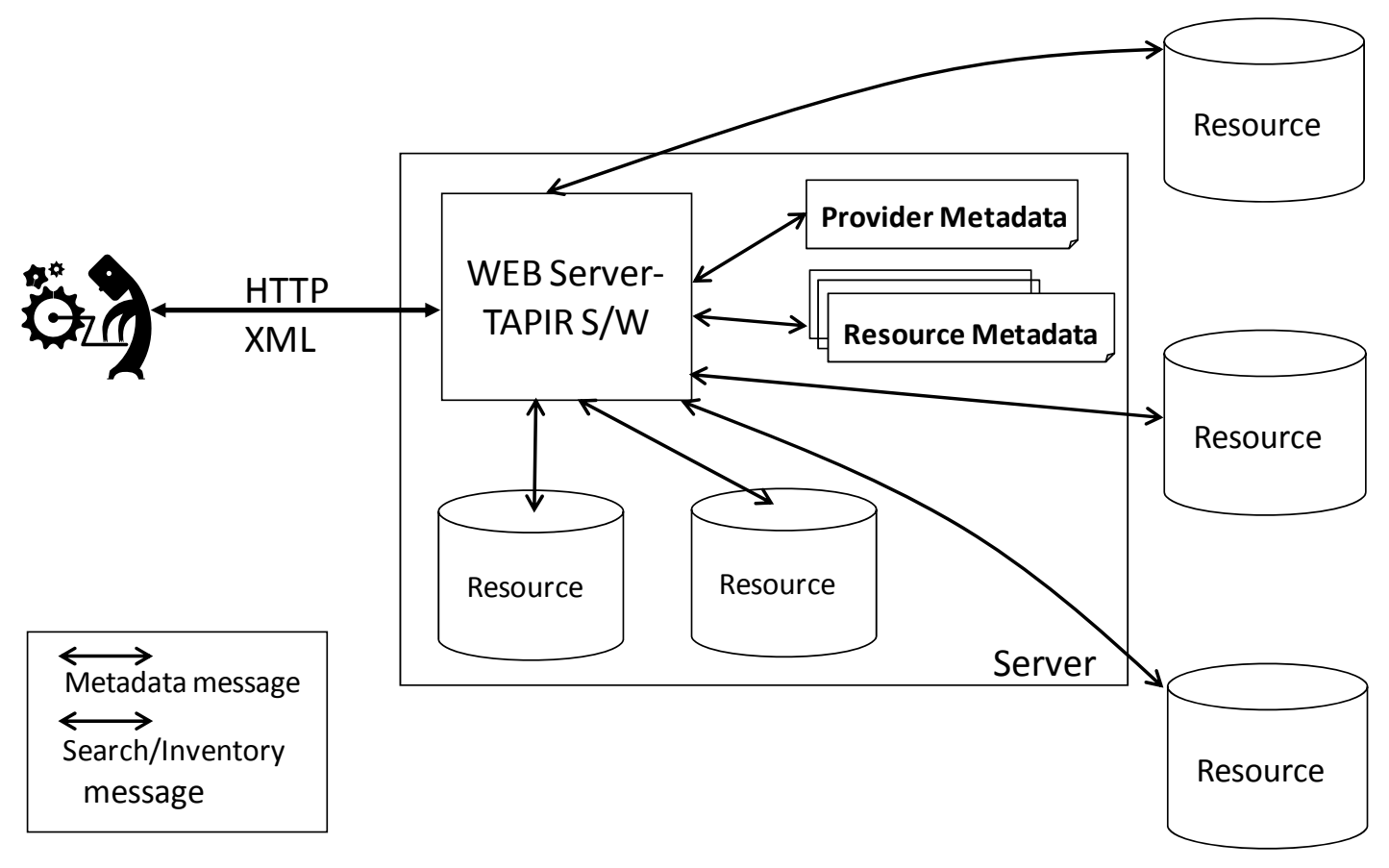

Figura 31 - Arquitetura de software do provedor TapirLink

Fonte: (TDWG, 2007) 


\begin{tabular}{|c|c|c|c|c|c|c|c|c|c|}
\hline concept & searchable & & & & & & ping & & \\
\hline$\left.{ }^{*}\right)$ GlobalUniqueldentifier & $\sqrt{v}$ & single column & - & view_dwc_1_4 [ & $\nabla$ & globalUniqueldentifier & - & text & $\rightarrow$ \\
\hline${ }^{(*)}$ DateLastModified & $\sqrt{\square}$ & single column & $\nabla$ & view_dwc_1_4 & 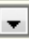 & dateLastModified & - & datetime & - \\
\hline$\left(^{*}\right)$ BasisOfRecord & $\sqrt{v}$ & single column & - & view_dwc_1_4 & 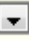 & basisOfRecord & - & text & $\rightarrow$ \\
\hline${ }^{*}$ InstitutionCode & $\sqrt{\nabla}$ & single column & - & view_dwc_1_4 & $\nabla$ & institution Code & - & text & $\rightarrow$ \\
\hline$\left.{ }^{*}\right)$ CollectionCode & $\sqrt{v}$ & single column & - & view_dwc_1_4 & - & collectionCode & - & text & $\rightarrow$ \\
\hline (*) CatalogNumber & $\sqrt{\nabla}$ & single column & - & view_dwc_1_4 & $\nabla$ & catalogNumber & - & text & $\rightarrow$ \\
\hline InformationWithheld & $\nabla$ & single column & - & view_dwc_1_4 & $\nabla$ & informationwithHeld & - & text & $\rightarrow$ \\
\hline$\underline{\text { Remarks }}$ & $\sqrt{\square}$ & single column & - & view_dwc_1_4 & 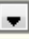 & remarks & - & text & $\rightarrow$ \\
\hline (*) ScientificName & $\nabla$ & single column & - & view_dwc_1_4 & $\nabla$ & scientificName & - & \begin{tabular}{|l|} 
numeric \\
\end{tabular} & - \\
\hline HiqherTaxon & $\sqrt{\square}$ & single column & - & view_dwc_1_4 & - & higherTaxon & - & text & $\rightarrow$ \\
\hline Kinqdom & $\sqrt{\square}$ & single column & - & view_dwc_1_4 & $\nabla$ & \begin{tabular}{|l} 
kingdom \\
\end{tabular} & - & text & $\rightarrow$ \\
\hline
\end{tabular}

Figura 32 - Exemplo de mapeamento de campos no Tapilink

\subsubsection{Primeira Versão da PDD}

A primeira versão da PDD foi implementada com a primeira versão da Interaction Extension (item 5.1.1) e as extensões Pollination Extension e Environment Measurements Extension. Assim como era proposto na primeira versão do esquema de interação, de uma só vez era possível registrar os 45 elementos do Simple Darwin Core dos dois espécimes, em um mesmo formulário, além dos dados das extensões auxiliares. A PDD também oferecia a possibilidade de se cadastrar um esquema Simple Darwin Core, ou seja, sem os dados de interação.

A utilização desta primeira versão evidenciou, principalmente, a multiplicidade de interações entre os espécimes, que resultou na criação da segunda versão do Interaction Extension, que é a base para a segunda versão da PDD.

\subsubsection{Segunda Versão da PDD}

A versão atual da PDD acompanha a mudança de estratégia utilizada na segunda versão do Interaction Extension, e passa a considerar de forma independente os registros de interação entre espécimes. Agora, ao invés de agregar 
um esquema Simple Darwin Core, os dados de interação podem ser diretamente catalogados, manipulados e publicados.

O usuário deve cadastrar uma interação a partir de dois espécimes previamente cadastrados, pois ele utiliza o GUI desses espécimes para identificálos. A PDD também faz uma diferença clara entre os espécimes preservados e observados para facilitar a compreensão dos usuários, principalmente, no registro de espécimes (preservados e observados) e os espécimes observados em campo, para evitar a impressão de estar salvando dados de espécimes e espécies em um mesmo registro, o que é impossível.

Também é possível consultar e apagar os registros de espécimes (Simple Darwin Core) e de interações.

\subsection{Comentário Final}

A utilização dos protocolos de comunicação TAPIR e do esquema conceitual Darwin Core2 na PDD corresponderam às expectativas quanto à troca de dados de espécimes. Este resultado era esperado devido à utilização desses padrões em sistemas importantes como o GBIF e a IABIN, que manipulam milhões de registros.

O esquema conceitual de interação entre espécimes foi o principal beneficiado pela realização da prova de conceito. A PDD possibilitou um desenvolvimento interativo do esquema com a participação da comunidade científica e com a utilização prática do esquema em um sistema de informação.

As três versões do esquema foram fruto da incorporação dos comentários e melhoramentos obtidos nos testes, mas também permitiram uma análise mais detalhada do tratamento da interação entre espécies em termos computacionais. 


\section{CAPÍTULO 6 - CONSIDERAÇÕES FINAIS}

\subsection{Contribuições}

Como contribuições para a comunidade científica brasileira, que pesquisa as abelhas nativas, e que demanda novas funcionalidades para a Webbee, a arquitetura de referência (SOWB) guiará um desenvolvimento distribuído e padronizado, que irá assegurar a integração e a interoperabilidade das novas aplicações na Webbee, e com outros sistemas sobre biodiversidade.

A criação de um novo esquema para os dados de interação entre espécimes é outra importante contribuição, devido, principalmente, ao fato de o esquema ter sido pioneiro na padronização desse tipo de dado. Como decorrência do seu ineditismo, o esquema foi publicado na principal iniciativa de padronização da área, o TDWG, onde está sendo validado pela comunidade científica, e também foi apresentado pelo autor no primeiro Congresso Interamericano de Informática para a Biodiversidade, realizado na Costa Rica, em outubro de 2007 (INBI, 2007), em que participaram profissionais de diversas iniciativas de Informática da Biodiversidade, tais como InBio, GBIF, IABIN, entre outras.

A PDD, criada para a realização das provas de conceito, contribuirá com a digitalização dos dados na Webbee e em outras iniciativas, como na IABIN-PTN, por exemplo, que já disponibiliza a ferramenta para os seus parceiros e provedores de dados (http://groselha.pcs.usp.br/pdd/).

As discussões sobre o desenvolvimento da arquitetura e dos seus padrões e ferramentas, disseminaram os conceitos da Informática da Biodiversidade não só entre a equipe de TI envolvida, mas também, entre os profissionais da área biológica. 


\subsection{Conclusões}

Este trabalho apresentou uma proposta de arquitetura de referência, chamada de SOWB, para a construção da nova Webbee baseada no paradigma de computação orientada a serviços. As etapas de desenvolvimento focalizaram o papel da TI na padronização dos dados e da comunicação entre sistemas de informação sobre biodiversidade, nos novos requisitos para o sistema, e no trabalho realizado pelas iniciativas globais que facilitam o acesso as informações sobre biodiversidade.

$\mathrm{Na}$ Biodiversidade, embora haja necessidade de um esforço global na obtenção de mais dados de campo, também é consenso que é necessário "saber o que já se conhece". Isto é, é necessário integrar todas as fontes de dados para que se aquilatar o que já se conhece sobre a biodiversidade do planeta e, a partir disso, direcionar os esforços para coletar dados sobre as espécies e regiões menos conhecidas. Para isso é preciso digitalizar as informações das coleções dispersas pelo mundo, e é preciso integrá-las para que essa consolidação do conhecimento possa ser feita.

Para atender esses requisitos, é necessário mudar o paradigma de muitos dos sistemas de informação sobre biodiversidade, que são fechados, proprietários e de difícil integração, como é o caso da Webbee atual, para sistemas baseados em componentes, abertos, baseados em rede. Além disso, existe outro requisito importante para estes sistemas: integrar múltiplas fontes de dados, em escala que vai da regional à global, das mais diferentes variáveis - climatológicas, econômicas, biológicas, geológicas; e integrar múltiplos sistemas dispersos pelas diversas instituições relevantes - modelos de simulação, sistemas para tomada de decisão, bancos de dados. Essa integração é importante para permitir a análise dos

processos biológicos sem tantas simplificações, de modo a aumentar o entendimento que se tem sobre eles, e fornecer uma base mais sólida para a tomada de decisão.

Estes requisitos dos sistemas de informação sobre biodiversidade têm sido discutidos por iniciativas que se propõe a facilitar o acesso aos dados sobre biodiversidade, que também têm criado ferramentas e padrões para atendê-los. 
Iniciativas como o TDWG, o GBIF e a IABIN-PTN têm desenvolvido importantes padrões abertos para a Internet, com a utilização de XML e dos Web services. O TAPIR, o Darwin Core2 e o SPM são exemplos para a padronização e a comunicação de dados de espécies e espécimes em grandes sistemas de informação sobre a biodiversidade, que atuam em redes de dados sob a orientação de serviços (em arquiteturas orientadas a serviços).

A nova arquitetura proposta para a Webbee incorpora os padrões da Informática da Biodiversidade adotados também por grandes sistemas da área, e se organiza em uma arquitetura orientada a serviços para atender, principalmente, os requisitos de integração e interoperabilidade da nova versão.

As atividades futuras relacionadas a este trabalho se concentram no desenvolvimento de aplicações sobre esta arquitetura de referência. Está sendo planejado o desenvolvimento de novas versões dos serviços legados da Webbee: a ficha de espécies e plantas (em nível de espécies) e a navegação dos dados de interação (em nível de espécies e espécimes). Além disso, o novo portal da Webbee está em fase de especificação, o qual na SOWB, será a porta de entrada para os usuários finais.

Além disso, esta arquitetura, pela sua especificação, está aberta para o desenvolvimento (padronizado) de novas versões de diversas aplicações sobre abelhas já existentes, e da integração de outras novas, que envolvam os serviços oferecidos pelas redes de dados sobre biodiversidade: aplicações para limpeza de dados, qualidade dos dados, validação de nomes entre outras. 


\section{REFERÊNCIAS}

ABCD. Biodiversity Information Standards - TDWG. Access to Biological Collection Data. Disponível em: http://www.bgbm.org/TDWG/CODATA/Schema/ . Acesso em 31 jan. 2008.

APACHE. Apache Software Foundation. Disponível em: http://www.apache.org . Acesso em: 08 mar. 2007.

BISBY, F.A. The quiet revolution: biodiversity informatics and the internet. Science, v. 289, n. 5488, p. 2309-2312, Sep 2000.

BIOTA. BIOTA-FAPESP. Disponível em: http://www.biota.org.br/ . Acesso em 23 set. 2007.

BLUTHGEN, N.; FRUND, J.; VAZQUEZ, D.P.; MENZEL, F. What do interaction network metrics tell us about specialization and biological traits? Ecology, v. 89, n. 12 , p. $3387-3399$, Dec. 2008.

CANHOS, V.P.; SOUZA, S.; GIOVANNI, R.; CANHOS, D.A.L. Global biodiversity informatics: setting the scene for a "New World" of ecological modeling. Biodiversity Informatics, v. 1, p. 1-13, 2004.

CARTOLANO-JÚNIOR, E.A.; SARAIVA, A.M.; CORREA, P.L.P.; GIANNINI, T. C. Uma proposta de esquema de dados de relacionamento entre espécies. In: TALLER LATINOAMERICANO DE INFORMÁTICA PARA LA BIODIVERSIDAD INBI, San Jose, 2007. Proceedings. San Jose, Costa Rica, 2007. / em CD-ROM /.

CBD. Convention on Biological Diversity. Disponível em: http://www.biodiv.org . Acesso em: 21 fev. 2008. 
CHAPMAN, A.D. Principles and Methods of Data Cleaning - Primary Species and Species. Report for the Global Biodiversity Information Facility, v. 1.0, Copenhagen. 2005.

- Principles of Data Quality. Report for the Global Biodiversity Information Facility, v. 1.0, Copenhagen. 2005b

. Uses of Primary Species-Occurrence Data. Report for the Global Biodiversity Information Facility, v. 1.0, Copenhagen. 2005c.

CHAPMAN, A.D.; MUNOZ, M.E.S.; KOCH, I. Environmental information: placing biodiversity phenomena in an ecological and environmental context. Biodiversity Informatics, v. 2, p. 24-41, 2005.

CHESTER, T.M. Cross-platform integration with XML and SOAP. IT Professional/IEEE Computer Society, v. 3, n. 5, 2001.

COLAN, M. Service-Oriented Architecture expands the vision of Web Services. IBM. 2009. Disponível em: http://www.ibm.com/developerworks/library/wssoaintro.html. Acessado em 25 jun. 2009.

COPP, C.; DE GIOVANNI, R. Biodiversity Information Standards - TDWG. TAPIR - Network Builders Guide, 2008. Disponível em: http://www.tdwg.org/activities/tapir/network-builders-guide Acesso em: 20 set. 2008:

COYLE, F.P. Breathing life into legacy. IT Professional/IEEE Computer Society, v. 3, n. 5, p. 7, 2001.

CRIA. Centro de Referência em Informações Ambientais. SpeciesLink. Disponível em: http://splink.cria.org.br/ . Acesso em: 19 jan. 2008. 
CUNHA, R.S.; SARAIVA, A.M.; CUGNASCA, C.E.; HIRAKAWA, A.R.; IMPERATRIZ-FONSECA, V.L.; HILARIO, S.D. An Internet-based monitoring system for behavior studies of stingless bees. IN: EUROPEAN CONFERENCE OF THE EUROPEAN FEDERATION FOR INFORMATION TECHNOLOGY IN AGRICULTURE, FOOD AND THE ENVIRONMENT, 3., Montpellier, 2001. Proceedings. Montpellier: ENSAM, 2001, p.279-284.

CUNHA, R.S. WebBee - Um Sistema de Informação via Internet Aplicado ao Estudo de Meliponíneos. 2001. 88p. Dissertação (Mestrado) - Escola Politécnica, Universidade de São Paulo. São Paulo, 2001.

DIGIR. DiGIR Open Source Project. Disponível em: http://digir.sourceforge.net/ . Acesso em: 10 abr. 2007.

FAO. 2005. Protecting Pollinators. Disponível em: http://www.fao.org/Ag/Magazine/0512sp1.htm . Acesso em: 06 jun. 2008.

FERREIRA, M.S.J. Uma Arquitetura de Sistemas Distribuídos para Weblabs de Serviços Ambientais. 2007. 83p. Dissertação (Mestrado) Departamento de Engenharia de Computação e Sistemas Digitais, Escola Politécnica, Universidade de São Paulo. São Paulo, 2007.

GBIF. Global Biodiversity Information Facility. Disponível em: http://www.gbif.org . Acesso em: 06 mar. 2007.

GBIF. Global Biodiversity Information Facilities. GBIF Training Manual 1: Digitisation of History Collections Data. v1.0, 2008.

GOTTSCHALK, K.; GRAHAM, S.; KREGER, H.; SNELL, J. Introduction to Web Services architecture. IBM Systems Journal, v. 41, n. 2, p. 170-177, 2002. 
GRAHAM, C.H.; FERRIER, S.; HUETTMAN, F.; MORITZ, C.; PETERSON, A. T. New developments in museum-based informatics and applications in biodiversity analysis. Trends in Ecology \& Evolution, v. 19, n. 9, p. 497-503, Set. 2004.

GURALNICK, R.P.; HILL, A. Biodiversity informatics: automated approaches for documenting global biodiversity patterns and processes. Bioinformatics, v. 25, n. 4, p. 8, 2009.

GURALNICK, R.P.; HILL, W.; LANE, M. Towards a collaborative, global infrastructure for biodiversity assessment. Ecology Letters, v. 10, p. 663-672, 2007.

HORTAL, J.; LOBO, J.M.; JIMENEZ-VALVERDE, A. Limitations of biodiversity databases: case study on seed-plant diversity in Tenerife, Canary Islands. Conservation Biology, v. 21, n. 3, p. 853-863, 2007.

HOWERTON, J.T. Service-Oriented Architecture and Web 2.0. IT Professional/IEEE Computer Society, v. 9, n. 3, p. 2, 2007.

IABIN. Inter-American Biobiversity Network. Disponível em: http://www.iabin.net . Acesso em: 03 mar. 2007.

IBP. Iniciativa Brasileira dos Polinizadores. Disponível em: http://www.webbee.org.br/bpi/ . Acesso em: 03 mar. 2007.

IMPERATRIZ-FONSECA, V.L.; CORTOPASSI-LAURINO, M.; MARTINS, C. F.; KOEDAM, D. \& MACEDO, E.R.M. A meliponicultura da jandaíra como atividade de desenvolvimento sustentado. In: CONGRESSO BRASILEIRO DE APICULTURA, 12., Florianópolis. Anais. 2000. p.E-015.

A meliponicultura e a Inciativa Brasileira dos Polinizadores. XV Congresso Brasileiro de Apicultura / I Congresso Brasileiro de Meliponicultura. Natal, 2004. 
A iniciativa brasileira de polinizadores e os avanços atuais para a compreensão do papel dos polinizadores como produtores de serviços ambientais. Bioscience Journal, v. 23, p. 7, 2007.

A criação da abelha jandaíra no nordeste brasileiro. Instituto de Biociências da USP. Disponível em: http://www.ib.usp.br/jandaira . Acesso em: 08 fev. 2008.

IMPERATRIZ-FONSECA, V.L.; SANTOS, I.A. Classificação das abelhas brasileiras. Instituto de Biociências da USP. Disponível em: http://www.ib.usp.br/beetaxon . Acesso em: 08 fev. 2008.

ITIS. Integrated Taxonomic Information System. Disponível em: http://www.itis.gov . Acesso em: 19 jan. 2008.

JOHNSON, N.F. Biodiversity informatics. Annual Review of Entomology, v. 52, p. 421-438, 2007.

JONES, A.C. Applying computer science research to biodiversity informatics: Some experiences and lessons. Transactions on Computational Systems Biology, v. 3939, p. 44-57, 2006.

KELLING, S. Significance of organism observations: Data discovery and access in biodiversity research. Report for the Global Biodiversity Information Facility, 2008.

KLEIN, A.M.; VAISSIERE, B.E.; CANE, J.H.; STEFFAN-DEWENTER, I.; CUNNINGHAM, S.A.; KREMEN, C.; TSCHARNTKE, T. Importance of pollinators in changing landscapes for world crops. Proceedings of the Royal Society BBiological Sciences, v. 274, n. 1608, p. 303-313, Fev. 2007. 
KLEINERT, A.M.P.; IMPERATRIZ-FONSECA, V.L, Utilização de recursos florais por abelhas sem ferrão em diferentes ecossistemas. Instituto de Biociências da USP. Disponível em: http://www.ib.usp.br/beeplant. Acesso em: 08 fev. 2008.

KREMEN, C.; WILLIAN, N.M.; AIZEN, M.A.; RICKETTS, T.H. Pollination and other ecosystem services produced by mobile organisms: a conceptual framework for the effects of land-use change. Ecology Letters, v. 10, n. 4, p. 299-314, Abr. 2007.

KSOURIS, G. How to become a GBIF data provider. GBIF. 2009. Disponível em: http://circa.gbif.net/Public/irc/gbif/ict/library?l=/digir_provider_package. Acesso em: 23 jun. 2009.

LE BLEVEC, Y.; GHEDIRA, C.; BENSliMANE, D.; DELATTE, X. ServiceOriented Computing: Bringing Business Systems to the Web. IT Professional/IEEE Computer Society, v. 9, n. 3, p. 5, 2007.

LEYMANN, F.; ROLLER, D.; SCHMIDT,M.T. Web Services and business process management. IBM Systems Journal, v. 41, n. 2, p. 198-211, 2002.

LOURIDAS, P. SOAP and Web Services. IEEE Software, v. 23, n. 6, p. 6, 2006.

MA, K. J. Web Services: what's real and what's not? IT Professional/IEEE Computer Society, v. 7, n. 2, p. 7, 2005.

MEMMOTT, J.; CRAZE, P.G.; WASER, N.M.; PRICE, M.V.; Global warming and the disruption of plant-pollinator interactions. Ecology Letters, v. 10, n. 8, p. 710-717, Ago. 2007.

MICHAELLIS. Dicionário Michaellis. Disponível em : http://michaelis.uol.com.br/moderno/portugues. Acesso em 23 jun. 2009. 
MULLER, D. XML, Standards et Applications. Lyon: École Centrale de Lyon, 2006. I Apostila do curso Technologies de l'Information et de la Communication /.

MYERS, N.; MITTERMEIER, R.A.; MITTERMEIER, C.G.; DA FONSECA, G. A. B.; KENT, J. Biodiversity hotspots for conservation priorities. Nature, v. 403, n. 6772, p. 853-858, Fev. 2000.

MYSQL. MySQL. Disponível em: http://www.mysql.com . Acesso em: 18 mar. 2007.

NOSS, R.F. Indicators for Monitoring Biodiversity - A Hierarchical Approach. Conservation Biology, v. 4, n. 4, p. 355-364, Dez. 1990.

NOGUEIRA-NETO, P.; IMPERATRIZ-FONSECA, V.L. As abelhas sociais sem ferrão: arquivos de imagens e vídeos. Instituto de Biociências da USP. Disponível em: http://www.ib.usp.br/beelife . Acesso em: 08 fev. 2008.

OASIS. Organization for the Advancement of Structured Information Standards. Disponível em: http://www.oasis-open.org . Acesso em: 18 mar. 2007.

PAGE, R.D.M. Biodiversity informatics: the challenge of linking data and the role of shared identifiers. Briefings in Bioinformatics, v. 9, n. 5, p. 345-354, 2008.

PAPAZOGLOU, M.P.; HEUVEL, W. Service oriented architectures: approaches, technologies and research issues. The International Journal on Very Large Data Bases, v. 16, n. 3, 2007.

PHP. Disponível em: http://www.php.net . Acesso em: 18 mar. 2007.

Plinian Core. Disponível em: http://www.pliniancore.org/ . Acesso em: 24 mar. 2007. 
ROY, J.; RAMANUJAN, A. XML: data's universal language. IT Professional/IEEE Computer Society, v. 2, n. 3, p. 4, 2000.

- Understanding Web Services. IT Professional/IEEE Computer Society, v. 3, n. 6, p. 4, 2001a.

$\mathrm{XML}$ schema language: taking $\mathrm{XML}$ to the next level. IT Professional/IEEE Computer Society, v. 3, n. 2, p. 4, 2001 b.

SANTANA, F.S.; SIQUEIRA, M.F.; SARAIVA, A.M.; CORREA, P.L.P. 2008. A reference business process for ecological niche modelling. Ecological Informatics Journal 3-1: 75-86.

SARAIVA, A.M. Tecnologia da informação na agricultura de precisão e biodiversidade: estudos e proposta de utilização de Web Services para desenvolvimento e integração de sistemas. 2003. 209p. Tese (Livre Docência) Departamento de Engenharia de Computação e Sistemas Digitais, Escola Politécnica, Universidade de São Paulo, São Paulo, 2003.

SARAIVA, A.M.; CARTOLANO-JUNIOR, E.A. WebBee - a Web - based Information Network on Bees. Revista de Engenharia de Computação e Sistemas Digitais, v. 1, n. 1, p. 10, 2003.

SARAIVA, A.M.; IMPERATRIZ-FONSECA, V.L. WebBee: Uma rede de informações sobre biodiversidade brasileira em abelhas nativas. In: ENCONTRO SOBRE ABELHAS, 5., Ribeirão Preto. 2002. Anais. Ribeirão Preto: FFCLRP/FMRP/USP, 2002. p.108-113.

SARKAR, I.N. Biodiversity informatics: organizing and linking information across the spectrum of life. Briefings in Bioinformatics, v. 8, p. 347-357, 2007.

SAUTTER, G.; BOHM, K.; AGOSTI, D. A quantitative comparison of XML schemas for taxonomic publications. Biodiversity Informatics, v. 4, p. 1-13, 2007. 
SCHNASE, J. L.; CUSHING, J.; FRAME, M.; FRONDORF, A.; LANDIS, E.; MAIER, D.; SILBERSCHATZ, A. Information technology challenges of biodiversity and ecosystems informatics. Information Systems, v. 28, n. 4, p. 339-345, Jun. 2003.

SCHNASE, J.L.; CUSHING, J.; SMITH, J.A. Biodiversity and ecosystem informatics. Journal of Intelligent Information Systems, v. 29, n. 1, p. 1-6, 2007.

SILVA, M. Bioinformatics, The clearing-house mechanism, and the convention on biological diversity. Biodiversity Informatics, v. 1, p. 23-29, 2004.

SOBERON, J.; PETERSON, A.T. Biodiversity informatics: managing and applying primary biodiversity data. Philosophical Transactions of the Royal Society of London Series B-Biological Sciences, v. 359, n. 1444, p. 689-698, Apr. 2004.

SPECIES2000. Species2000. Disponível em: http://www.sp2000.org . Acesso em: 19 jan. 2008.

SPECIFY. Biodiversity Collections Management. Kansas University. Disponível em: http://usobi.org/specify. Acesso em: 27 jan. 2008.

STAL, M. Web Services: beyond component-based computing. Communications of the ACM, v. 45, n. 10, 2002.

STEINHAGE, V. Automated identification of bee species in biodiversity information systems. Disponível em: http://enviroinfo.isep.at/UI\%20200/Steinhage Biodev 1007200.el.ath.pdf. Acesso em: 12 dez. 2008.

STOCKWELL, D.R.B. Overview of computational biodiversity research. Publicado em 03/02/97. Disponível em: http://biodi.sdsc.edu/doc/bis/overview.html. Acesso em: 22 jan. 2007. 
TDWG. Biodiversity Information Standards. Disponível em: http://www.tdwg.org . Acesso em 30 jan. 2007.

THOMAS, C.D.; CAMERON, A. ; GREEN, R.E. ; PHILLIPS, O.L. Extinction risk from climate change. Nature, v. 427, n. 6970, p. 145-148, Jan. 2004.

UDDI. Universal Description, Discovery and Integration. Disponível em: http://uddi.xml.org . Acesso em: 11 mar. 2007.

VINCES. Virtual Networking Center of Ecosystem Services. Disponível em: http://www.ib.usp.br/vinces/ . Acesso em: 11 set. 2008.

W3C, World Wide Web Consortium. Extensible Markup Language (XML). Disponível em: http://www.w3.org/XML/ . Acesso em: 11 mar. 2007. 2007a.

. World Wide WEB Consortiun. Web Services Activity. Disponível em: http://www.w3.org/2002/ws/ . Acesso em: 11 mar. 2007. 2007b.

. World Wide WEB Consortiun. SOAP 1.2 Part 0: primer (Second Edition). W3C. Disponível em: http://www.w3.org/TR/soap12-part0 . Acesso em: 11 mar. 2007. 2007c. . World Wide WEB Consortiun. Web Services Description Language (WSDL) 1.1. Disponível em: http://www.w3.org/TR/wsdl . Acesso em: 11 mar. 2007. 2007d. 


\section{APÊNDICE A}

\section{EXTENSIBLE MARKUP LANGUAGE - XML}

A eXtensible Markup Language (XML), é um conjunto de regras para concepção de arquivos do tipo texto que permitem a estruturação dos dados (em blocos de endereços, parâmetros de configuração, transações financeiras, desenhos técnicos, e outros) de forma não-ambígua, extensível e insensível aos problemas de internacionalização/localização e de dependência de plataformas computacionais (W3C, 2007a). Ela é um padrão aberto; um projeto patrocinado pelo World Wide Web Consortium (W3C), que supervisiona o seu desenvolvimento através dos W3C's XML Working Group.

O uso da XML nas aplicações comerciais têm se mostrado cada vez maior. Ela tem substituído tecnologias da informação e da comunicação de diversos domínios, principalmente na Internet. Para os sistemas de informação que trabalham com a biodiversidade, a XML tem um papel fundamental, pois é ela quem padroniza os dados trocados e viabiliza a comunicação entre aplicações diferentes, que são inerentes ao domínio (Copp; De Giovanni, 2008). Numerosas publicações abordam o assunto, como (Saraiva, 2003), (Copp; De Giovanni, 2008), (Muller, 2006), (Ma, 2005), além do site de desenvolvimento da XML no W3C (W3C, 2007a), que foram as fontes para este texto, que aborda os conceitos básicos da tecnologia.

\subsection{SGML, HTML e XML}

A XML foi criada a partir de um subconjunto da Standard Generalized Markup Language (SGML), um padrão complexo de descrição de conteúdo e estrutura de documentos. A SGML surgiu no final da década de 60 para facilitar o intercâmbio e a manipulação por computadores de uma grande quantidade de documentos. Ela é um sistema para criar linguagens de marcações, onde marcações (tags) descrevem 
a estrutura de um documento e outros atributos do mesmo, em vez de especificar como deve ser feito o seu processamento. Estas tags, que são definidas rigorosamente, não restringem os documentos a uma única aplicação, estilo de formatação, ou sistema de processamento, desde que as suas regras de construção sejam conhecidas.

A SGML tornou-se norma internacional em 1986 (ISO 8879), mas nunca foi largamente usada, por ser extremamente geral e complexa, dificultando a escrita de programas para seu processamento. No início, seus casos de sucesso na indústria limitaram-se ao intercâmbio e o armazenamento de documentos, cujas principais linguagens foram a DocBook (projetada para marcação de documentação técnica) e a TEI - Text Encoding Initiative (projetada para marcação de textos literários).

No entanto, foi com uma linguagem de marcação para a composição e a apresentação de documentos na World Wide Web - WWW, que a SGML teve o seu maior sucesso. A Hypertext Markup Language, a HTML, foi criada por Tim BernersLee no início dos anos 90 para usar um pequeno subconjunto de marcadores da especificação SGML. Essa simplificação facilitou a construção de aplicações e contribuiu para a disseminação da HTML como uma linguagem de publicação na Web, ao mesmo tempo em que limitou sua utilidade e flexibilidade.

A evolução da Internet como meio de comunicação, alçada no sucesso da HTML, criou demanda por linguagens mais flexíveis e poderosas. Todavia, a independência de plataforma e a possibilidade de criar um sem número de estruturas de documentos, abriram precedentes para que se criassem subconjuntos da SGML para atender esta demanda, dando origem a XML.

A XML também é uma metalinguagem, ou seja, uma linguagem para descrever outras linguagens, e, portanto, permite definir linguagens de marcação (aplicações) específicas para classes diferentes de documentos. Criada a partir dos aspectos mais utilizados e menos complexos da SGML, a XML tornou-se uma metalinguagem mais fácil de entender, de utilizar para o desenvolvimento de aplicações e para promover a interoperabilidade, em particular, na Internet.

Uma comparação entre a XML e a SGML pode ser consultada em http://www.w3.org/TR/NOTE-sgml-xml-971215. 


\subsection{Marcadores: tags}

Assim como na HTML (uma aplicação da SGML), os documentos XML também identificam os seus marcadores ao envolvê-los com os símbolos "<" e ">" que, eventualmente, são acrescidos de atributos (nome='valor'). Por terem seus dados delimitados por marcadores, os arquivos XML (formato texto) são comparativamente maiores que os arquivos armazenados em formato binário. Essa desvantagem é amplamente conhecida, mas ela é compensada pelo custo decrescente do espaço em disco, pelas técnicas de compressão de arquivos, pela velocidade de processamento e dos canais de comunicação, e pela característica dos protocolos de comunicação na Internet que, em sua maioria, utilizam técnicas de compressão antes de enviá-los.

Exemplo de documento XML:

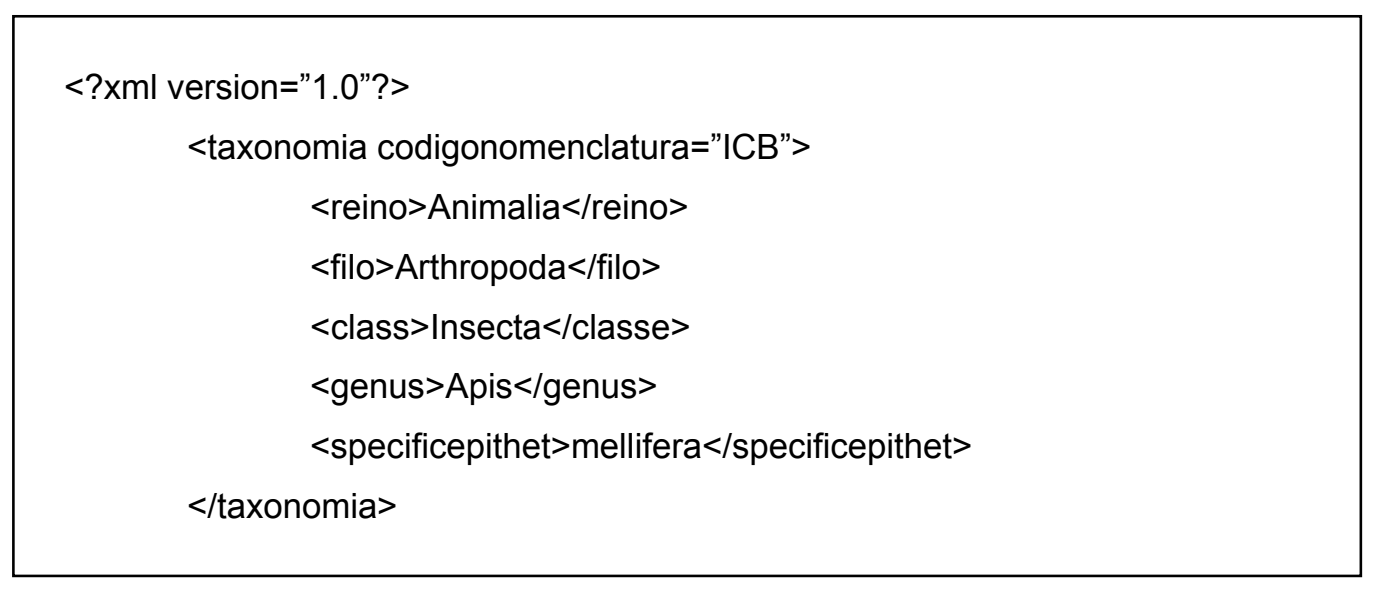

Um arquivo XML é um documento do tipo texto que, conseqüentemente, pode ser lido pelas pessoas em qualquer editor de texto, o que agiliza a depuração de erros pelos programadores. Entretanto, ter acesso ao conteúdo do documento não garante ao leitor a compreensão dos dados, que só pode ser garantida com a sintaxe (regras de construção da linguagem de marcação) que rege de cada arquivo. Esta dependência garante que um arquivo XML só será interpretado por uma aplicação se ele estiver corretamente construído, ou seja, se obedecer estritamente a sua sintaxe. 


\subsection{Espaço de Nomes: XML Namespaces}

Os "espaços de nomes" (XML Namespaces) são objeto de recomendação da W3C desde janeiro de 1999. Eles permitem evitar conflitos potenciais entre os nomes dos marcadores e dos atributos quando se desejar mesclar o vocabulário de duas aplicações diferentes em um mesmo documento XML. Um namespace permite essa unicidade ao identificar uma origem ou referência dos nomes utilizados no documento. Ele é uma coleção de nomes de elementos e atributos, identificada por um nome único, referenciada por um URI (Universal Resource Indicator).

Considerando os documentos XML de duas aplicações diferentes:

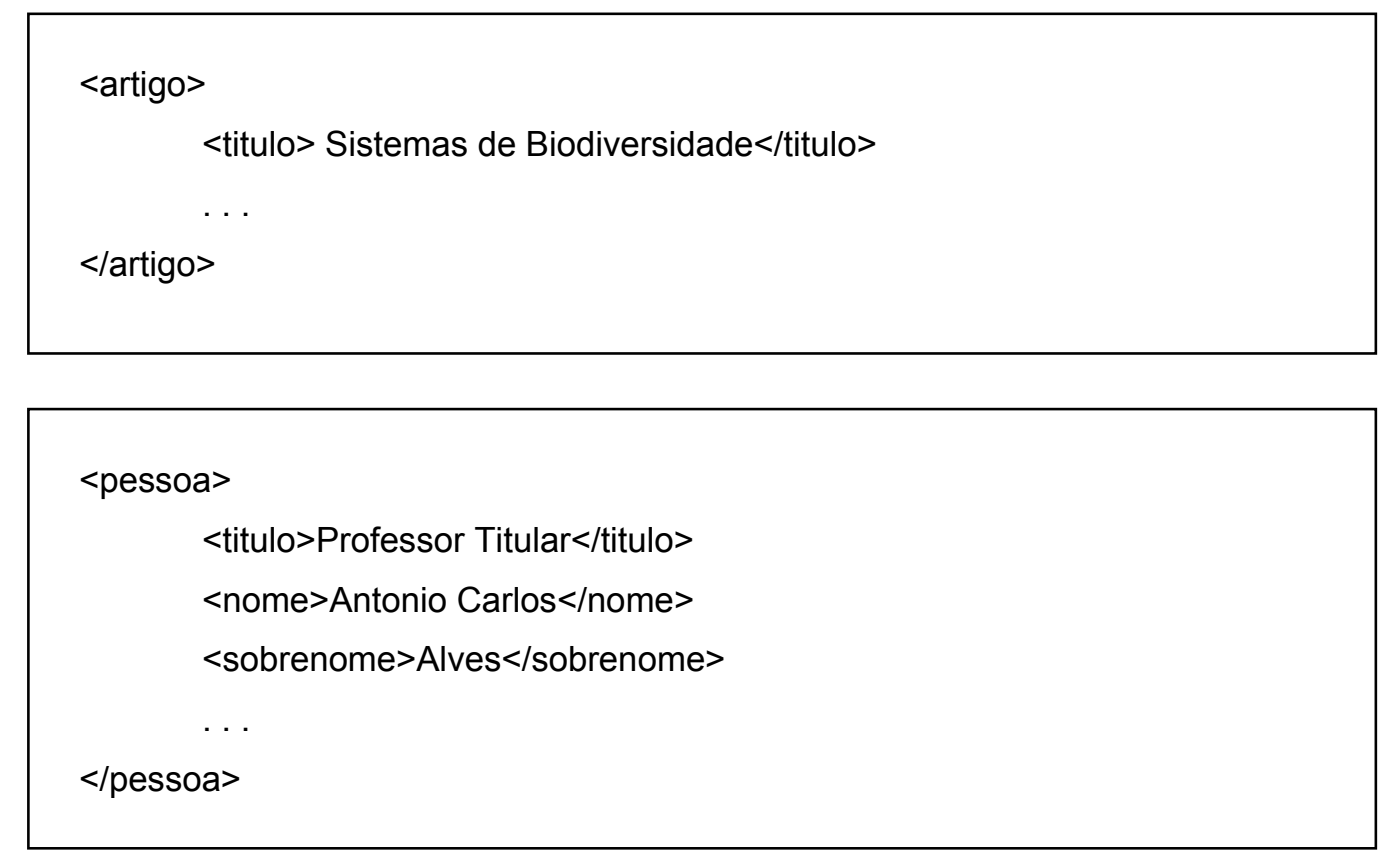

A mescla dos marcadores em um mesmo documento sem erros de interpretação, pode ser bem-resolvida com a utilização dos namespaces: 
<publicacao:artigo>

<publicacao:titulo>Sistemas de Biodiversidade</publicacao:titulo>

$<$ publicacao:autor>

<pessoa:titulo>Professor Titular</ pessoa:titulo>

$<$ pessoa:nome $>$ Antonio Carlos </ pessoa:nome $>$

$<$ pessoa:sobrenome>Alves</ pessoa:sobrenome>

$<$ publicacao:autor>

$<$ /publicacao:artigo >

Mesmo com nomes ("titulo") duplicados, a especificação do namespace ao qual se referem, dirime a ambigüidade, ao criar um nome com duas partes, uma das quais é o namespace. Vale lembrar que não é o prefixo que identifica o "espaço de nomes" e sim, o seu URI associado ao prefixo.

\subsection{Gramática: DTD e XML Schema}

A definição da estrutura legal de um documento $X M L$, ou a sua gramática, é a responsável por especificar quais marcações (tags) estão disponíveis, onde e quantas vezes elas podem ocorrer no documento e como elas se relacionam. Herdadas da sua origem na SGML, as construções coletadas em um documento do tipo Document Type Definition (DTD) (ou no próprio documento $\mathrm{XML}$ ) podem definir uma gramática para a linguagem de marcação atribuída ao documento XML.

Exemplo de declaração com o local onde a DTD pode ser encontrada ("turmapoli.dtd") e uma construção (declaração de um elemento), no próprio documento $\mathrm{XML}$, ao mesmo tempo:

\footnotetext{
$<$ ! DOCTYPE classe SYSTEM "turma-poli.dtd" [

$<$ ! ELEMENT classe (turma,estudante+)>

$1>$
} 
Quando um documento XML atende as regras de construção de uma DTD, o documento XML é dito "válido". Apesar de permitir a sua validação, essas construções apresentam algumas deficiências para definir documentos XML. Elas são muito limitadas em relação aos tipos de dados que oferecem. Além disso, a própria sintaxe das construções difere daquela do $X M L$, o que é um empecilho ao seu aprendizado. E talvez o mais importante, elas não permitem utilizar o conceito de namespaces, para identificação unívoca dos nomes. Para preencher estas lacunas, uma aplicação XML foi especificada pela W3C (maio 2001), a XML Schema Language.

A principal vantagem da XML Schema Language é a sua capacidade de estruturação. Com ela, é possível criar um rico espectro de tipos de dados como os comumente encontrados nas linguagens de programação (inteiro, string, booleano, data e hora, etc.), inclusive, o tipo complexo, que se vale de outra propriedade da aplicação, o reuso. Pode-se quebrar um schema em componentes previamente definidos e aproveitá-los na composição de outros elementos. A XML Schema também suporta o conceito de herança, de forma que se podem criar esquemas derivando características de outros existentes. Outra característica distintiva da XML Schema Language é sua integração com o conceito de XML Namespaces, considerada uma importante ausência nas DTDs.

Considerando um documento XML de uma aplicação simples, que também possui um XML Schema associado:

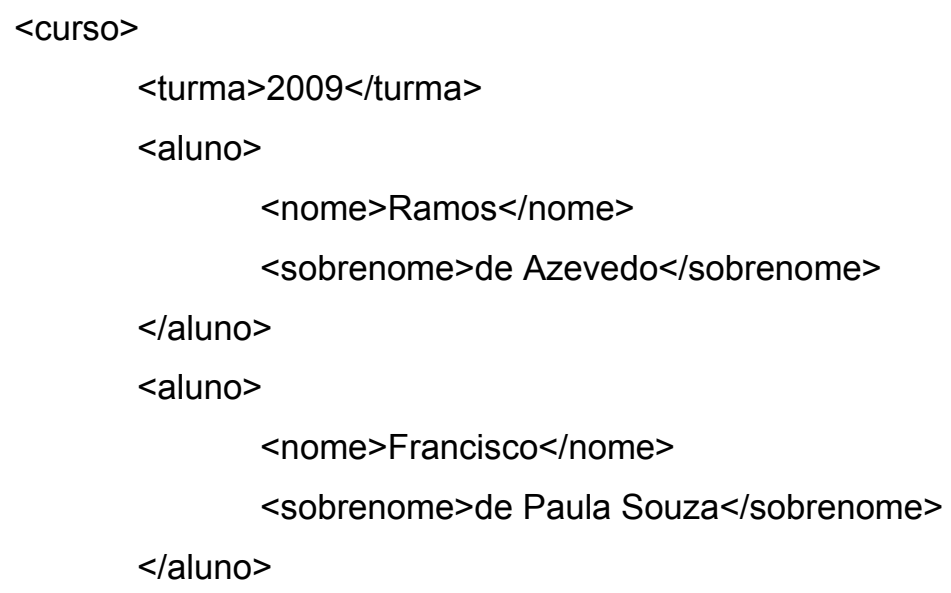


No seu schema, seriam declarados os seguintes elementos:

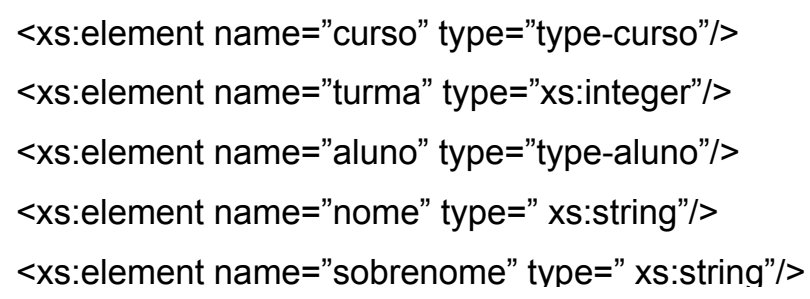

E em outro trecho, os tipos complexos. O tipo "aluno" é composto por dois elementos, um "nome" e um "sobrenome":

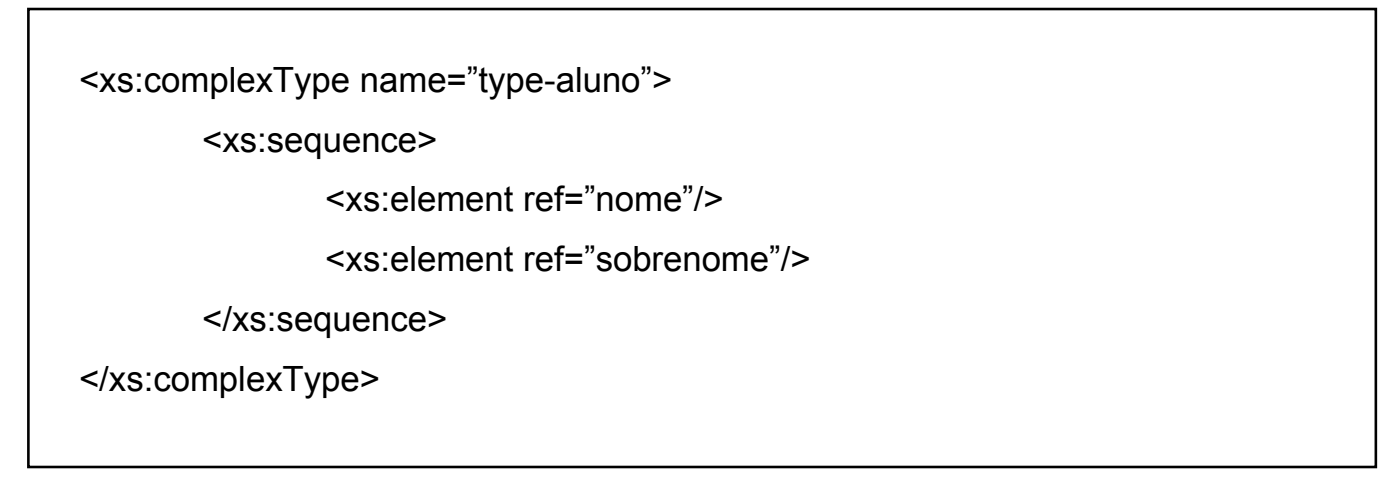

Já o tipo "classe" é composto por um elemento "turma" e diversos elementos "aluno".

$<x s:$ complexType name="type-classe">

$<x$ s:sequence>

$<$ xs:element ref="turma"/>

$<x$ s:element ref="aluno" maxOccurs="unbounded"/>

$</ x s$ :sequence $>$

$</ x s:$ complexType>

Por fim, os XML Schema também são documentos XML e, portanto, seguem suas regras de formação e podem ser manipulados por suas ferramentas, diferentemente dos DTDs. Desse modo, um schema comum permite que, tanto do lado do servidor como do cliente, os documentos XML possam ser validados de 
maneira fácil e eficiente. Por todas essas características, os schemas podem modelar dados complexos eficientemente, facilitando o processamento, além de fazê-lo de um modo elegante e de mais fácil leitura pelos desenvolvedores (Saraiva, 2003).

\subsection{Processadores de documentos XML: parses}

Por definição, um processador XML é um analisador sintático (parser) usado para analisar documentos XML e fornecer acesso ao seu conteúdo e sua estrutura. Eles são, necessariamente, a interface entre outros módulos de software e os documentos XML.

A recomendação "1.0" da XML (publicada pela W3C, desde 1998) contém as regras que definem o comportamento exigido de um parser ao ler um documento $\mathrm{XML} e$ as informações que ele deve entregar aos aplicativos. O trabalho do processador é verificar, obrigatoriamente, se um documento é "bem formado", ou seja, se está de acordo com a recomendação da W3C. A maior parte dos parsers também é capaz de dizer se um documento é "válido" em relação a sua DTD ou XML Schema.

Segundo Muller (2006), existem inúmeros parsers XML disponíveis no mercado (muitos de código aberto) com os quais é possível fazer interface ao desenvolver aplicativos. A interface com um parser pode ser feita por dois tipos de APIs (Application Programming Interfaces): baseada em eventos (SAX - Simple API for $\mathrm{XML}$ ) e baseada em uma estrutura de árvores em memória (DOM - Document Object Model).

- DOM - Document Object Model - é uma interface neutra em relação a plataforma e linguagem, que representa o documento XML como uma árvore cujos nós são os elementos, texto, etc. Um processador DOM fornece ao programa de aplicação meios de acesso e manipulação desses nós ao criar a estrutura do documento inteiro em memória. Ao fazer isso ele é conveniente para modificar estruturalmente ou criar 
dinamicamente um documento XML, e para compartilhar um documento em memória com outras aplicações.

- SAX - simple API for XML - em vez de criar a estrutura em memória, o SAX varre o documento XML de entrada e gera eventos, como inicio e fim de um elemento. O programa de aplicação implementa handlers que recebem esses eventos e os processam adequadamente. Desse modo ele é conveniente para processar grandes documentos, que não caberiam na memória, e para extrair conteúdos específicos do documento.

\subsection{Aplicações XML e Restrições}

Diversas tecnologias XML têm sido criadas para trabalhar e expandir as funcionalidades dos arquivos XML, tais como, construtores de páginas Internet (eXtensible Hypertext Markup Language - XHML), processadores de transformação de XML em XML e navegadores internos (Extensible Stylesheet Language Family XSL), apontadores (XML Pointer - XPointer), protocolos de comunicação (XML Remote Procedure Call - XML-RPC), etc. Estes módulos são sintaxes com marcadores e atributos próprios que definem o comportamento da aplicação associada a cada elemento de estrutura extraído pelos processadores XML.

Ao prover definições flexíveis de documentos e possibilidades de processamento, e ao separar definição de conteúdo das instruções de apresentação, a XML facilita a troca de mensagens e a formatação visual em diversas plataformas, o que pode ser considerada uma base para a interoperabilidade (Saraiva, 2003). Outra contribuição importante da XML é a busca e recuperação mais rápidas de informação, devido ao fato dos documentos XML também conterem metadados.

Entretanto, há limitações e pontos a serem mais bem desenvolvidos (Roy; Ramanujan, 2000) apud (Saraiva, 2003). Por exemplo, a XML pode não ser uma boa solução para sistemas stand-alone, ainda apresenta restrições do ponto de vista de 
segurança e quando uma comunicação de baixo-nível eficiente é necessária. Outro obstáculo importante para a sua adoção é a confusão na interpretação da informação, causada por adoção de schemas diferentes para a mesma atividade. 


\section{APÊNDICE B}

\section{WEBBEE - VERSÃO STAND-ALONE}

\subsection{Introdução}

Segundo Saraiva; Imperatriz-Fonseca (2002), o Brasil é rico em espécies de abelhas, que habitam todo o seu território nacional e têm grande importância ecológica e econômica. Sua importância decorre da atuação como agentes polinizadores, tanto em áreas naturais, contribuindo para a manutenção da diversidade, como em culturas agrícolas.

O uso e conservação de abelhas como polinizadores de importância agrícola foi considerado prioritário pela COP5 da CDB (item 3.2.1), que identificou um impacto negativo de 65 bilhões de dólares por ano, causada pelo declínio dos serviços de polinização das abelhas na agricultura. Por isso, é importante desenvolver a criação comercial das abelhas nativas, e os apicultores brasileiros têm manifestado interesse nisso, mas ainda é baixa a disponibilidade de informações em português sobre o assunto para o público em geral. Faltam informações sobre a identificação das espécies encontradas numa localidade, faltam dados sobre a biologia e sobre os problemas relativos à sua criação (Saraiva, 2003).

Pesquisas têm sido feitas para atender esta demanda por informações, importantes para expandir o uso das abelhas como agente polinizador e melhorar a produtividade das criações. Elas buscam conhecer seus hábitos de vida dentro e fora das colônias, suas preferências florais, e a influência do clima na sua vida em geral e especificamente na atividade de vôo para a coleta de néctar, pólen e resina. Entretanto, diversas dificuldades relacionadas à coleta de dados inviabilizam a multiplicação dos experimentos e prejudicam a qualidade dos dados: erros humanos, ambientes hostis, grande massa de dados, acesso à tecnologia, entre outros. Esta realidade carece de sistemas automatizados de coleta e de publicação 
que delegue aos pesquisadores as tarefas mais nobres, tais como a análise dos dados.

Buscando suprir essa lacuna, o Laboratório de Abelhas vem trabalhando na confecção de páginas Internet com conteúdo diverso: como um serviço de identificação de abelhas (Imperatriz-Fonseca; Santos, 2008), páginas com informações sobre as espécies de abelhas (Nogueira-Neto; Imperatriz-Fonseca, 2008), sua criação (Imperatriz-Fonseca et al., 2008) e sobre plantas apícolas (Kleinert; Imperatriz-Fonseca, 2008). Todavia, a atualização do conteúdo demanda programação e não proporciona uma forma eficiente de disponibilizar e recuperar o vasto corpo de conhecimento acumulado pelos pesquisadores, e que compreende material em várias mídias: textos, imagens e vídeos, e diversas fontes: dados do clima, de movimentação, de comportamento, etc.

Iniciou-se, então, uma cooperação com o Laboratório de Automação Agrícola e, como resultado, foi proposto o desenvolvimento de um sistema, denominado Webbee (Cunha, 2001; Cunha et al., 2001; Saraiva; Cartolano-Júnior 2003), com os objetivos de coletar dados das colônias e de organizar as informações e o conhecimento gerados nas pesquisas sobre os meliponíneos, facilitando o acesso remoto a esses conteúdos, contribuindo para a sua difusão.

A Webbee é um projeto multidisciplinar construído para reunir em um único sistema, diversos tipos de informações sobre a biodiversidade brasileira em espécies de abelhas nativas (Saraiva; Cartolano-Júnior 2003). O objetivo desta concentração e organização de informações é contribuir para o mapeamento e quantificação da biodiversidade brasileira, cujo público alvo é formado por pesquisadores, alunos de pós-graduação e de graduação nas áreas de biologia, ecologia e agronomia; e apicultores e agricultores. O sistema foi o primeiro banco de dados sobre abelhas nativas do Brasil na Internet, ao criar uma plataforma para integração de informações em textos, imagens e vídeo além de disponibilizar dados em tempo real sobre colônias de abelhas do biotério na Universidade de São Paulo, monitoradas por sistemas de instrumentação especialmente desenvolvidos para esse fim. 


\subsection{Arquitetura}

O foco estratégico da Webbee é a cooperação entre vários centros de pesquisa via Internet, seja na realização de experimentos, ou na contribuição com informações sobre espécies: textos, imagens, vídeos, etc. (Saraiva; ImperatrizFonseca, 2002). A arquitetura da Webbee reflete esta estratégia e integra ao mesmo tempo um sistema de instrumentação, um sistema de informação e uma rede de informações, como será detalhado nos próximos itens.

\subsubsection{Sistema de Instrumentação}

O sistema de instrumentação da Webbee compreende a monitoração de colônias de abelhas localizadas no Laboratório de Abelhas. Neste sistema, uma placa de aquisição de dados colocada num computador pessoal recebe sinais de sensores de temperatura e de umidade relativa do ar colocados dentro de uma colônia, e de um sensor de fluxo de abelhas, colocado na entrada da colônia. Fora do âmbito da colônia, uma estação meteorológica coleta dados sobre o ambiente. Esses dados coletados são enviados na forma de arquivos, via Internet, para outro computador, onde são armazenados no banco de dados (Figura 9).

\subsubsection{Sistema de Informação}

O sistema de informação é o núcleo da Webbee, pois é ele que recebe os dados automaticamente coletados e permite disponibilizá-los na rede (Cunha, 2001). 
O sistema está dividido em três módulos:

- Módulo de Serviços, composto pelos programas servidores de banco de dados SQL (Structured Query Language) e Web (HTTP), e uma linguagem de programação interpretada;

- Módulo de Manutenção, composto pelo programa de manutenção; que é utilizado pelo administrador e pelos pesquisadores para inserção de dados;

- Módulo Web, composto pelo Navegador Web. É a interface do usuário com o sistema em qualquer ponto da Internet;

\subsubsection{Ferramentas}

Para o Módulo de Serviços. a ferramenta selecionada para a base de dados foi o gerenciador de banco de dados relacional MySQL (MySQL, 2007), hoje comercializado pela Sun, e que possui distribuição gratuita para aplicações não comerciais. Para o Servidor Web (HTTP) foi selecionado o programa APACHE (Apache, 2007), da Apache Software Fondation, acrescido de um interpretador PHP (Hypertext Preprocessor) (PHP, 2007) para manipulação dos dados via Internet, ambos também gratuitos.

O Módulo de Manutenção foi desenvolvido como um programa de ambiente Windows, utilizando a ferramenta Microsoft Visual Basic. Este programa roda em um ambiente de rede local com interfaces de conexão direta com o banco de dados. Para o Módulo Web, são utilizados quaisquer navegadores que suportem as linguagens HTML 4.0 e JAVASCRIPT 1.2. 


\subsubsection{Arquitetura}

A Figura 33 apresenta a arquitetura desse sistema e os módulos citados acima. O princípio de funcionamento do sistema está baseando na troca de mensagens entre os programas clientes dos Módulos de Manutenção e Web, e os programas servidores do Módulo de Serviços. No Módulo de Manutenção, um programa dedicado realiza requisições de dados ao servidor SQL via um driver ODBC (Open Data Base Connectivity). O servidor por sua vez realiza a consulta aos dados e devolve como resultado o conjunto de registros selecionado ao programa cliente.

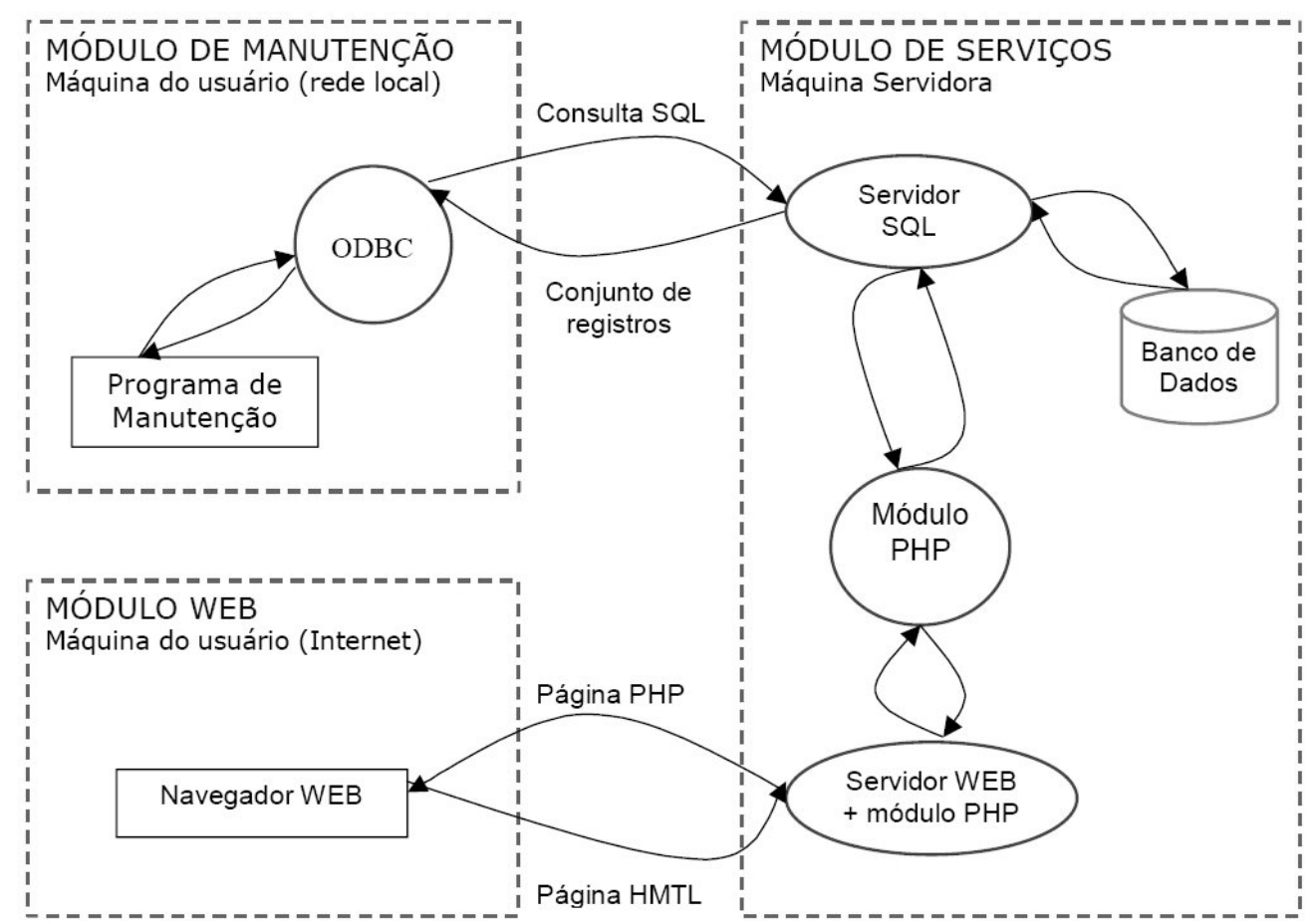

Figura 33 - Estrutura do sistema de informação da Webbee e interface entre os módulos Fonte: (Saraiva, 2003)

No módulo Web, um navegador realiza requisições de páginas PHP ao servidor Web, que são repassadas ao interpretador PHP para execução. Se a página contiver instruções de consulta à base de dados, o interpretador realizará a requisição de dados ao servidor SQL. O servidor, assim como no caso anterior, realiza a consulta na base de dados e devolve o conjunto de registros selecionado. 
De posse do resultado da consulta, o interpretador PHP formata os dados em HTML, seguindo as instruções PHP, e repassa de volta ao servidor Web a página gerada. Este por sua vez retorna ao cliente a página HTML criada pelo PHP como resposta.

O banco de dados foi estruturado para organizar e conter dados sobre as espécies de meliponíneos, bem como diversos outros dados de interesse relacionados, como espécies de plantas visitadas, distribuição geográfica, entre outras. O banco foi modelado tendo por base as informações coletadas para o banco de dados do projeto BIOTA-SP FAPESP (BIOTA, 2007), e inúmeras outras solicitações dos especialistas consultados. A Figura 10 apresenta um diagrama simplificado do banco de dados, com as suas principais entidades de dados (retângulos). Na Figura 34 é apresentada uma descrição simplificada do significado dessas entidades de dados.

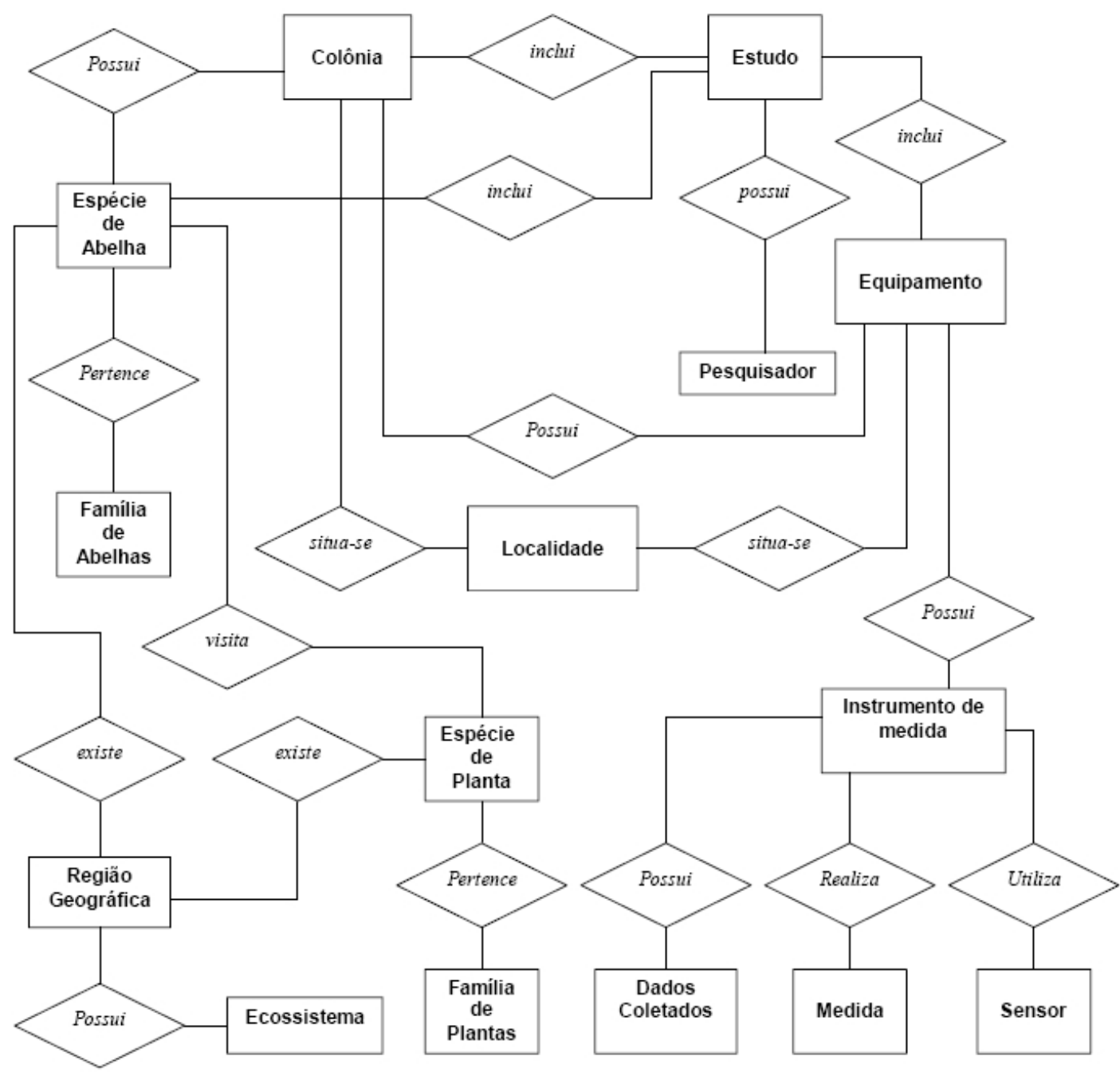

Figura 34 - Diagrama de Entidade-Relacionamento mínimo (sem atributos)

Fonte: (Cunha, 2001) 
Entidade

Estudo

Colônia

Espécie de abelhas

Família de abelhas

Equipamento

Instrumento

Sensor

Medida

Dados Coletados

Localidade

Espécie de Plantas

Família de Plantas

Pesquisador

Ecossistemas

Região Geográfica

\section{Descrição}

Dados sobre os Estudos realizados.

Dados sobre as colônias.

Dados sobre as espécies de abelhas.

Dados das famílias de abelhas

Dados dos equipamentos utilizados nas aquisições de dados.

Dados sobre os instrumentos de um equipamento

Dados dos sensores utilizados nos equipamentos de aquisição de dados.

Dados relacionados com os tipos de medições realizados em um dado instrumento de um equipamento.

Dados coletados pelos vários equipamentos de aquisição.

Dados de localização das colônias e equipamentos

Dados sobre as espécies de plantas visitadas.

Dados das Famílias Botânicas visitadas.

Dados sobre os pesquisadores envolvidos nos estudos.

Dados dos ecossistemas das regiões geográficas.

Dados sobre a região geográfica onde são encontradas as espécies de abelhas e plantas visitadas.

Quadro 12 - Tabela Descrição das Entidades do Banco de dados

(adaptada de Cunha, 2001)

\subsubsection{Interface do Programa de Operação}

A Figura 35 apresenta um exemplo de tela de inserção de dados no programa de manutenção. Através dela os pesquisadores podem editar o conteúdo do banco de dados, além de inserir arquivos relacionados (imagens, textos e vídeos) os quais são armazenados numa estrutura de diretórios, e não no banco propriamente dito. 


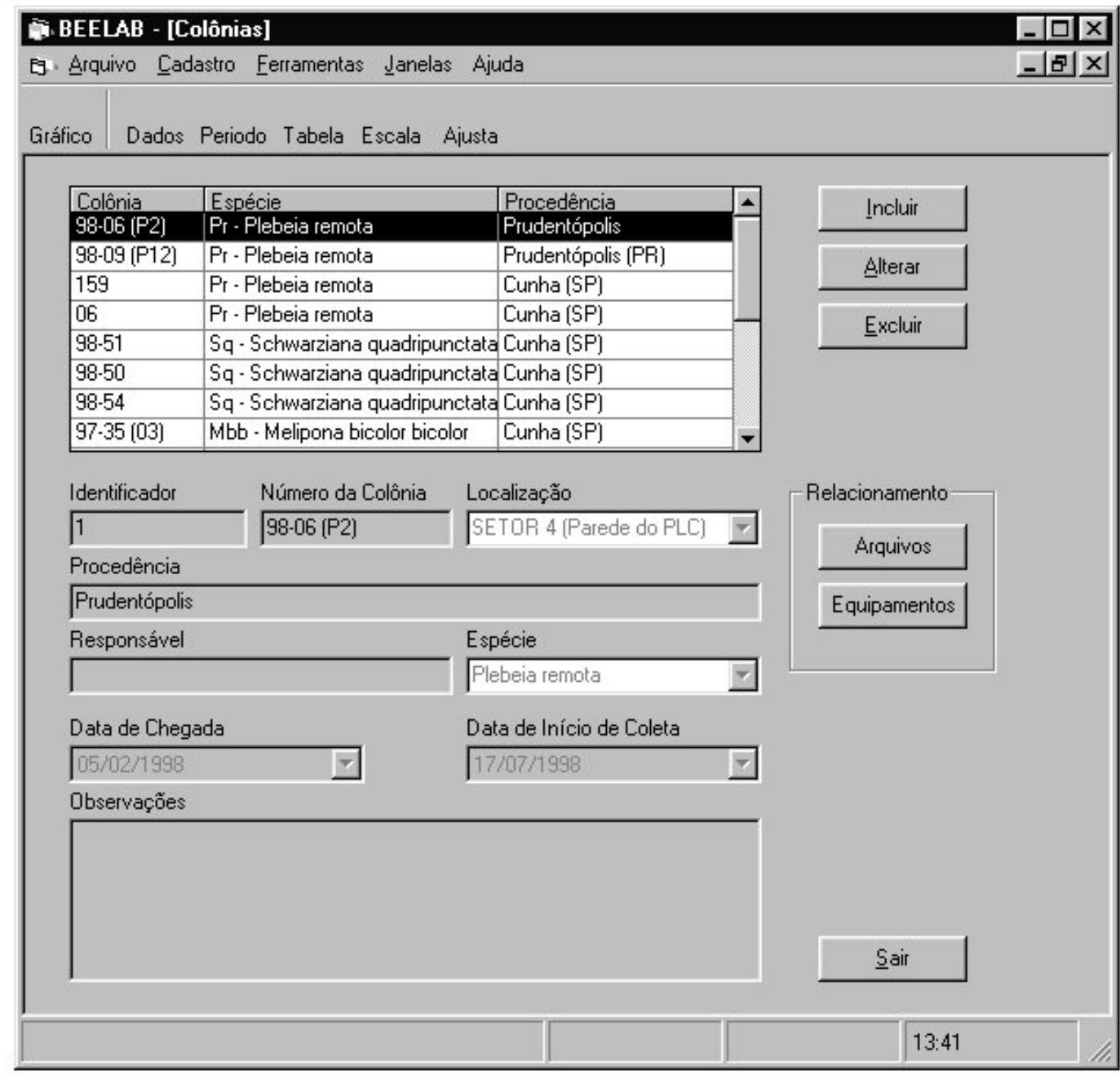

Figura 35 - Janela da Interface de Operação, para inserção dos dados das colônias

Fonte: (Cunha, 2001)

\subsubsection{A interface de operação via Internet}

A definição das formas de exibição do conteúdo do banco de dados da Webbee foi feita em parceria pelos pesquisadores Laboratório de Automação Agrícola e do Laboratório de Abelhas e foi implementada como parte de um trabalho de iniciação científica (Saraiva; Cartolano-Júnior 2003).

Optou-se pela distribuição das espécies de abelhas e plantas em fichas com imagens e textos específicos sobre cada espécie Figura 38. Estas fichas contêm imagens sobre partes das espécies e textos que fornecem dados sobre cada 
imagem. A partir da ficha de uma abelha é possível listar as plantas visitadas por ela e a partir dessa lista, abrir a ficha das plantas (Figura 12). O mesmo acontece na ficha das plantas, onde é possível listar as espécies de abelhas visitantes. Considerando a grande quantidade de espécies, torna-se inviável criar manualmente uma página Web para cada ficha, daí a necessidade de utilizar um script para criar dinamicamente estas páginas (no caso, o PHP).

O acesso às fichas das espécies é feito por meio de um catálogo que possibilita ao usuário configurar a ordem de indexação, e quais grupos de espécies deverão ser exibidos, separados por letra e ordenados por nome popular, nome científico ou legenda, Figura 36.

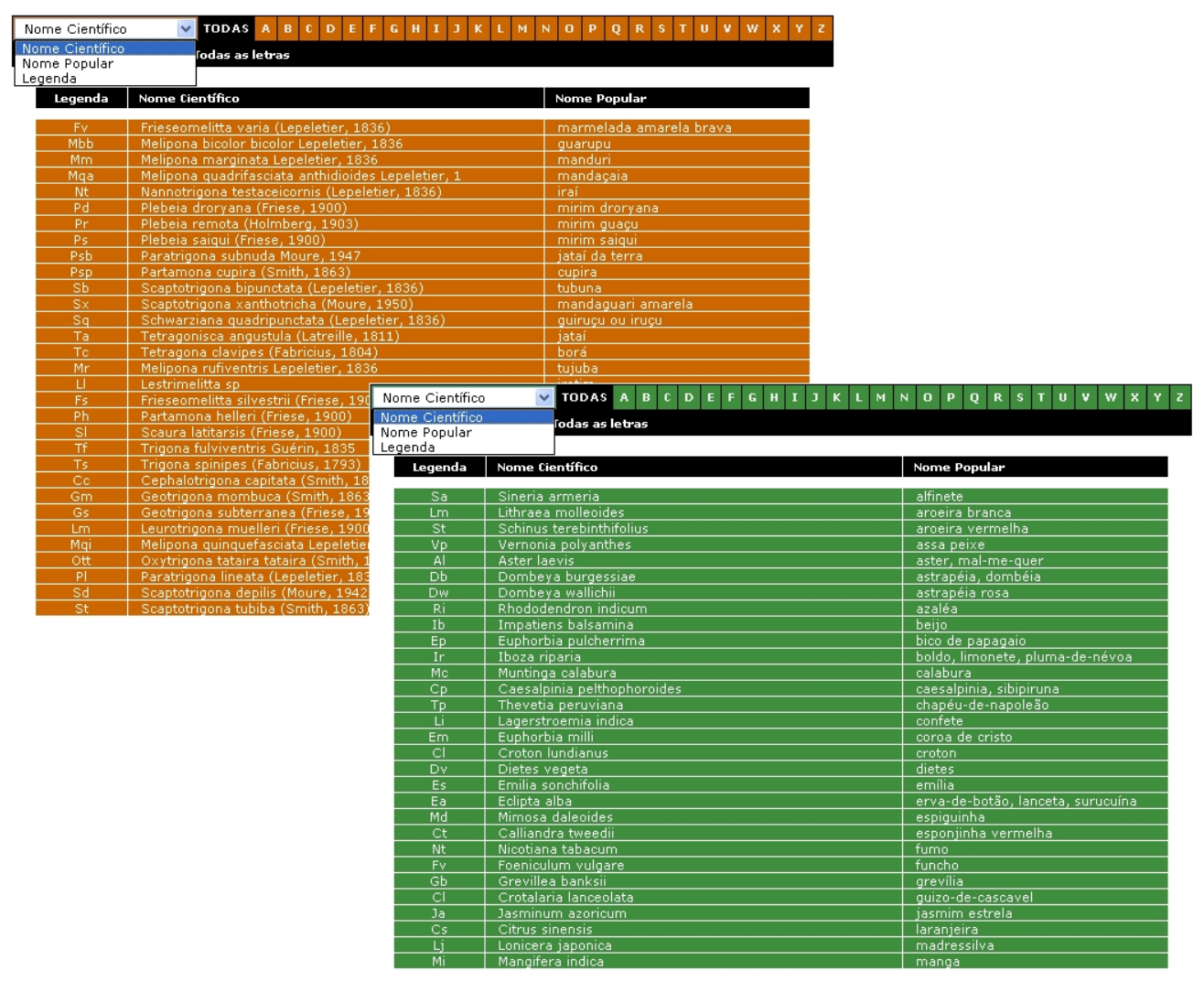

Figura 36 - Catálogo das Espécies de Abelhas e Plantas.

Dentro da ficha, o usuário pode navegar entre as imagens, que têm uma definição adequada para não sobrecarregar o acesso devido às conexões de rede baixas da velocidade. Existem dois componentes básicos na ficha, denominados navegador e tela. Estas duas partes da ficha são, na verdade, dois frames HTML que exibem páginas diferentes, Figura 37. No navegador estão miniaturas das 
imagens disponíveis para a espécie; através destas miniaturas o usuário pode controlar as imagens que aparecem na tela. Ao clicar sobre uma miniatura a imagem correspondente aparece na tela e com ela a sua descrição.

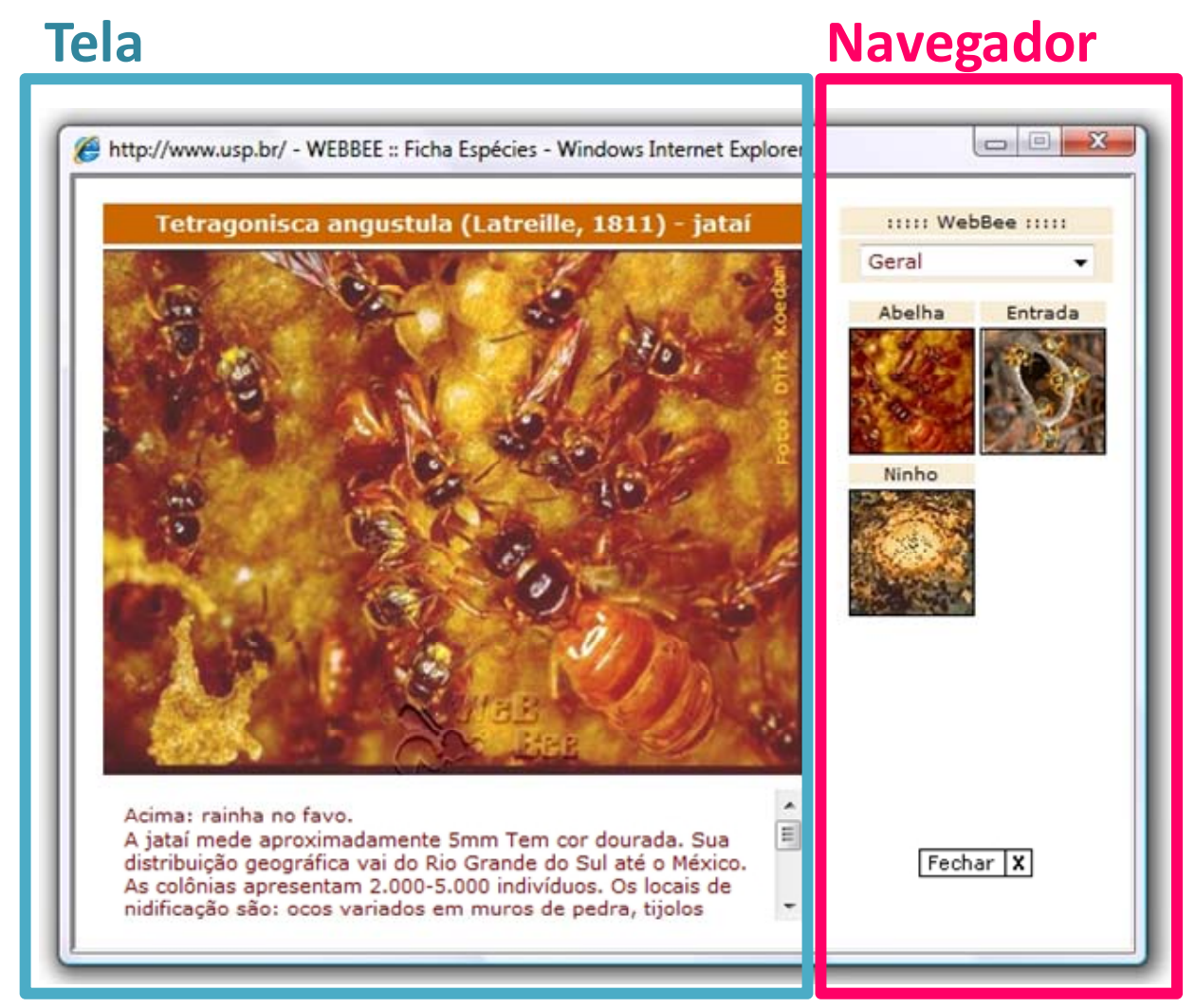

Figura 37 - Estrutura de Navegação da Ficha de Espécies da Webbee. 

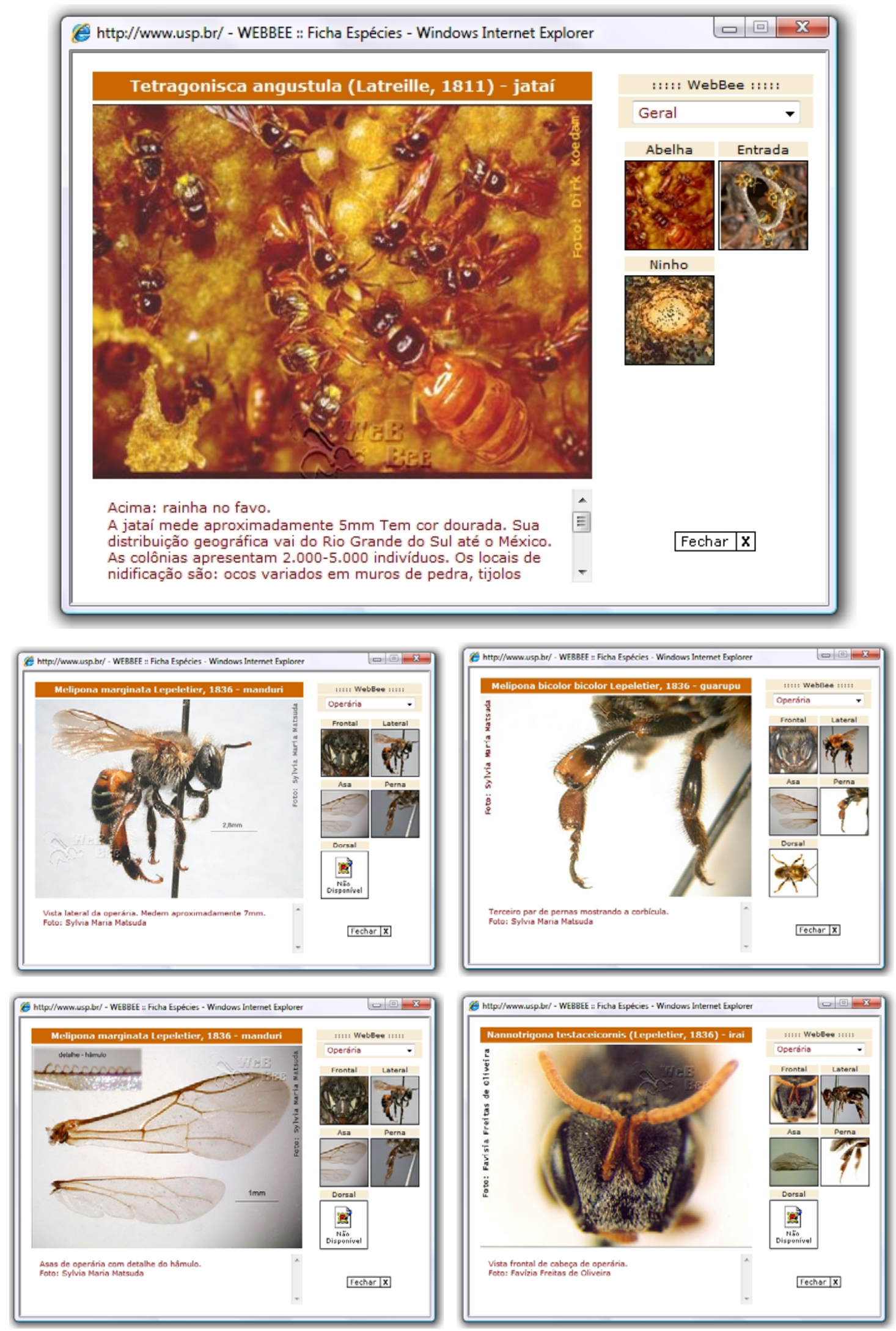

Figura 38 - Imagens de Fichas de Espécies 
Além dos dados de espécies, a banco de dados possui dados meteorológicos, obtidos da estação meteorológica do Laboratório de Abelhas. Esses tipos de dados são importantes para, juntamente com a monitoração das colméias (temperatura e umidade relativa do ar internas, e fluxo de abelhas) permitirem estudar a termoregulação e a atividade de vôo, e como estas atividades são afetadas pelo clima.

Estes dados são exibidos na forma de gráficos de variável versus tempo, após configurar-se o intervalo de tempo e variável desejada, dentre: temperatura do ar, umidade relativa do ar, velocidade do vento, precipitação pluviométrica, radiação solar total, radiação ultra-violeta, e pressão atmosférica.

\subsubsection{Uma rede de informações: um trabalho cooperativo}

Uma importante característica da Webbee é a sua proposta de servir como plataforma multi-institucional para a disponibilização de informações sobre abelhas nativas para diferentes públicos. O sistema está continuamente aberto à participação de qualquer pessoa que disponha de informações sobre o tema e que manifeste seu interesse em integrar-se a essa Rede de Informações sobre Biodiversidade Brasileira em Abelhas Nativas (Saraiva; Imperatriz-Fonseca, 2002).

Outro aspecto da Webbee é a meta de disponibilizar informações para diferentes públicos, visando servir não apenas ao público acadêmico, mas também meliponicultores e a sociedade em geral, os quais se ressentem da falta de informações sobre a biologia e a criação das abelhas nativas.

A disseminação da informação poderá ampliar o número de meliponicultores, sua eficiência, e a receita dos criadores, especialmente como atividade complementar. O conhecimento ampliado vai gerar maior eficiência na criação destas abelhas. A atividade promove a restauração ambiental, através do cultivo de plantas apícolas para a alimentação das abelhas, de árvores que servirão de locais de nidificação, e de conscientização ecológica; promove ainda a criação de novas formas de comunicação dos criadores e comunidade em geral com os pesquisadores, através da Internet (Saraiva, 2003). 